Forschungszentrum Karlsruhe

Technik und Umwelt

Wissenschaftliche Berichte

FZKA 5510

\title{
Stellar Neutron Capture Cross Sections of the Gd Isotopes
}

K. Wisshak, F. Voss, F. Käppeler, K. Guber, L. Kazakov, N. Kornilov, M. Uhl, G. Reffo Institut für Kernphysik 



\section{FORSCHUNGSZENTRUM KARLSRUHE}

Technik und Umwelt

Wissenschaftliche Berichte

FZKA 5510

\section{STELLAR NEUTRON CAPTURE CROSS SECTIONS OF THE Gd ISOTOPES}

K. WISSHAK, F. VOSS, F. KÄPPELER, K. GUBER ${ }^{1}$, L. KAZAKOV², N. KORNILOV ${ }^{2}$, M. $\mathrm{UHL}^{3}$, and G. REFFO

Institut für Kernphysik

${ }^{1}$ Oak Ridge National Laboratory, Oak Ridge, TN 37831-6371, USA

${ }^{2}$ Institute for Physics and Power Engineering, Obninsk-Kaluga Region, Russia

${ }^{3}$ Institut für Radiumforschung und Kernphysik, Boltzmanngasse 3, A-1090 Wien, Österreich

${ }^{4}$ ENEA, Settore Fisica Applicata, Viale Ercolani 8, I-40138 Bologna, Italy

Forschungszentrum Karlsruhe GmbH, Karlsruhe 1995 
Als Manuskript gedruckt

Für diesen Bericht behalten wir uns alle Rechte vor

Forschungszentrum Karlsruhe $\mathrm{GmbH}$

Postfach 3640, 76021 Karlsruhe

ISSN 0947-8620 


\section{ABSTRACT}

The neutron capture cross sections of ${ }^{152} \mathrm{Gd},{ }^{154} \mathrm{Gd},{ }^{155} \mathrm{Gd},{ }^{156} \mathrm{Gd},{ }^{157} \mathrm{Gd}$, and ${ }^{158} \mathrm{Gd}$ were measured in the energy range from 3 to $225 \mathrm{keV}$ at the Karlsruhe $3.75 \mathrm{MV}$ Van de Graaff accelerator. Neutrons were produced via the ${ }^{7} \mathrm{Li}(\mathrm{p}, \mathrm{n}){ }^{7} \mathrm{Be}$ reaction by bombarding metallic Li targets with a pulsed proton beam. Capture events were registered with the Karlsruhe $4 \pi$ Barium Fluoride Detector, which was improved by replacing crystals with high $\alpha$ background and by introducing a pierced crystal at zero degrees with respect to the beam axis. These changes resulted in a significantly increased efficiency for capture events. The main experimental problem was that the samples of the two s-only isotopes ${ }^{152} \mathrm{Gd}$ and ${ }^{154} \mathrm{Gd}$ showed only relatively low enrichment, but the spectroscopic quality of the $\mathrm{BaF}_{2}$ detector allowed to determine the resulting corrections for isotopic impurities reliably. The cross section ratios could be determined with an overall uncertainty of typically $1 \%$, an improvement by factors of five to ten compared to existing data. Severe discrepancies were found with respect to previous results. Maxwellian averaged neutron capture cross sections were calculated for thermal energies between $\mathrm{kT}=10 \mathrm{keV}$ and $100 \mathrm{keV}$. The new stellar cross sections were used for an updated analysis of the s-process reaction flow in the mass region between samarium and gadolinium, which is characterized by branchings at ${ }^{151} \mathrm{Sm},{ }^{154} \mathrm{Eu}$, and ${ }^{156} \mathrm{Eu}$. With the classical approach, the s-process temperature could be constrained corresponding to a range of thermal energies between $\mathrm{kT}=28 \mathrm{keV}$ and 33 $\mathrm{keV}$. The ${ }^{152} \mathrm{Gd}$ production in low mass stars was found to depend strongly on the neutron freeze-out at the end of the helium shell burning episodes. 


\section{ZUSAMMENFASSUNG}

\section{DIE STELLAREN $(\mathrm{n}, \gamma)$ QUERSCHNITTE DER Gd ISOTOPE}

Die Neutroneneinfangquerschnitte von ${ }^{152} \mathrm{Gd},{ }^{154} \mathrm{Gd},{ }^{155} \mathrm{Gd},{ }^{156} \mathrm{Gd},{ }^{157} \mathrm{Gd}$ und ${ }^{158} \mathrm{Gd}$ wurden im Energiebereich von 3 bis $225 \mathrm{keV}$ am Karlsruher Van de Graaff Beschleuniger relativ zu Gold als Standard bestimmt. Neutronen wurden über die ${ }^{7} \operatorname{Li}(\mathrm{p}, \mathrm{n}){ }^{7} \mathrm{Be}-$ Reaktion durch Beschuß metallischer Li-Targets mit einem gepulsten Protonenstrahl erzeugt. Der zum Nachweis von Einfangereignissen benutzte Karlsruher $4 \pi$ Barium Fluorid Detektor wurde verbessert, indem Kristalle mit hohem $\alpha$ Untergrund ersetzt und ein durchbohrter Kristall unter null Grad zur Strahlrichtung zusätzlich eingebaut wurden. Beide Maßnahmen führten zu einer deutlichen Erhöhung der Nachweiswahrscheinlichkeit für Einfangereignisse. Die Hauptschwierigkeit des Experiments bestand darin, daß für die reinen s-Kerne ${ }^{152} \mathrm{Gd}$ und ${ }^{154} \mathrm{Gd}$ nur schwach angereicherte Proben zur Verfügung standen. Aufgrund der spektroskopischen Qualität des $\mathrm{BaF}_{2}$ Detektors konnten die so bedingten Korrekturen für Fremdisotope jedoch mit guter Genauigkeit durchgeführt werden. Entsprechend gelang es, die Unsicherheiten der Querschnittsverhältnisse auf $1 \%$ zu verringern. Dies entspricht einer Verbesserung um Faktoren fünf bis zehn im Vergleich zu früheren Ergebnissen. Die stellaren Einfangquerschnitte, die für thermische Energien von $\mathrm{kT}=10 \mathrm{keV}$ bis $100 \mathrm{keV}$ berechnet wurden, bildeten die Grundlage für detaillierte Untersuchungen des Reaktionsflusses im s-Prozeß, der im Bereich zwischen Samarium und Gadolinium Verzweigungen beim ${ }^{151} \mathrm{Sm},{ }^{154} \mathrm{Eu}$ und ${ }^{155} \mathrm{Eu}$ aufweist. Mit Hilfe der klassischen Näherung ergibt sich eine Einschränkung der Temperatur im s-Prozeß, mit thermischen Energien zwischen $\mathrm{kT}=28 \mathrm{keV}$ und $33 \mathrm{keV}$. Für den s-Prozeß in massearmen Sternen wurde eine interessante Abhängigkeit der ${ }^{152} \mathrm{Gd}$-Produktion vom Ausfrierverhalten der Neutronen am Ende der kurzzeitigen Helium-Brennphasen gefunden. 


\section{Contents}

1 INTRODUCTION 1

2 EXPERIMENT 3

2.1 Experimental Method . . . . . . . . . . . . . . . . . . . 3

2.2 Samples ............................ . . . 4

2.3 Measurements . . . . . . . . . . . . . . . . . 6

3 DATA ANALYSIS $\quad 7$

3.1 Total Cross Sections . . . . . . . . . . . . . . . . 7

3.2 Capture Cross Sections . . . . . . . . . . . . . . . . . . 8

4 RESULTS FOR THE NEUTRON CAPTURE CROSS SECTIONS 34

5 DISCUSSION OF UNCERTAINTIES

6 MAXWELLIAN AVERAGED CROSS SECTIONS 48

7 ASTROPHYSICAL IMPLICATIONS

7.1 The s-Process Branchings between ${ }^{150} \mathrm{Sm}$ and ${ }^{156} \mathrm{Gd} \ldots \ldots \ldots \ldots . . \ldots 54$

7.2 Input data . . . . . . . . . . . . . . . . . . 54

7.3 s-Process models . . . . . . . . . . . . . . . . 56

7.4 Results and Discussion ................... 58

8 SUMMARY $\quad 62$

9 ACKNOWLEDGMENTS

10 REFERENCES 


\section{INTRODUCTION}

The present experiment on the gadolinium isotopes continues the accurate determination of neutron capture cross sections for s-only isotopes with the Karlsruhe $4 \pi \mathrm{BaF}_{2}$ detector. After tellurium [1], samarium [2], and barium [3], gadolinium is the forth of the six elements with two even s-only isotopes. As described in the above references these are particularly important cases where accurate cross sections allow to investigate the related s-process branchings in great detail, in particular with respect to the physical conditions in the helium burning zones of Red Giant stars.

The neutron capture path from samarium to gadolinium (Fig.1) shows that the two isotopes ${ }^{152} \mathrm{Gd}$ and ${ }^{154} \mathrm{Gd}$ are shielded from the $\mathrm{r}$-process by their stable samarium isobars. The unstable isotopes ${ }^{151} \mathrm{Sm},{ }^{154} \mathrm{Eu}$, and ${ }^{155} \mathrm{Eu}$ are possible branching points due to the competition between neutron captures and $\beta$-decays. These branchings are all affected by the stellar temperature. In addition, there is also a weak dependence on electron density for the decays of ${ }^{151} \mathrm{Sm},{ }^{152} \mathrm{Eu}$, and ${ }^{155} \mathrm{Eu}$. Accordingly, the resulting abundance pattern may yield information on the temperature and the electron density (and hence the mass density) during the s-process.

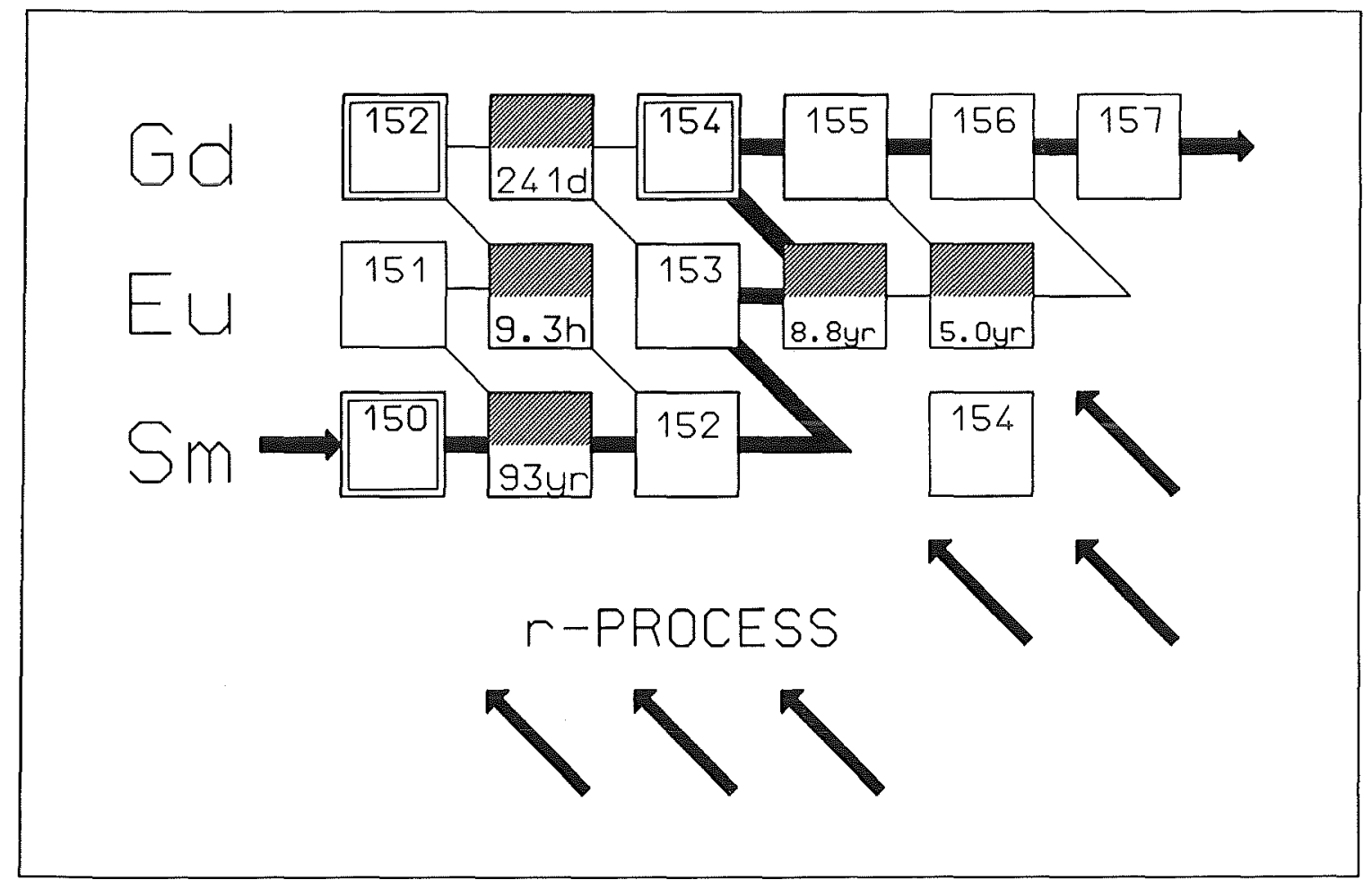

Figure 1: The s-process path in the region of the gadolinium isotopes. 
For the branchings at the tellurium, samarium, and barium isotopes $[1,2,3]$, the branching factors, $f_{n}$, were small and of the order of 0.1 . This implies that only a small part of the s-process flow is bypassing the lighter s-only isotope and that the $\mathrm{N}_{s}<\sigma>$ values of both s-isotopes are about equal. The branching at ${ }^{151} \mathrm{Sm}$ shows an opposite behavior. Now, $f_{n}$ is of the order of 0.90 , and most of the s-process flow is bypassing ${ }^{152} \mathrm{Gd}$. Changing the cross section ratio of the s-only isotopes by $1 \%$ in the first cases results in a $10 \%$ change of $f_{n}$, indicating that the sensitivity of the branching to $f_{n}$ and, hence, to the neutron flux is large. Clearly, the uncertainty of the cross section measurement determines the uncertainty of the derived neutron flux. In case of ${ }^{152} \mathrm{Gd}$, the situation is opposite: a $1 \%$ change in the cross section affects the branching factor only by $1 \%$, resulting in a low sensitivity for the neutron flux. However, the sensitivity is shifted to the $\beta$-decay part of the branching, since now $f_{\beta}=1-f_{n}$ is small. Therefore, this branching is suited for determining the s-process temperature via the temperature-dependent half-life of ${ }^{151} \mathrm{Sm}$ [42].

The branching at ${ }^{154} \mathrm{Eu}$ is of the first type with a small branching factor, $f_{n}$. Since both s-only isotopes, ${ }^{152} \mathrm{Gd}$ and ${ }^{154} \mathrm{Gd}$ are affected by branchings, the full $\mathrm{N}_{s}<\sigma>$ flow has to be normalized at ${ }^{150} \mathrm{Sm}$, the closest $\mathrm{s}$-only isotope that is not affected by branchings. Due to the chemical similarity of the rare earth elements samarium and gadolinium, their solar abundance ratio is known to $\pm 1.3 \%$ [5].

The isotope ${ }^{152} \mathrm{Gd}$ was long considered to exhibit a strong p-process component [6] using systematics of neighboring p-only nuclei such as ${ }^{156} \mathrm{Dy},{ }^{154} \mathrm{Dy}$ or ${ }^{144} \mathrm{Sm}$. In contrast, recent model calculations indicate that the $\mathrm{p}$-process yield of ${ }^{152} \mathrm{Gd}$ is much smaller, probably not exceeding $12 \%[7,8]$. On the other hand, there is a non-negligible ${ }^{152} \mathrm{Gd}$ contribution from the s-process in massive stars, which amounts to $\sim 6 \%$ for a weighted average over a generation of massive stars [9]. This means that about $80 \%$ of the ${ }^{152} \mathrm{Gd}$ abundance should result from the main s-process component due to helium burning in low mass stars.

The ${ }^{151} \mathrm{Sm}$ branching is also interesting with respect to the pulsed s-process scenario described by the stellar models. The $\beta$-decay of ${ }^{151} \mathrm{Sm}$ in the interpulse phase may increase the amount of ${ }^{152} \mathrm{Gd}$ compared to a steady flow situation. This aspect can be tested with improved cross sections as well.

The analysis of the s-process branchings defined by ${ }^{152} \mathrm{Gd}$ and ${ }^{154} \mathrm{Gd}$ is confronted with the additional problem that not only the $\beta$-decay rates of the branch point isotopes, but also the neutron capture rates may depend on temperature, in particular those of ${ }^{152} \mathrm{Sm}$ and ${ }^{154} \mathrm{Gd}[10,11]$. Existing model calculations yield contradictory values for this effect, an uncertainty that can possibly be constrained by the s-process abundance systematics.

The experimental status of the gadolinium cross sections is unsatisfactory. The two s-only isotopes ${ }^{152} \mathrm{Gd}$ and ${ }^{154} \mathrm{Gd}$ have low natural abundances of 0.20 and $2.18 \%$, respectively. Therefore, highly enriched samples are not available. In a previous experiment, the enrichments were $32 \%$ for ${ }^{152} \mathrm{Gd}$ and $66 \%$ for ${ }^{154} \mathrm{Gd}[6]$, leading to large corrections for isotopic impurities. These corrections are particularly difficult to deal with in experiments based on the pulse height weighting technique [6], where the efficiency for capture events is proportional to the binding energy. Therefore, it is larger for odd than for even isotopes. Since the magnitude of the cross sections is also correlated with the binding energy, this effect is further enhanced, resulting in an $\sim 80 \%$ correction for isotopic impurities 
in the most recent measurement on ${ }^{152} \mathrm{Gd}[6]$. In view of the large discrepancies between calculated and measured weighting functions [12], the correlated systematic uncertainty is certainly a problem, which is aggrevated by the fact that two of the major impurity isotopes, ${ }^{156} \mathrm{Gd}$ and ${ }^{158} \mathrm{Gd}$, were not included in that experiment.

With the Karlsruhe $4 \pi \mathrm{BaF}_{2}$ detector this situation is quite different since the efficiency is equal for odd and even isotopes. Furtheron, the good resolution in $\gamma$-ray energy allows to distinguish capture events from odd and even isotopes by their different binding energies, so that the contributions from odd impurities can be partly separated from the capture events of the even isotopes. The isotopic corrections could be determined from a nearly complete set of 6 isotopes which were investigated simultaneously. The only missing stable isotope was ${ }^{160} \mathrm{Gd}$, but its influence was small because its cross section is lower by a factor of seven compared to the s-only isotopes. Therefore, this correction could be determined with considerably improved reliability.

Apart from the problems with the isotopic corrections, the experimental situation is quite similar as in the measurement of the samarium cross sections [2]. The ratio of total to capture cross sections is only between 10 and 30, thus yielding a favorable signal to background ratio.

Experiment and data analysis are described in Secs. 2 and 3. The differential cross sections are presented in Sec 4, and the uncertainties are discussed in Sec 5. The determination of stellar cross sections and the discussion of the astrophysical implications for astrophysics are presented in Secs. 6 and 7.

\section{EXPERIMENT}

\subsection{Experimental Method}

The neutron capture cross sections of the gadolinium isotopes 152 and 154 to 158 have been measured in the energy range from 3 to $225 \mathrm{keV}$ using gold as a standard. Since the experimental method has been published in detail $[1,2,13,14]$, only a more general description is given here, complemented with the specific features of the present measurement. Neutrons were produced via the ${ }^{7} \mathrm{Li}(\mathrm{p}, \mathrm{n}){ }^{7} \mathrm{Be}$ reaction by bombarding metallic $\mathrm{Li}$ targets with the pulsed proton beam of the Karlsruhe 3.75 MV Van de Graaff accelerator. The neutron energy was determined by time of flight (TOF), the samples being located at a flight path of $78 \mathrm{~cm}$. The important parameters of the accelerator were: pulse width $<1 \mathrm{~ns}$, repetition rate $250 \mathrm{kHz}$, and average beam current $1.5 \mu \mathrm{A}$. In different runs, the proton energies were adjusted 30 and $100 \mathrm{keV}$ above the threshold of the ${ }^{7} \mathrm{Li}(\mathrm{p}, \mathrm{n})^{7} \mathrm{Be}$ reaction at $1.881 \mathrm{MeV}$. In this way, continuous neutron spectra in the energy range of interest for s-process studies were obtained, ranging from 3 to $100 \mathrm{keV}$, and 3 to $200 \mathrm{keV}$, respectively. The run with lower maximum energy offers a significantly better signal to background ratio.

Capture events were registered with the Karlsruhe $4 \pi$ Barium Fluoride Detector via the prompt capture $\gamma$-ray cascades. This detector consists of 42 hexagonal and pentagonal crystals forming a spherical shell of $\mathrm{BaF}_{2}$ with $10 \mathrm{~cm}$ inner radius and $15 \mathrm{~cm}$ thickness. 
It is characterized by a resolution in $\gamma$-ray energy of $7 \%$ at $2.5 \mathrm{MeV}$, a time resolution of $500 \mathrm{ps}$, and a peak efficiency of $90 \%$ at $1 \mathrm{MeV}$. For a comprehensive description see Ref.[13].

Previously, two of the $42 \mathrm{BaF}_{2}$ crystals had to be removed for the neutron beam to pass the detector, resulting in an effective solid angle of $94 \%$ of $4 \pi$. In the present experiment, a pierced crystal with a hole of $50 \mathrm{~mm}$ diameter was mounted at the exit of the neutron beam. The hole reduces the crystal volume only from 1.51 to 1.21 , thus increasing the total solid angle by $2 \%$. The scintillation light from the additional crystal is registered by a ring of 6 photomultiplier tubes (EMI9902 QKA) with $38 \mathrm{~mm}$ diameter.

Furtheron, 6 crystals with high intrinsic background rates due to a natural radium contamination ( $\sim 1000$ counts/s for the integral of the four $\alpha$ lines) have been replaced. Two of the new cristals have background rates of 200 counts/s as most of the others, but four crystals exhibit very low radium impurities giving rise to less than 10 counts/s only. With this change the total intrinsic background rate could be reduced by almost a factor of two. This means that the threshold in the sum energy spectrum of the detector could be reduced from 2.4 to $1.4 \mathrm{MeV}$ while recording the same integral count rate.

These two improvements, the increase in solid angle and the reduction of the sum energy threshold have led to a significantly increased detection efficiency (see Sec.3).

The experiment was divided into three runs, two with the conventional data acquisition technique in the calorimeter mode, and one with the ADC system for obtaining more detailed spectroscopic information.

\subsection{Samples}

The samples have been prepared from isotopically enriched $\mathrm{Gd}_{2} \mathrm{O}_{3}$ powder. The relevant parameters of the samples are compiled in Table 1. In addition to the six gadolinium samples, a gold sample, a graphite sample, and an empty position in the sample ladder were used in all runs. Compared to the previous experiment by Beer and Macklin[6], the sample masses could be reduced by factors of 2.3 to 8.6. Accordingly, the sample-related corrections for neutron multiple scattering and self-shielding were significantly smaller, and, therefore, less uncertain.

The samples were prepared in the same way as the samarium samples in Ref.[2]. When heated to $1000^{\circ} \mathrm{C}$, five of the samples lost less than $0.5 \%$ in weight, but for ${ }^{156} \mathrm{Gd}$ the loss was $10.7 \%$. This shows strikingly that the contamination with water is a severe problem for the oxides of rare earth elements and has always to be checked. After heating, the composition of the samples was very stable and no further absorption of water was observed. In fact, the weight of all samples could be perfectly reproduced at the end of the measurements.

The isotopic composition of the samples quoted by the supplier are listed in Table 2. Similar to the previous measurement[6] the enrichment of the ${ }^{152} \mathrm{Gd}$ and ${ }^{154} \mathrm{Gd}$ samples are rather low, $32.5 \%$ and $57.0 \%$, respectively.

Despite of their chemical stability the samples were canned in aluminum containers with $0.14 \mathrm{~mm}$ thick walls to avoid any losses of material. Accordingly, a bare aluminum canning was mounted in the "empty" position of the sample ladder (Table 1).

The neutron transmissions of the samples were calculated with the SESH code[15], 
Table 1: SAMPLE CHARACTERISTICS

\begin{tabular}{lcccccc}
\hline Sample & $\begin{array}{c}\text { Thickness }^{1} \\
\left(10^{-3} \text { at/barn }\right)^{5}\end{array}$ & $\begin{array}{c}\text { Weight } \\
(\mathrm{g})\end{array}$ & $\begin{array}{c}\text { Canning }^{3} \\
(\mathrm{~g})\end{array}$ & $\begin{array}{c}\text { Impurity }^{4} \\
(\%)^{6}\end{array}$ & $\begin{array}{c}\text { Neutron Binding } \\
\text { Energy }(\mathrm{MeV})\end{array}$ \\
\hline${ }^{158} \mathrm{Gd}$ & 5.8 & 8.6244 & 4.6062 & 0.3459 & $<0.3$ & 5.943 \\
Graphite & 2.5 & 21.6874 & 0.7644 & 0.2136 & & \\
${ }^{152} \mathrm{Gd}$ & 1.6 & 2.1742 & 1.1427 & 0.1890 & $<0.1$ & 6.247 \\
${ }^{197} \mathrm{Au}$ & 0.3 & 2.2475 & 1.2990 & 0.1849 & & 6.513 \\
${ }^{154} \mathrm{Gd}$ & 1.8 & 2.4185 & 1.2677 & 0.1830 & $<0.4$ & 6.439 \\
${ }^{155} \mathrm{Gd}$ & 0.9 & 1.3086 & 0.6878 & 0.1830 & $<0.1$ & 8.536 \\
${ }^{156} \mathrm{Gd}$ & 2.3 & 3.1241 & 1.6507 & 0.2138 & $<0.2$ & 6.360 \\
${ }^{157} \mathrm{Gd}$ & 1.7 & 2.3882 & 1.2689 & 0.1805 & $<0.2$ & 7.937 \\
Empty & 0.3 & & & 0.1810 & & \\
\hline
\end{tabular}

${ }^{1}$ all samples $15 \mathrm{~mm}$ in diameter

${ }^{2}$ for gadolinium samples: weight of $\mathrm{Gd}_{2} \mathrm{O}_{3}$

3 aluminum box

${ }^{4}$ elements apart from oxygen

${ }^{5}$ for gadolinium samples: sum of all $\mathrm{Gd}$ isotopes

$6 \%$ of weight

Table 2: ISOTOPIC COMPOSITION (\%)

\begin{tabular}{cccccccc}
\hline Sample & \multicolumn{7}{c}{ Isotope } \\
& ${ }^{152} \mathrm{Gd}$ & ${ }^{154} \mathrm{Gd}$ & ${ }^{155} \mathrm{Gd}$ & ${ }^{156} \mathrm{Gd}$ & ${ }^{157} \mathrm{Gd}$ & ${ }^{158} \mathrm{Gd}$ & ${ }^{160} \mathrm{Gd}$ \\
\hline${ }^{152} \mathrm{Gd}$ & 32.50 & 5.45 & 16.68 & 15.56 & 9.03 & 12.13 & 8.65 \\
${ }^{154} \mathrm{Gd}$ & 0.0 & 57.00 & 32.70 & 5.30 & 2.10 & 1.90 & 1.00 \\
${ }^{155} \mathrm{Gd}$ & $<0.01$ & 0.22 & 91.60 & 6.34 & 0.78 & 0.73 & 0.33 \\
${ }^{156} \mathrm{Gd}$ & $<0.1$ & 0.20 & 1.30 & 93.50 & 3.30 & 1.30 & 0.40 \\
${ }^{157} \mathrm{Gd}$ & $<0.04$ & 0.05 & 0.30 & 1.71 & 89.60 & 7.78 & 0.56 \\
${ }^{158} \mathrm{Gd}$ & $<0.08$ & $<0.08$ & 0.17 & 0.33 & 0.78 & 97.30 & 1.42 \\
\hline
\end{tabular}

and are generally larger than $95 \%$ (Table 3). Since reliable total cross sections of the gadolinium isotopes were not available in literature, the spectra measured with a ${ }^{6} \mathrm{Li}-$ glass detector at $260 \mathrm{~cm}$ flight path were used for a rough determination of the total cross sections. Though the accuracy of this method is inferior to that obtained in a dedicated experiment, the derived total cross sections are sufficient for the reliable calculation of the multiple scattering corrections (Sec. 3). Normalization of the spectra to equal neutron flux was performed for all samples by means of a second ${ }^{6} \mathrm{Li}$-glass monitor located close to the neutron target. 
Table 3: NEUTRON TRANSMISSION ${ }^{1}$

\begin{tabular}{lccccc}
\hline Sample & \multicolumn{5}{c}{ Neutron Energy (keV) } \\
& 10 & 20 & 40 & 80 & 160 \\
\hline${ }^{197} \mathrm{Au}$ & 0.959 & 0.965 & 0.970 & 0.974 & 0.979 \\
${ }^{152} \mathrm{Gd}$ & 0.983 & 0.985 & 0.987 & 0.989 & 0.990 \\
${ }^{154} \mathrm{Gd}$ & 0.970 & 0.973 & 0.976 & 0.979 & 0.981 \\
${ }^{155} \mathrm{Gd}$ & 0.976 & 0.978 & 0.980 & 0.982 & 0.984 \\
${ }^{156} \mathrm{Gd}$ & 0.940 & 0.947 & 0.953 & 0.958 & 0.963 \\
${ }^{157} \mathrm{Gd}$ & 0.954 & 0.960 & 0.964 & 0.968 & 0.971 \\
${ }^{158} \mathrm{Gd}$ & 0.863 & 0.869 & 0.877 & 0.884 & 0.893 \\
\hline
\end{tabular}

${ }^{1}$ Monte Carlo calculation with SESH code[15].

Table 4: PARAMETERS OF THE INDIVIDUAL MEASUREMENTS

\begin{tabular}{cccccccc}
\hline Run & $\begin{array}{c}\text { Flight } \\
\text { Path }\end{array}$ & $\begin{array}{c}\text { TOF } \\
\text { Scale }\end{array}$ & $\begin{array}{c}\text { Number } \\
\text { of } \\
\text { Cycles }\end{array}$ & $\begin{array}{c}\text { Maximum } \\
\text { Neutron } \\
\text { Energy } \\
(\mathrm{keV})\end{array}$ & $\begin{array}{c}\text { Measuring } \\
\text { Time }\end{array}$ & $\begin{array}{c}\text { Average } \\
\text { Beam } \\
\text { Current } \\
(\mu \mathrm{A})\end{array}$ & $\begin{array}{c}\text { Threshold } \\
\text { in Sum } \\
\text { Energy } \\
(\mathrm{MeV})\end{array}$ \\
\hline 1 & 787.6 & 0.7600 & 190 & 100 & 16 & 1.5 & 2.0 \\
2 & 787.6 & 0.7600 & 140 & 200 & 11 & 1.6 & 1.4 \\
3 & 787.4 & 0.7133 & 190 & 100 & 17 & 1.4 & 1.4 \\
\hline
\end{tabular}

\subsection{Measurements}

The samples were moved cyclically into the measuring position by a computer controlled sample changer. The data acquisition time per sample was about $10 \mathrm{~min}$, a complete cycle lasting about $1.5 \mathrm{~h}$. From each event, a 64 bit word was recorded on magnetic tape containing the sum energy and TOF information together with 42 bits identifying those detector modules that contributed. Three runs were performed using neutron spectra with different maximum energies. The relevant parameters are compiled in Table 4 . The data in Run 3 were recorded with the ADC system. The overall recorded information was 19Gbyte. 


\section{DATA ANALYSIS}

\subsection{Total Cross Sections}

The total cross sections of the gadolinium isotopes were determined in the neutron energy range from 10 to $200 \mathrm{keV}$ via the TOF spectra measured with the ${ }^{6} \mathrm{Li}$ glass detector at a flight path of $260 \mathrm{~cm}$. The total cross sections and the related uncertainties were obtained as described in Ref.[2], and are listed in Table 5. The oxygen cross section was taken from a recent evaluation (Joint Evaluated File, JEF)[16]. The total cross sections deduced for the carbon sample agree with the JEF data within $\pm 3.7 \%$, comparable to the results reported in Ref.[2], where systematic differences of $3 \%$ were found. This difference may be due to the fact that the sample diameter of $15 \mathrm{~mm}$ is just sufficient to shade the lithium glass scintillator. Hence, even a small misalignment of the detector could have caused the observed deviations. Correspondingly, this effect was avoided in the barium experiment[3], where the larger sample diameter of $22 \mathrm{~mm}$ resulted in a significantly better agreement with the evaluated total cross section of carbon.

In view of this difficulty only rough estimates for the total cross sections of the gadolinium isotopes were obtained. For the isotopes ${ }^{152} \mathrm{Gd}$ and ${ }^{154} \mathrm{Gd}$, additional uncertainties due to the sizable isotopic corrections had to be considered. The total cross section of elemental gadolinium calculated from the isotopic cross sections of Table 5 and assuming the cross sections for ${ }^{158} \mathrm{Gd}$ and ${ }^{160} \mathrm{Gd}$ to be equal, is about $10 \%$ larger than the data given in Ref.[17].

Table 5: THE MEASURED TOTAL CROSS SECTIONS ${ }^{1}$

\begin{tabular}{ccccccccc}
\hline $\begin{array}{c}\text { Neutron Energy } \\
(\mathrm{keV})\end{array}$ & \multicolumn{7}{c}{ Total Cross Section (barn) } \\
\hline $10-15$ & 15.5 & 18.4 & 13.3 & 15.4 & 15.1 & 10.3 & 4.92 & 16.5 \\
$15-20$ & 20.3 & 14.5 & 13.5 & 13.6 & 15.5 & 12.4 & 4.56 & 16.5 \\
$20-30$ & 18.2 & 14.3 & 8.8 & 11.7 & 11.1 & 10.3 & 4.26 & 11.3 \\
$30-40$ & 15.5 & 12.7 & 11.8 & 11.6 & 12.3 & 10.4 & 4.26 & 11.9 \\
$40-60$ & 13.6 & 11.4 & 12.0 & 10.8 & 11.3 & 9.7 & 4.37 & 12.4 \\
$60-80$ & 13.7 & 12.0 & 12.3 & 12.2 & 10.3 & 9.8 & 4.43 & 12.1 \\
$80-100$ & 13.0 & 10.7 & 8.3 & 10.1 & 8.8 & 9.2 & 4.11 & 10.0 \\
$100-150$ & 13.9 & 12.1 & 11.0 & 10.5 & 10.1 & 9.1 & 4.21 & 11.7 \\
$150-200$ & 9.6 & 11.2 & 10.4 & 9.5 & 9.2 & 9.1 & 4.13 & 10.3 \\
\hline Uncertainty & $\sim 20 \%$ & $\sim 15 \%$ & $24.9 \%$ & $9.5 \%$ & $12.4 \%$ & $4.8 \%$ & $3.7 \%$ & $11.1 \%$ \\
\hline
\end{tabular}

${ }^{1}$ determined from the count rate of the ${ }^{6} \mathrm{Li}$ glass neutron monitor at $260 \mathrm{~cm}$ flight path 
Table 6: MATRIX FOR ISOTOPIC CORRECTIONS (\%) ${ }^{1}$

\begin{tabular}{cccccccc}
$\begin{array}{c}\text { Corrected } \\
\text { Spectrum }\end{array}$ & ${ }^{152} \mathrm{Gd}$ & ${ }^{154} \mathrm{Gd}$ & $\begin{array}{c}\text { Measured spectrum } \\
{ }^{155} \mathrm{Gd}\end{array}$ & ${ }^{156} \mathrm{Gd}$ & ${ }^{157} \mathrm{Gd}$ & ${ }^{158} \mathrm{Gd}$ & $\begin{array}{c}\text { Corrected Sample } \\
\text { Thickness }\left(10^{-3} \text { at/barn) }\right.\end{array}$ \\
\hline${ }^{152} \mathrm{Gd}$ & 100 & -8.4915 & -24.2017 & -10.3656 & -8.2259 & -4.2108 & 0.7066 \\
${ }^{154} \mathrm{Gd}$ & & 100 & -65.8754 & -2.4846 & -1.9211 & -0.5735 & 1.3765 \\
${ }^{155} \mathrm{Gd}$ & & -0.1958 & 100 & -2.8257 & -0.3324 & -0.1206 & 1.1959 \\
${ }^{156} \mathrm{Gd}$ & -0.4427 & -3.0621 & 100 & -4.7786 & -0.4579 & 2.9159 \\
${ }^{157} \mathrm{Gd}$ & -0.0795 & -0.4713 & -1.3589 & 100 & -2.2868 & 2.1368 \\
${ }^{158} \mathrm{Gd}$ & & +0.0092 & -1.1804 & -0.8933 & -3.0953 & 100 & 8.4645 \\
\hline
\end{tabular}

${ }^{1}$ using the approximation that the abundance of ${ }^{160} \mathrm{Gd}=0.65 \times{ }^{158} \mathrm{Gd}$

\subsection{Capture Cross Sections}

The data analysis was carried out analoguously to the procedure described previously $[1,2,14]$. All events stored on dat tape were sorted into two-dimensional spectra containing 128 sum energy versus 4096 TOF channels according to various event multiplicities (Evaluation 1). In Evaluation 2, this procedure was repeated by rejecting those events, where only neighboring detector modules contributed to the sum energy signal. In this way, background from the natural radioactivity of the $\mathrm{BaF}_{2}$ crystals and from scattered neutrons can be reduced. For all samples, the resulting spectra were normalized to equal neutron flux using the count rate of the second lithium glass monitor close to the neutron target. The corresponding normalization factors are below $0.3 \%$ for all runs. The calculation of the two-dimensional spectra from the data recorded with the ADC system is slightly more complicated and was performed as described in Ref.[2].

In the next step of data analysis, the spectra measured with the empty sample canning were subtracted to remove sample-independent backgrounds. A remaining constant background was determined at very long flight times, where no time-correlated events are expected. The two-dimensional spectra of run 3 containing all events with multiplicity $>2$ are shown in Fig. 2, Fig. 3 and Fig. 4. The TOF is given on the $x$-axis and the sum energy on the y-axis. Events at low sum energy and large TOF are suppressed by the preprocessing unit coupled to the ADC system.

At this point, the spectra contain only events that are correlated with the sample. The next correction to be made is for isotopic impurities (see Ref.[2] for details). The respective coefficients are compiled in Table 6 . To correct for ${ }^{160} \mathrm{Gd}$ impurities, the spectra of the ${ }^{158} \mathrm{Gd}$ sample were used, since this isotope has a very similar binding energy. The respective ${ }^{160} \mathrm{Gd}$ abundances, however, were scaled by a factor of 0.65 to account for its smaller capture cross section[18].

As mentioned before, the correction for isotopic impurities needs special consideration in the present experiment. It is obvious from Table 6 that the ${ }^{152} \mathrm{Gd}$ and ${ }^{154} \mathrm{Gd}$ samples 
required rather large correction factors. The left part of Fig.5 shows the sum energy of the capture events before this correction. The spectra of ${ }^{152} \mathrm{Gd}$ and ${ }^{154} \mathrm{Gd}$ exhibit clearly two peaks according to capture events in the even and odd isotopes, respectively. The right part of Fig.5 shows the same spectra after the correction. For comparison, the same spectra are given for the ${ }^{156} \mathrm{Gd}$ sample in the lower part of the figure, where the correction for isotopic impurities is small (the events around channel 100 are due to capture of scattered neutrons in the odd barium isotopes of the scintillator). In all three cases, the resulting sum energy spectra exhibit the same shape, demonstrating the reliability with which the correction could be performed.

Another important feature can be seen from Fig. 5 as well. Thanks to the good energy resolution of the detector, most of the capture events in the odd isotopes appear in the sum energy spectra above the binding energies of the even isotopes. Since this energy range (above channel $\sim 80$ ) is not used for evaluating the cross sections of the even isotopes, these events can be completely suppressed. This distinction is a further advantage compared to experiments using detectors with poor energy resolution, where such a separation is impossible.

The corrections are indicated in Fig.6, showing the TOF spectra before background subtraction together with the background from isotopic impurities. The worst case of the ${ }^{152} \mathrm{Gd}$ sample the correction is about $50 \%$ of the observed effect. For the other isotopes, which are not shown explicitely, the corrections are even smaller than for ${ }^{156} \mathrm{Gd}$. For a comparable experiment using the pulse height weighting technique, where the observed effect of each isotope is proportional to $\mathrm{N} \sigma \mathrm{B}_{n}, \mathrm{~N}$ being the abundance and $\mathrm{B}_{n}$ the binding energy, the respective correction can be estimated to $75 \%$ : While the correction for isotopic impurities in the present experiment equals the number of true captures in ${ }^{152} \mathrm{Gd}$, it is three times larger if the pulse height weighting technique is applied.

Following the correction for isotopic impurities, the background due to capture of sample scattered neutrons was removed from the spectra by means of the data measured with the carbon sample. This correction is comparably small due to the favorable ratios of total and capture cross sections in the Gd isotopes, and was performed in the same way as described for the samarium isotopes[2]. After this last correction, the spectra contain only the net capture events of the respective isotopes (lowest spectra in Figs. 2, 3, and 4).

Figure 2: The different steps of background subtraction in the two dimensional sum energy $\times$ TOF spectra. The data are shown for ${ }^{152} \mathrm{Gd}$ and ${ }^{154} \mathrm{Gd}$ measured in run 3 with 100 $\mathrm{keV}$ maximum neutron energy and events with multiplicity $>2$. (The original resolution of $128 \times 2048$ channels was compressed into $64 \times 64$ channels. Events at low sum energy and large TOF were cut by the preprocessing unit of the ADC system). 

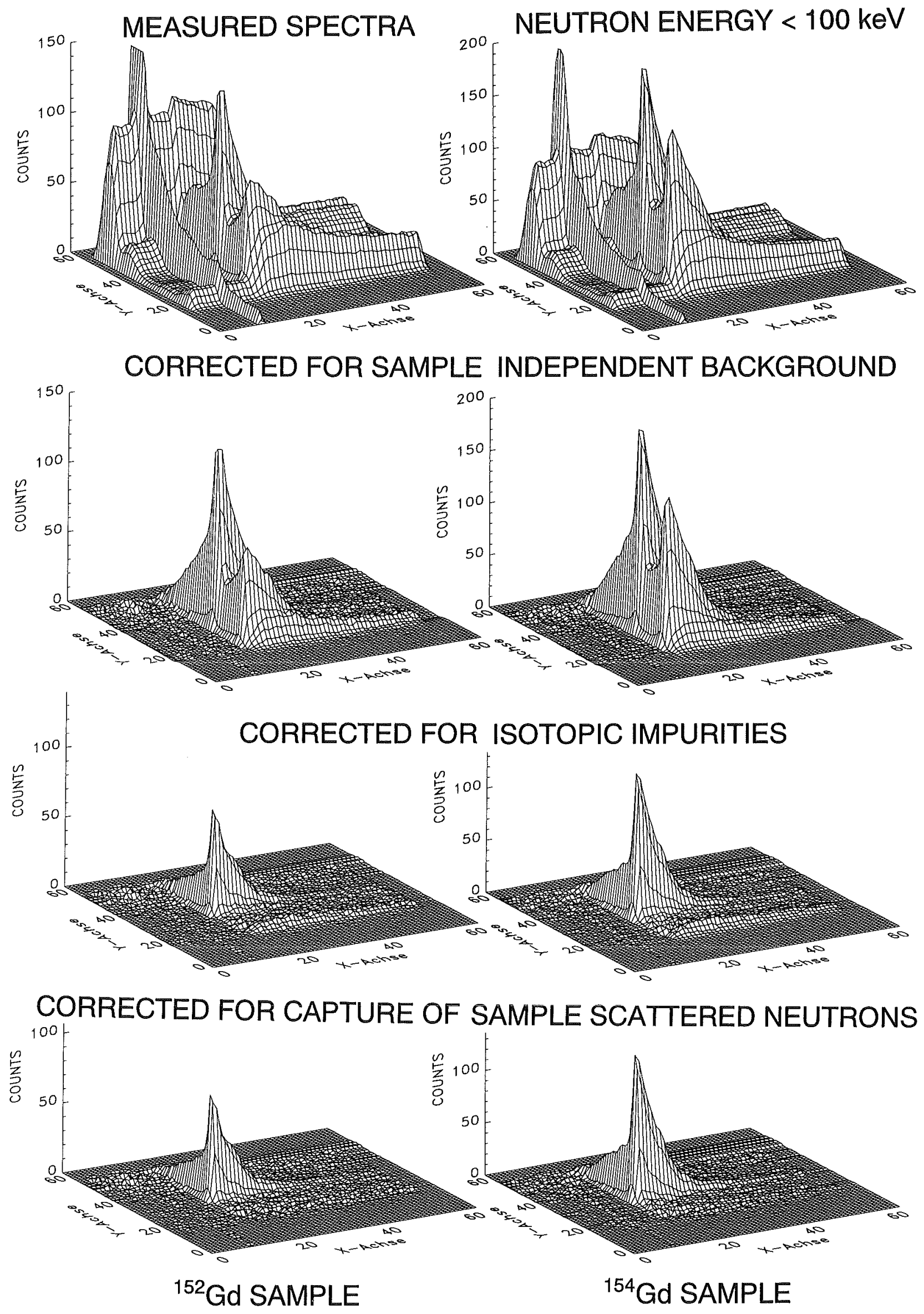

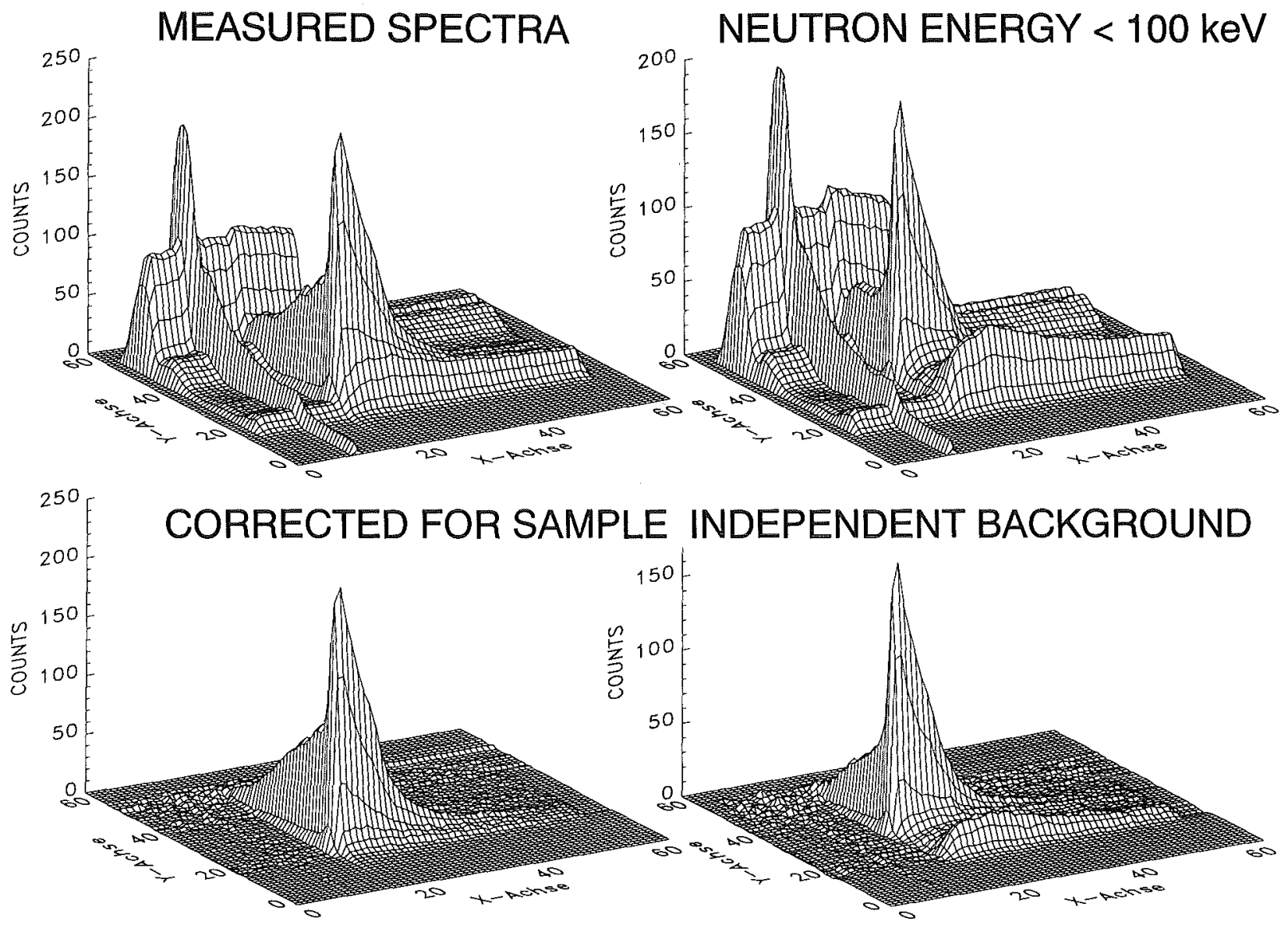

CORRECTED FOR CAPTURE OF SAMPLE SCATTERED NEUTRONS

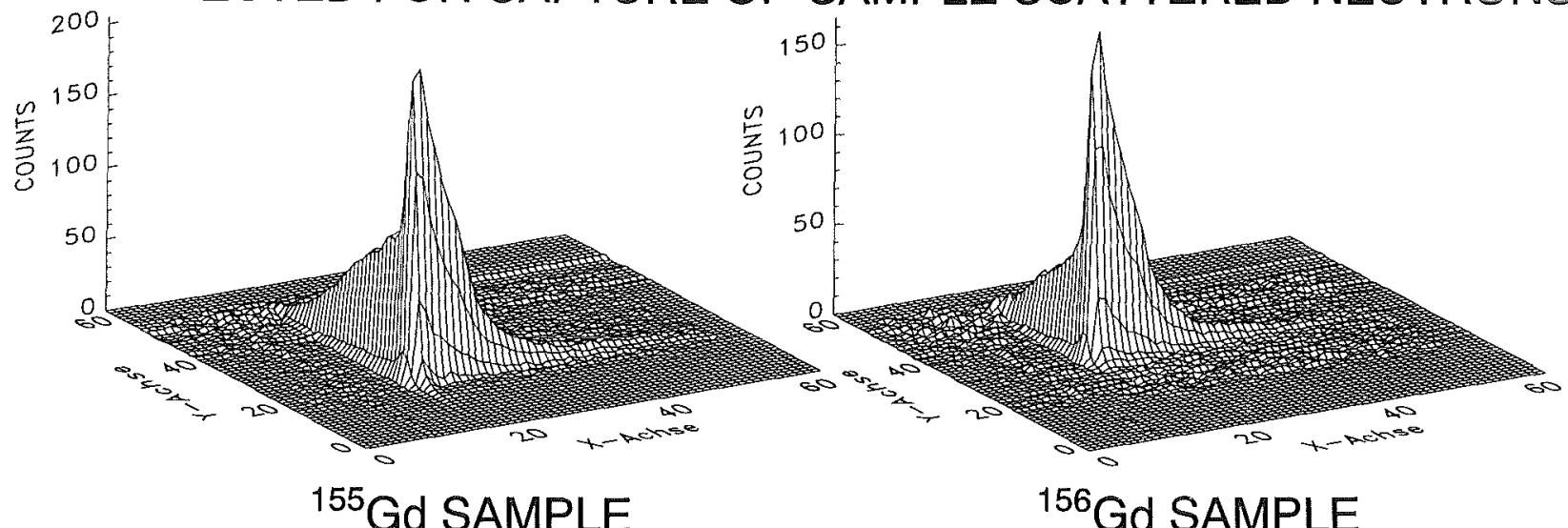

Figure 3: The same as Fig. 2 but for the ${ }^{155} \mathrm{Gd}$ and ${ }^{156} \mathrm{Gd}$ samples. The correction for isotopic impurities was omitted since the difference is not visible in these spectra. 

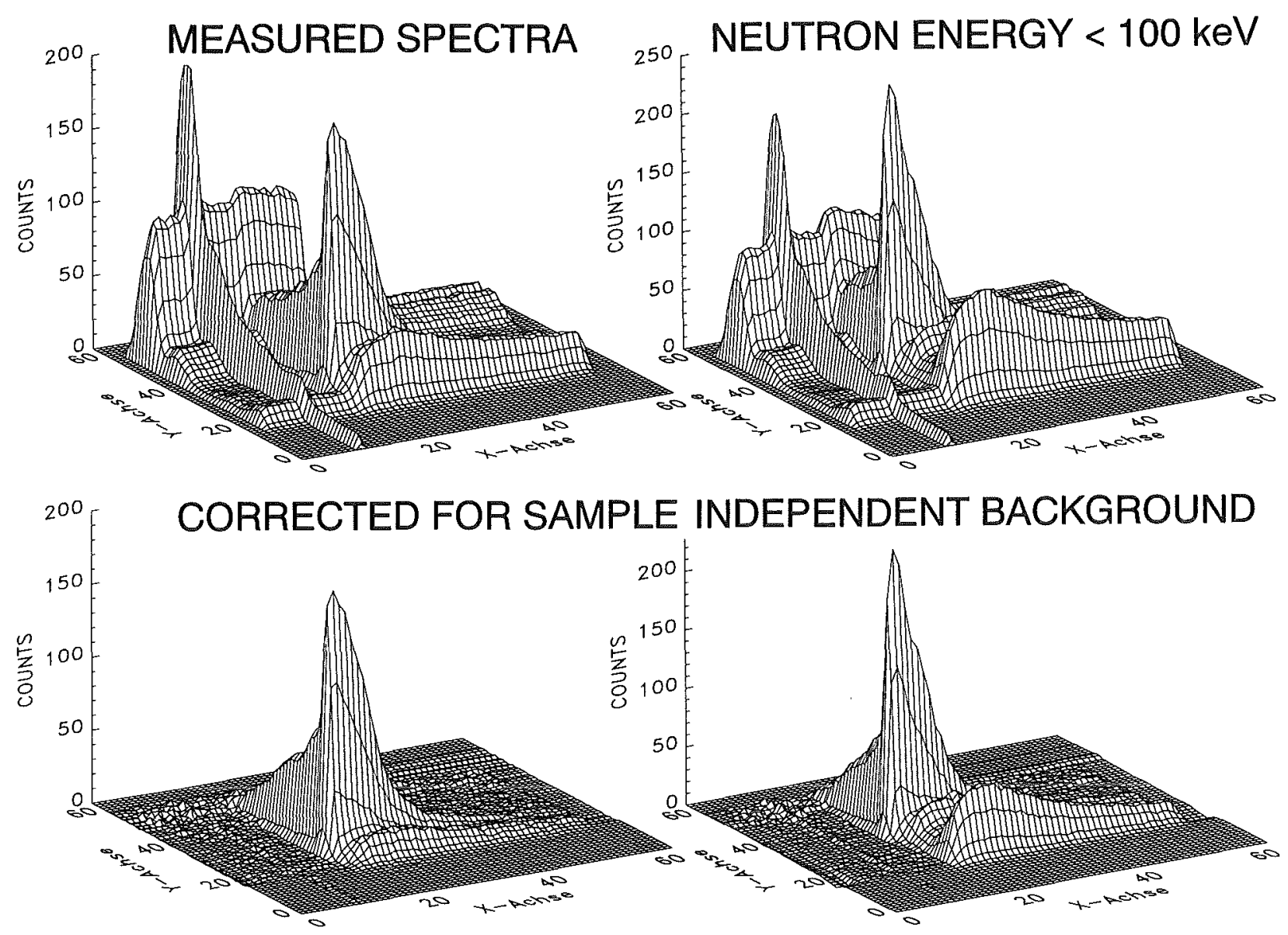

CORRECTED FOR CAPTURE OF SAMPLE SCATTERED NEUTRONS

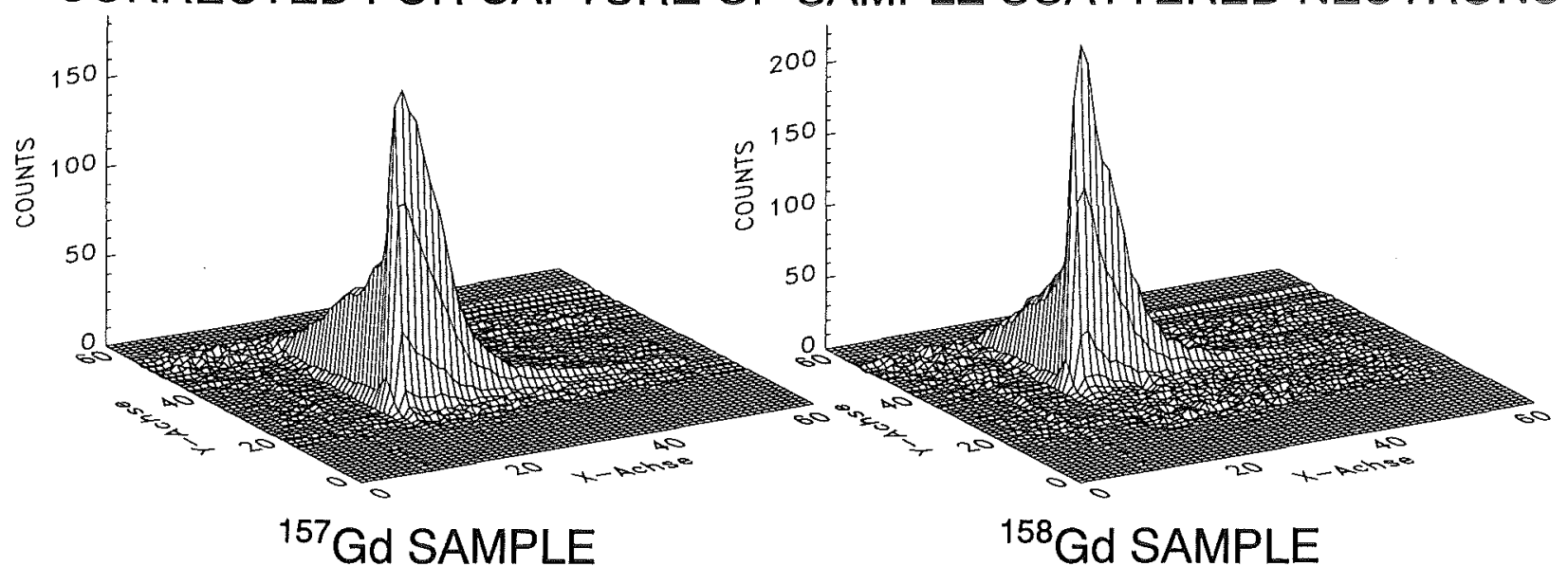

Figure 4: The same as Fig. 3 but for the ${ }^{157} \mathrm{Gd}$ and ${ }^{158} \mathrm{Gd}$ samples. 


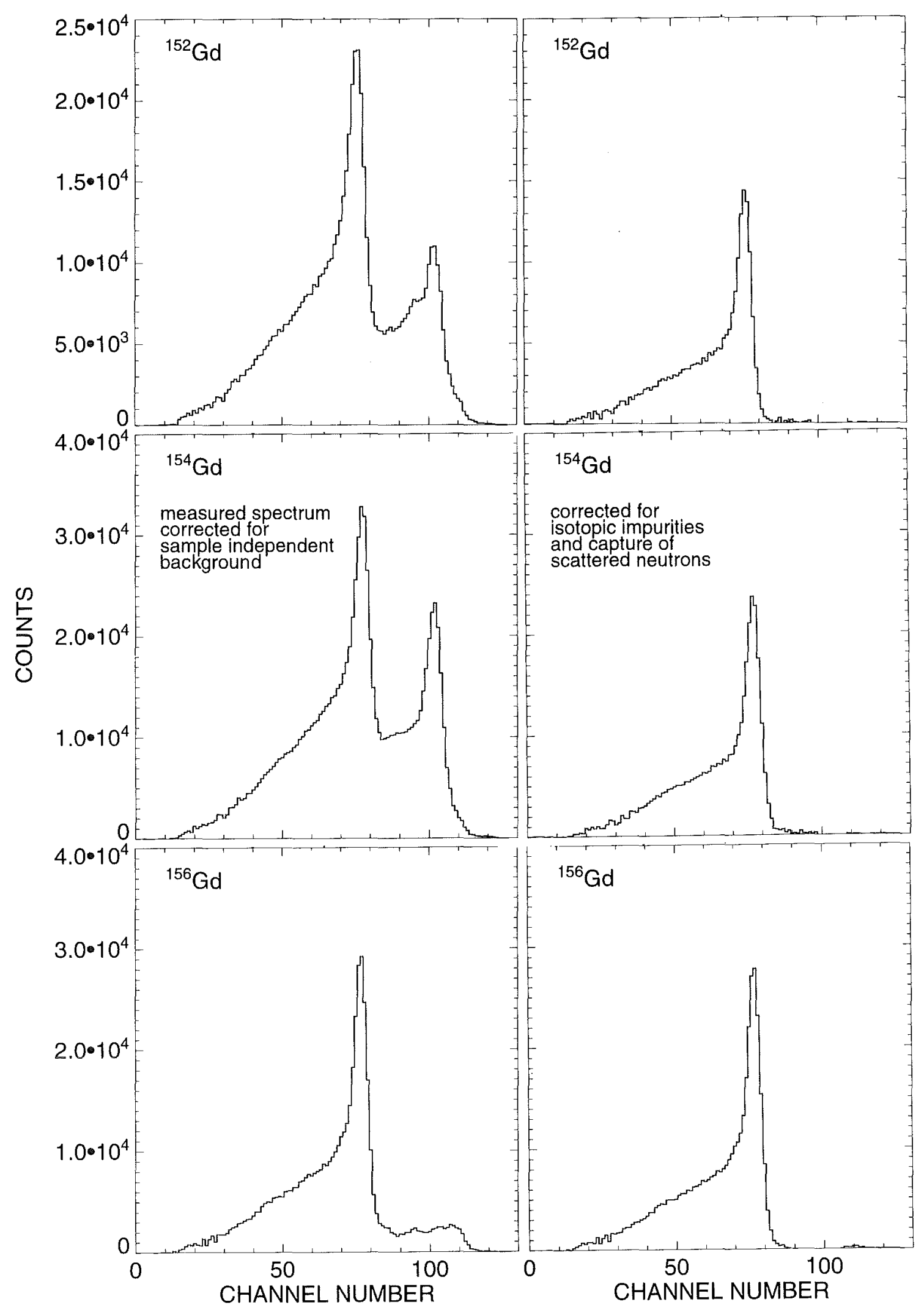

Figure 5: Sum energy spectra of the ${ }^{152} \mathrm{Gd},{ }^{154} \mathrm{Gd}$, and ${ }^{156} \mathrm{Gd}$ samples before and after correction for isotopic impurities and capture of scattered neutrons. 


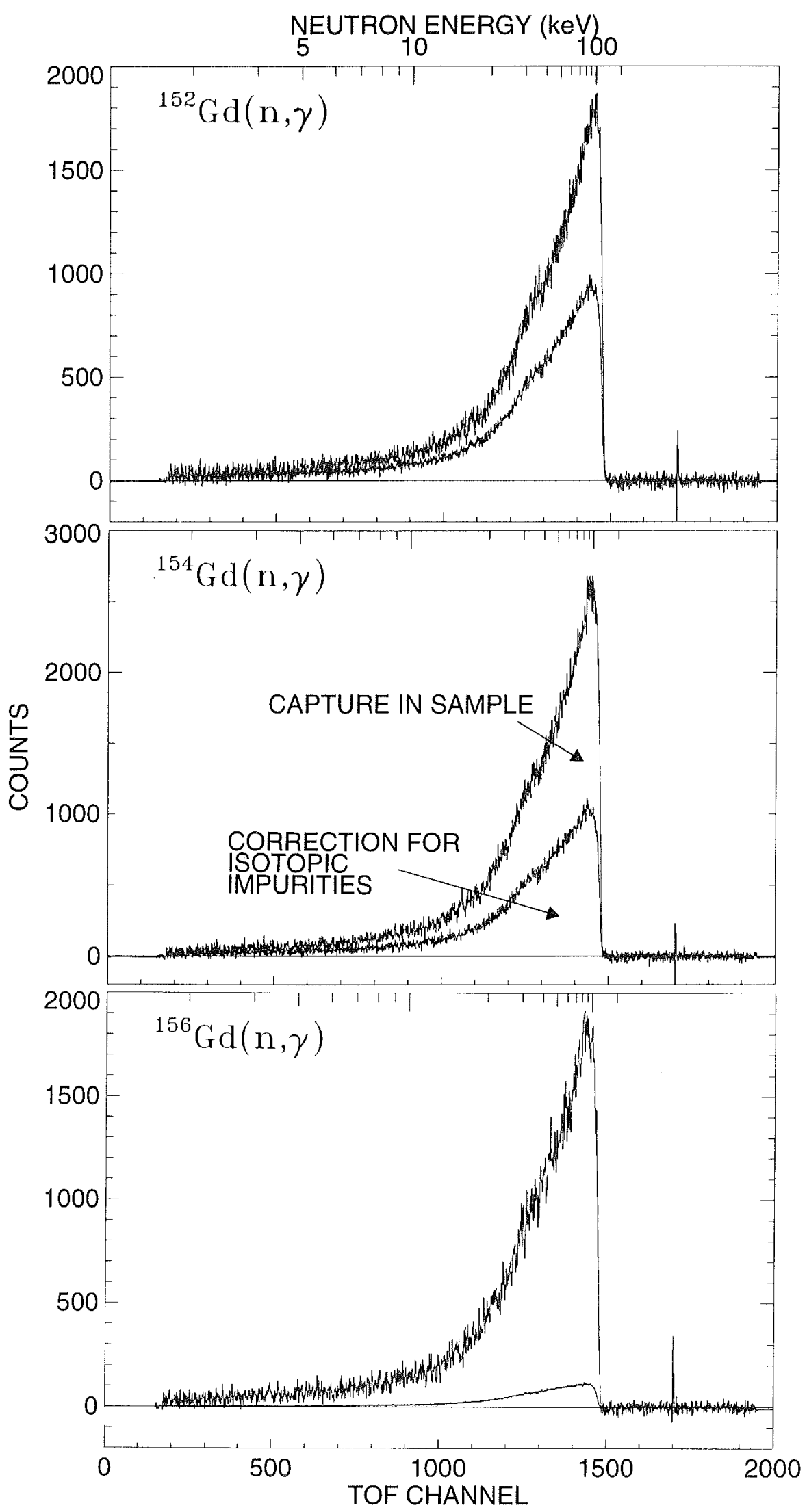

Figure 6: TOF spectra of the ${ }^{152} \mathrm{Gd},{ }^{154} \mathrm{Gd}$, and ${ }^{156} \mathrm{Gd}$ samples. The background due to isotopic impurities is shown separately. 
Table 7: SIGNAL-TO-BACKGROUND RATIO FOR RUNS WITH DIFFERENT MAXIMUM NEUTRON ENERGY

\begin{tabular}{lccccc}
\hline Sample & $\begin{array}{c}\sigma_{t} / \sigma_{\gamma} \\
\text { at } 30 \mathrm{keV}\end{array}$ & $\begin{array}{c}\text { Maximum Neutron } \\
\text { Energy }(\mathrm{keV})\end{array}$ & \multicolumn{3}{c}{$\begin{array}{c}\text { Signal/Background ratio } \\
\text { neutron energy (keV) }\end{array}$} \\
& & & 30 & 20 & 10 \\
\hline${ }^{152} \mathrm{Gd}$ & 23.5 & 100 & 14.3 & 7.0 & 3.9 \\
${ }^{154} \mathrm{Gd}$ & 19.3 & & 14.4 & 6.6 & 3.8 \\
${ }^{155} \mathrm{Gd}$ & 6.0 & & 10.5 & 5.8 & 3.1 \\
${ }^{156} \mathrm{Gd}$ & 28.4 & & 9.1 & 4.0 & 2.8 \\
${ }^{157} \mathrm{Gd}$ & 12.0 & & 11.1 & 5.2 & 3.0 \\
${ }^{158} \mathrm{Gd}$ & 46.5 & & 7.6 & 3.5 & 2.2 \\
${ }^{197} \mathrm{Au}$ & 24.0 & & 10.4 & 4.5 & 3.3 \\
& & & & & \\
${ }^{152} \mathrm{Gd}$ & & 200 & 11.1 & 6.1 & 3.5 \\
${ }^{154} \mathrm{Gd}$ & & & 10.7 & 5.4 & 3.1 \\
${ }^{155} \mathrm{Gd}$ & & & 9.0 & 4.6 & 3.0 \\
${ }^{156} \mathrm{Gd}$ & & & 7.6 & 3.7 & 2.7 \\
${ }^{157} \mathrm{Gd}$ & & & 8.1 & 4.5 & 2.4 \\
${ }^{158} \mathrm{Gd}$ & & & 5.6 & 3.2 & 2.0 \\
${ }^{197} \mathrm{Au}$ & & & 8.0 & 4.3 & 3.0 \\
\hline
\end{tabular}

${ }^{1}$ the ratios are defined as (effect+background)/(background)

The corrections for capture of scattered neutrons are shown in Fig. 7, and their influence at different neutron energies is documented in Table 7 for the runs with maximum neutron energies of $100 \mathrm{keV}$ and $200 \mathrm{keV}$.

After background subtraction, the TOF spectra in Fig.7 were used to determine the cross section shape. For normalization, the two-dimensional data were projected onto the sum energy axis using the TOF region of optimum signal to background ratio as indicated in Fig.7 by dashed boxes. The resulting pulse height spectra are shown in Fig. 8 for the events with multiplicity $>2$. Note, that the threshold in sum energy could be lowered to $1.4 \mathrm{MeV}$.

In Fig.9, the sum energy spectra of the gadolinium isotopes are shown for different multiplicities. (These multiplicities correspond to the number of detector modules contributing per event. The true multiplicities are slightly smaller, because of cross talking effects). While 30 to $40 \%$ of the capture events in even isotopes are observed with multiplicities $\geq 5$, the respective number is 50 to $60 \%$ for the odd isotopes. The arrows in Fig. 9 indicate the range of sum energy channels that were combined to yield the TOF spectra of Fig.7, which were used to determine the cross section shapes.

Closer inspection of Fig. 9 shows a small negative dip in the spectrum of the ${ }^{154} \mathrm{Gd}$ with multiplicity $\geq 5$, indicating that the isotopic impurity of ${ }^{155} \mathrm{Gd}$ was slightly overcompensated. In principle one could use this information to improve the isotopic composition of the sample. The resulting difference is well within the quoted uncertainties and will be discussed in Sec.5. For the ${ }^{152} \mathrm{Gd}$ sample the correction is smaller by a factor of three and, 
therefore, the respective dip is hardly visible. Since $62 \%$ of the capture events in ${ }^{155} \mathrm{Gd}$ have multiplicities $\geq 5$, this effect is not observable in the spectra with lower multiplicity.

The cross section ratio of isotope $\mathrm{X}$ relative to the gold standard is then

$$
\frac{\sigma_{i}(X)}{\sigma_{i}(A u)}=\frac{Z_{i}(X)}{Z_{i}(A u)} \cdot \frac{\Sigma Z(A u)}{\Sigma Z(X)} \cdot \frac{\Sigma E(X)}{\Sigma E(A u)} \cdot \frac{m(A u)}{m(X)} \cdot F_{1} \cdot F_{2} .
$$

In this expression, $Z_{i}$ is the count rate in channel $i$ of the TOF spectrum, $\Sigma Z$ is the TOF rate integrated over the interval used for normalization (Fig.7), $\Sigma \mathrm{E}$ is the total count rate in the sum energy spectrum for all multiplicities summed over the normalization interval (Fig.8), and $\mathrm{m}$ is the sample thickness in atoms/barn. The factor $\mathrm{F}_{1}=(100$ $f(A u)) /(100-f(X))$ corrects for the fraction of capture events $f$ below the experimental threshold in sum energy, where $X$ refers to the respective gadolinium sample (Table 8 ), and $\mathrm{F}_{2}$ is the respective ratio of the multiple scattering and self-shielding corrections .

Table 8: FRACTION OF UNDETECTED CAPTURE EVENTS, $f(\%)$, AND THE RELATED CORRECTION FACTORS ${ }^{1}$

\begin{tabular}{|c|c|c|c|c|c|}
\hline & \multicolumn{4}{|c|}{ Threshold in Sum Energy $(\mathrm{MeV})$} & \multirow{2}{*}{$\begin{array}{c}\text { Assumption for } \\
\text { Gamma-Ray Cascades }\end{array}$} \\
\hline & 1.0 & 1.4 & 1.5 & 2.0 & \\
\hline$f(A u)$ & 2.16 & & 3.30 & 4.93 & Reffo \\
\hline$f\left({ }^{152} \mathrm{Gd}\right)$ & 1.08 & & 2.07 & 3.42 & \\
\hline$f\left({ }^{154} \mathrm{Gd}\right)$ & 0.82 & & 1.62 & 2.80 & \\
\hline$f\left({ }^{155} \mathrm{Gd}\right)$ & 0.45 & & 0.89 & 1.23 & \\
\hline$f\left({ }^{156} \mathrm{Gd}\right)$ & 0.96 & & 1.49 & 2.98 & \\
\hline$f\left({ }^{157} \mathrm{Gd}\right)$ & 0.55 & & 1.13 & 1.74 & \\
\hline$f\left({ }^{158} \mathrm{Gd}\right)$ & 1.41 & & 2.10 & 5.16 & \\
\hline$f(A u)$ & 3.02 & & 4.94 & 6.79 & Uhl \\
\hline$f\left({ }^{152} \mathrm{Gd}\right)$ & 1.88 & & 3.07 & 4.78 & \\
\hline$f\left({ }^{154} \mathrm{Gd}\right)$ & 1.37 & & 2.33 & 3.69 & \\
\hline$f\left({ }^{155} \mathrm{Gd}\right)$ & 0.39 & & 0.89 & 1.42 & \\
\hline$f\left({ }^{156} \mathrm{Gd}\right)$ & 1.60 & & 2.71 & 4.28 & \\
\hline$f\left({ }^{157} G d\right)$ & 0.67 & & 1.33 & 2.00 & \\
\hline$f\left({ }^{158} \mathrm{Gd}\right)$ & 2.04 & & 3.52 & 5.25 & \\
\hline $\mathrm{F}_{1}\left({ }^{152} \mathrm{Gd} / \mathrm{Au}\right)$ & 0.988 & 0.985 & 0.984 & 0.982 & (Reffo + \\
\hline $\mathrm{F}_{1}\left({ }^{154} \mathrm{Gd} / \mathrm{Au}\right)$ & 0.985 & 0.979 & 0.978 & 0.973 & Uhl) / 2 \\
\hline $\mathrm{F}_{1}\left({ }^{155} \mathrm{Gd} / \mathrm{Au}\right)$ & 0.979 & 0.969 & 0.967 & 0.954 & \\
\hline $\mathrm{F}_{1}\left({ }^{156} \mathrm{Gd} / \mathrm{Au}\right)$ & 0.987 & 0.981 & 0.979 & 0.977 & \\
\hline $\mathrm{F}_{1}\left({ }^{157} \mathrm{Gd} / \mathrm{Au}\right)$ & 0.980 & 0.972 & 0.970 & 0.959 & \\
\hline $\mathrm{F}_{1}\left({ }^{158} \mathrm{Gd} / \mathrm{Au}\right)$ & 0.990 & 0.986 & 0.985 & 0.984 & \\
\hline
\end{tabular}

${ }^{1}$ Solid angle $96 \%, \gamma$-ray threshold $50 \mathrm{keV}$ 


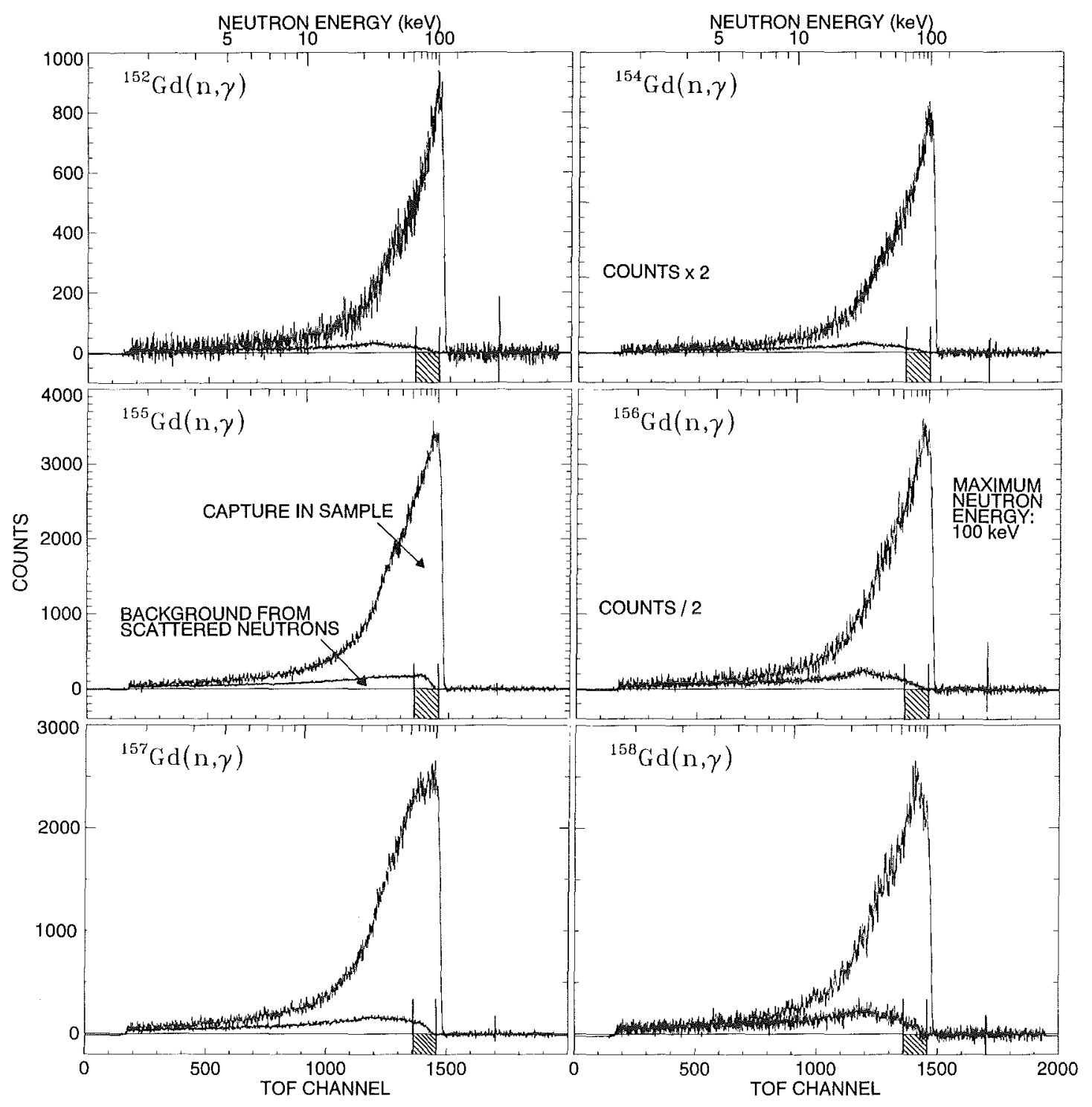

Figure 7: TOF spectra measured with the gadolinium samples in run 3 with $100 \mathrm{keV}$ maximum neutron energy. The background due to sample scattered neutrons is shown separately. The region used for the absolute normalization of the cross section is shown by hatched boxes. 


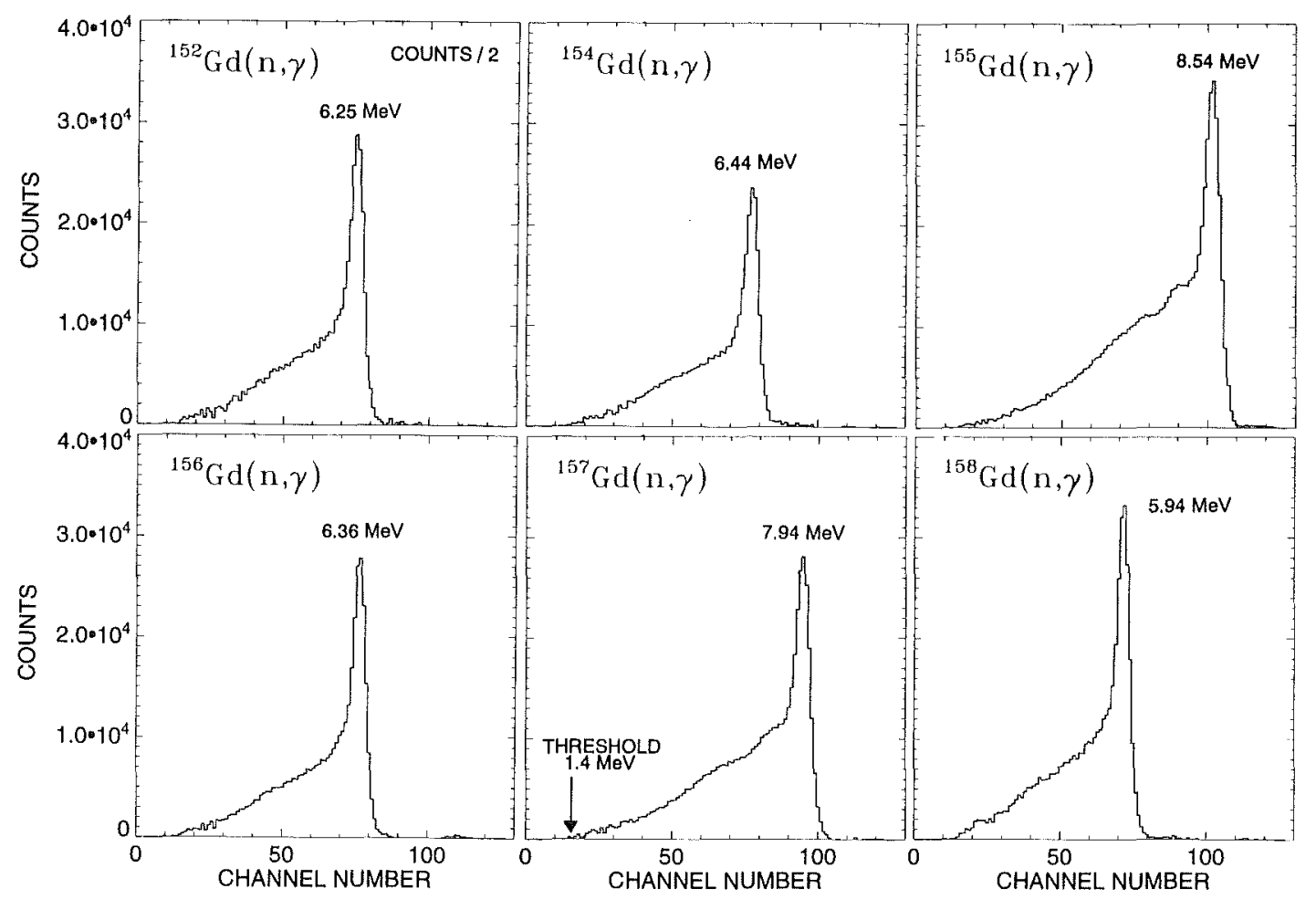

Figure 8: Sum energy spectra of all isotopes measured in run 2 containing all events with multiplicity $>2$. These spectra were obtained by projection of the two-dimensional spectra in the TOF region below the maximum neutron energy as indicated by hached boxes in Fig.7

The fraction of unobserved capture events, $f$, and the correction factor $F_{1}$ were calculated as described in detail in Ref.[14]. The required input for this calculation are the individual neutron capture cascades and their relative contributions to the total capture cross section as well as the detector efficiency for monoenergetic $\gamma$-rays in the energy range up to $10 \mathrm{MeV}$. Since this correction is limiting the accuracy of the present experimental technique, an attempt was made to compare these corrections with two independent sets of capture cascades and capture $\gamma$-ray spectra of the involved isotopes, one calculated by G. Reffo according to the statistical and optical models[19] as in the previous measurements with the $4 \pi \mathrm{BaF}_{2}$ detector[1,2,3], and a second set calculated by $\mathrm{M}$. Uhl [20]. Both calculations are based on the Hauser Feshbach approach, but the way how the gamma cascades are calculated is different. In Table 9, the cross sections are given as a function of cascade multiplicity together with the $\gamma$-ray energies of the 20 most probable cascades. The calculations are compared in Table 9 for the two s-only isotopes ${ }^{152} \mathrm{Gd}$ and ${ }^{154} \mathrm{Gd}$ as well as for the odd isotope ${ }^{155} \mathrm{Gd}$. Calculated average multiplicities are compiled in Table 10 for all isotopes. The capture $\gamma$-ray spectra of both calculations are compared in Fig.10 and Fig.11. 


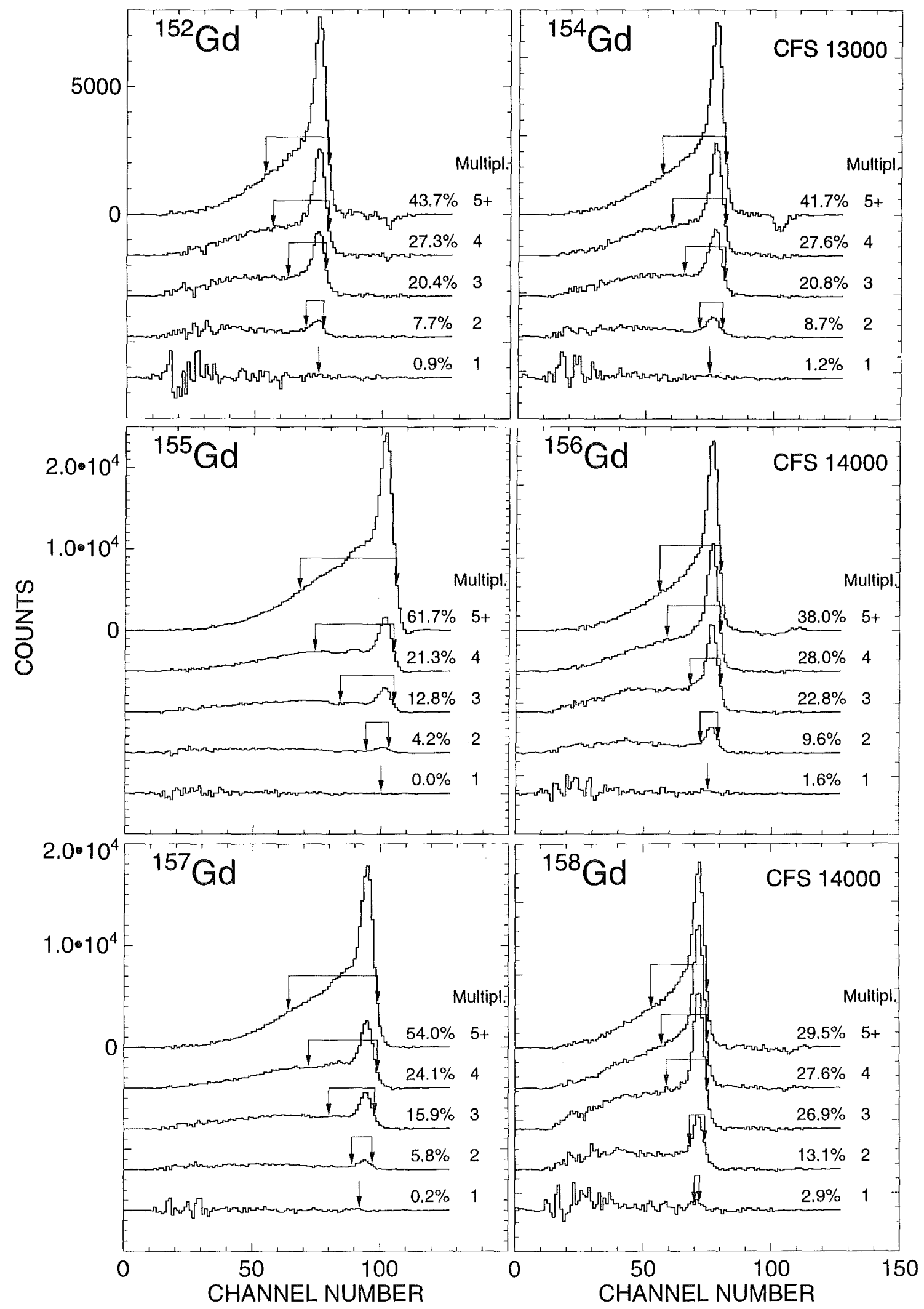

Figure 9: Sum energy spectra of all gadolinium isotopes in dependence of the detector multiplicity. The regions used to determine the cross section shape are indicated by arrows. 
Table 9: CALCULATED CAPTURE GAMMA-RAY CASCADES INCLUDING MULTIPLICITIES, PARTIAL CROSS SECTIONS, $\sigma_{p}$, AND GAMMA-RAY ENERGIES OF THE 20 MOST SIGNIFICANT CASCADES

\section{${ }^{152} \mathrm{Gd}$ Reffo}

$$
\begin{aligned}
& \sigma(30 \mathrm{keV})=935 \mathrm{mb} \quad \text { total capture cross section }{ }^{1} \\
& \sigma(\mathrm{mul} \mathrm{1})=4.9 \mathrm{mb} \\
& \sigma(\mathrm{mul} \mathrm{2})=55.3 \mathrm{mb} \\
& \sigma(\mathrm{mul} \mathrm{3})=207.8 \mathrm{mb} \\
& \sigma(\mathrm{mul} 4)=304.6 \mathrm{mb} \quad \text { average multiplicity }\langle\mathrm{m}>=4.2 \\
& \sigma(\mathrm{mul} 5)=239.5 \mathrm{mb} \\
& \sigma(\text { mul } 6)=98.0 \mathrm{mb} \\
& \sigma(\text { mul } 7)=24.9 \mathrm{mb}
\end{aligned}
$$

5726 cascades covering $95 \%$ of the cross section

\begin{tabular}{lccccc}
$\begin{array}{l}\sigma_{p} \\
(\mathrm{mb})\end{array}$ & $\begin{array}{c}\sigma_{p} / \sigma \\
(\%)\end{array}$ & $\mathrm{E}_{\gamma 1}$ & $\mathrm{E}_{\gamma 2}$ & $\begin{array}{c}\mathrm{E}_{\gamma 3} \\
(\mathrm{MeV})\end{array}$ & $\mathrm{E}_{\gamma 4}$ \\
7.58 & 0.81 & 5.411 & 1.106 & & \\
6.45 & 0.69 & 3.006 & 2.405 & 1.106 & \\
5.95 & 0.64 & 2.405 & 3.006 & 1.106 & \\
5.91 & 0.63 & 4.810 & 1.707 & & \\
5.67 & 0.61 & 3.608 & 1.804 & 1.106 & \\
& & & & & \\
5.63 & 0.60 & 4.209 & 2.308 & & \\
5.39 & 0.58 & 3.608 & 2.910 & & \\
4.84 & 0.52 & 3.006 & 3.511 & & \\
4.65 & 0.50 & 6.517 & & & \\
4.25 & 0.45 & 1.804 & 3.607 & 1.106 & \\
& & & & & \\
4.06 & 0.43 & 4.209 & 1.202 & 1.106 & \\
3.83 & 0.41 & 2.405 & 4.112 & & \\
3.43 & 0.37 & 2.405 & 2.405 & 1.707 & \\
3.35 & 0.36 & 3.006 & 2.405 & 1.064 & 0.042 \\
3.26 & 0.35 & 5.411 & 1.064 & 0.042 & \\
& & & & & \\
3.13 & 0.33 & 6.081 & 0.436 & & \\
3.09 & 0.33 & 2.405 & 3.006 & 1.064 & 0.042 \\
3.05 & 0.33 & 3.006 & 1.804 & 1.707 & \\
2.95 & 0.32 & 6.202 & 0.315 & & \\
2.93 & $\underline{0.31}$ & 3.608 & 1.804 & 1.064 & 0.042 \\
& $\Sigma=9.6 \%$ & & & & \\
\hline
\end{tabular}

${ }^{1}$ normalized to present experimental result 
${ }^{152} \mathrm{Gd}$ Uhl

$\sigma(100 \mathrm{keV})=604 \mathrm{mb}$ total capture cross section

$\sigma(\mathrm{mul} \mathrm{1})=2.8 \mathrm{mb}$

$\sigma(\mathrm{mul} \mathrm{2})=44.0 \mathrm{mb}$

$\sigma(\mathrm{mul} \mathrm{3})=164.0 \mathrm{mb}$

$\sigma(\mathrm{mul} \mathrm{4})=212.4 \mathrm{mb} \quad$ average multiplicity $\langle\mathrm{m}\rangle=4.0$

$\sigma(\mathrm{mul} \mathrm{5})=121.2 \mathrm{mb}$

$\sigma(\mathrm{mul} 6)=38.8 \mathrm{mb}$

$\sigma(\mathrm{mul} 7)=20.8 \mathrm{mb}$

10000 cascades covering $63 \%$ of the cross section

\begin{tabular}{lrrrrr}
$\begin{array}{l}\sigma_{p} \\
(\mathrm{mb})\end{array}$ & $\begin{array}{c}\sigma_{p} / \sigma \\
(\%)\end{array}$ & $\mathrm{E}_{\gamma 1}$ & $\mathrm{E}_{\gamma 2}$ & $\begin{array}{c}\mathrm{E}_{\gamma 3} \\
(\mathrm{MeV})\end{array}$ & $\mathrm{E}_{\gamma 4}$ \\
2.32 & 0.39 & 5.658 & 0.689 & \\
1.76 & 0.29 & 5.460 & 0.887 & \\
1.75 & 0.29 & 6.347 & & \\
1.65 & 0.27 & 5.063 & 1.284 & \\
1.50 & 0.25 & 5.261 & 1.086 & \\
& & & & \\
1.26 & 0.21 & 4.864 & 1.483 & \\
1.12 & 0.19 & 4.666 & 1.681 & \\
1.08 & 0.18 & 5.658 & 0.646 & 0.042 \\
0.99 & 0.16 & 4.467 & 1.880 & \\
0.96 & 0.16 & 5.460 & 0.845 & 0.042 \\
& & & & \\
0.94 & 0.16 & 4.269 & 2.078 & \\
0.92 & 0.15 & 6.032 & 0.315 & \\
0.88 & 0.15 & 5.911 & 0.436 & \\
0.86 & 0.14 & 4.070 & 2.277 & \\
0.83 & 0.14 & 5.063 & 1.242 & 0.042 \\
& & & & \\
0.80 & 0.13 & 4.666 & 1.639 & 0.042 \\
0.76 & 0.13 & 4.864 & 1.441 & 0.042 \\
0.73 & 0.12 & 6.026 & 0.321 & \\
0.71 & 0.12 & 6.218 & 0.087 & 0.042 \\
0.71 & $\underline{0.12}$ & 5.261 & 1.044 & 0.042 \\
& $\Sigma=3.6 \%$ & & & \\
\hline
\end{tabular}


$\sigma(30 \mathrm{keV})=965 \mathrm{mb}^{1} \quad$ total capture cross section

$\sigma(\operatorname{mul~1})=3.8 \mathrm{mb}$

$\sigma(\mathrm{mul} \mathrm{2})=46.6 \mathrm{mb}$

$\sigma(\mathrm{mul} \mathrm{3})=178.3 \mathrm{mb} \quad$ average multiplicity $<\mathrm{m}>=4.4$

$\sigma(\mathrm{mul} \mathrm{4})=289.0 \mathrm{mb}$

$\sigma(\mathrm{mul} \mathrm{5})=265.6 \mathrm{mb}$

$\sigma(\mathrm{mul} \mathrm{6})=140.3 \mathrm{mb}$

$\sigma(\mathrm{mul} \mathrm{7})=41.4 \mathrm{mb}$

6925 cascades covering $95 \%$ of the cross section

\begin{tabular}{|c|c|c|c|c|c|}
\hline $\begin{array}{l}\sigma_{p} \\
(\mathrm{mb})\end{array}$ & $\begin{array}{c}\sigma_{p} / \sigma \\
(\%)\end{array}$ & $\mathrm{E}_{\gamma 1}$ & $\mathrm{E}_{\gamma 2}$ & ${ }_{(\mathrm{MeV})^{\mathrm{E}^{3}}}$ & $\mathrm{E}_{\gamma^{4}}$ \\
\hline 10.6 & 1.10 & 5.415 & 1.053 & & \\
\hline 10.6 & 1.10 & 3.008 & 2.406 & 1.053 & \\
\hline 9.90 & 1.03 & 3.610 & 1.805 & 1.053 & \\
\hline 9.35 & 0.97 & 2.407 & 3.008 & 1.053 & \\
\hline 7.72 & 0.80 & 4.212 & 1.203 & 1.053 & \\
\hline 6.62 & 0.69 & 4.813 & 1.655 & & \\
\hline 6.47 & 0.67 & 1.805 & 3.610 & 1.053 & \\
\hline 5.67 & 0.59 & 4.212 & 2.257 & & \\
\hline 5.18 & 0.54 & 3.008 & 2.406 & 0.994 & 0.060 \\
\hline 5.04 & 0.52 & 3.610 & 2.858 & & \\
\hline 4.89 & 0.51 & 4.813 & 0.602 & 1.053 & \\
\hline 4.83 & 0.50 & 3.610 & 1.805 & 0.994 & 0.060 \\
\hline 4.58 & 0.47 & 2.407 & 3.008 & 0.994 & 0.060 \\
\hline 4.33 & 0.45 & 5.415 & 0.994 & 0.060 & \\
\hline 4.30 & 0.45 & 2.407 & 2.406 & 1.655 & \\
\hline 4.29 & 0.44 & 3.008 & 3.460 & & \\
\hline 4.00 & 0.41 & 3.008 & 1.805 & 1.655 & \\
\hline 3.76 & 0.39 & 4.212 & 1.203 & 0.994 & 0.060 \\
\hline 3.59 & 0.37 & 6.468 & & & \\
\hline 3.38 & $\Sigma=\frac{0.35}{\Sigma=12.4 \%}$ & 1.805 & 3.008 & 1.655 & \\
\hline
\end{tabular}

${ }^{1}$ normalized to experimental result 
${ }^{154} \mathrm{Gd} \mathrm{Uhl}$

$\sigma(100 \mathrm{keV})=641 \mathrm{mb}$ total capture cross section

$\sigma(\mathrm{mul} \mathrm{1})=2.8 \mathrm{mb}$

$\sigma(\mathrm{mul} \mathrm{2})=41.0 \mathrm{mb}$

$\sigma(\mathrm{mul} \mathrm{3})=155.7 \mathrm{mb}$

$\sigma(\mathrm{mul} \mathrm{4})=248.1 \mathrm{mb}$

average multiplicity $<\mathrm{m}>=4.0$

$\sigma(\mathrm{mul} \mathrm{5})=164.8 \mathrm{mb}$

$\sigma(\mathrm{mul} \mathrm{6})=27.0 \mathrm{mb}$

$\sigma(\mathrm{mul} \mathrm{7})=1.6 \mathrm{mb}$

10000 cascades covering $65 \%$ of the cross section

\begin{tabular}{lcccc}
$\begin{array}{l}\sigma_{p} \\
(\mathrm{mb})\end{array}$ & $\begin{array}{c}\sigma_{p} / \sigma \\
(\%)\end{array}$ & $\mathrm{E}_{\gamma 1}$ & $\mathrm{E}_{\gamma 2}$ & $\begin{array}{c}\mathrm{E}_{\gamma 3} \\
(\mathrm{MeV})\end{array}$ \\
1.83 & 0.29 & 6.537 & & \\
1.43 & 0.22 & 6.432 & 0.105 & \\
1.07 & 0.17 & 5.814 & 0.724 & \\
1.06 & 0.17 & 5.433 & 1.104 & \\
0.99 & 0.15 & 5.052 & 1.485 & \\
& & & & \\
0.99 & 0.15 & 5.242 & 1.295 & \\
0.98 & 0.15 & 5.623 & 0.914 & \\
0.96 & 0.15 & 3.528 & 3.009 & \\
0.94 & 0.15 & 6.268 & 0.164 & 0.105 \\
0.91 & 0.14 & 4.861 & 1.676 & \\
& & & & \\
0.90 & 0.14 & 4.480 & 2.057 & \\
0.90 & 0.14 & 3.581 & 2.956 & \\
0.88 & 0.14 & 4.671 & 1.866 & \\
0.87 & 0.14 & 3.337 & 3.200 & \\
0.87 & 0.14 & 3.909 & 2.628 & \\
& & & & \\
0.87 & 0.14 & 4.290 & 2.247 & \\
0.85 & 0.13 & 3.718 & 2.819 & \\
0.85 & 0.13 & 6.115 & 0.422 & \\
0.79 & 0.12 & 6.450 & 0.087 & \\
0.78 & $\underline{0.12}$ & 3.962 & 2.575 & \\
& $\Sigma=3.1 \%$ & & & \\
\hline & & & & \\
& & &
\end{tabular}


${ }^{155}$ Gd Reffo

$\sigma(30 \mathrm{keV})=2609 \mathrm{mb}^{1} \quad$ total capture cross section

$\sigma(\mathrm{mul} \mathrm{1})=5.9 \mathrm{mb}$

$\sigma(\mathrm{mul} \mathrm{2})=162.3 \mathrm{mb}$

$\sigma(\mathrm{mul} \mathrm{3})=750.9 \mathrm{mb} \quad$ average multiplicity $<\mathrm{m}>=4.0$

$\sigma(\mathrm{mul} \mathrm{4})=933.1 \mathrm{mb}$

$\sigma(\mathrm{mul} \mathrm{5})=563.3 \mathrm{mb}$

$\sigma(\mathrm{mul} \mathrm{6})=175.4 \mathrm{mb}$

$\sigma(\mathrm{mul} \mathrm{7})=18.1 \mathrm{mb}$

1605 cascades covering $95 \%$ of the cross section)

\begin{tabular}{lccccc}
$\begin{array}{l}\sigma_{p} \\
(\mathrm{mb})\end{array}$ & $\begin{array}{c}\sigma_{p} / \sigma \\
(\%)\end{array}$ & $\mathrm{E}_{\gamma 1}$ & $\mathrm{E}_{\gamma 2}$ & $\begin{array}{c}\mathrm{E}_{\gamma 3} \\
(\mathrm{MeV})\end{array}$ & $\mathrm{E}_{\gamma 4}$ \\
83.7 & 3.21 & 3.307 & 2.646 & 2.613 & \\
83.0 & 3.18 & 5.953 & 2.613 & & \\
76.3 & 2.92 & 2.646 & 3.307 & 2.613 & \\
73.6 & 2.82 & 3.969 & 1.984 & 2.613 & \\
53.8 & 2.06 & 1.984 & 3.969 & 2.613 & \\
& & & & & \\
49.9 & 1.91 & 4.630 & 1.323 & 2.613 & \\
44.5 & 1.71 & 5.292 & 3.186 & 0.089 & \\
37.4 & 1.43 & 4.630 & 3.847 & 0.089 & \\
30.2 & 1.16 & 3.969 & 4.509 & 0.089 & \\
27.8 & 1.07 & 2.646 & 2.646 & 3.186 & 0.089 \\
& & & & & \\
26.4 & 1.01 & 1.323 & 4.630 & 2.613 & \\
26.4 & 1.01 & 3.307 & 2.646 & 2.524 & 0.089 \\
26.2 & 1.00 & 5.953 & 2.524 & 0.089 & \\
25.1 & 0.96 & 3.307 & 1.984 & 3.186 & 0.089 \\
24.1 & 0.92 & 2.646 & 3.307 & 2.524 & 0.089 \\
& & & & & \\
23.3 & 0.89 & 3.969 & 1.984 & 2.524 & 0.089 \\
23.2 & 0.89 & 3.307 & 5.170 & 0.089 & \\
22.6 & 0.87 & 5.292 & 0.661 & 2.613 & \\
22.3 & 0.85 & 1.984 & 3.307 & 3.186 & 0.089 \\
22.2 & $\underline{0.85}$ & 2.646 & 1.984 & 1.323 & 2.613 \\
& $\Sigma=30.7 \%$ & & & & \\
\hline & & & & &
\end{tabular}

${ }^{1}$ normalized to experimental result 
TABLE 9 (continued)

${ }^{155} \mathrm{Gd}$ Uhl

$\sigma(100 \mathrm{keV})=1298 \mathrm{mb}$ total capture cross section

$\sigma(\mathrm{mul} \mathrm{1})=2.5 \mathrm{mb}$

$\sigma(\mathrm{mul} \mathrm{2})=42.9 \mathrm{mb}$

$\sigma(\mathrm{mul} \mathrm{3})=208.6 \mathrm{mb}$

$\sigma(\mathrm{mul} \mathrm{4})=445.7 \mathrm{mb}$

average multiplicity $<m>=4.4$

$\sigma(\mathrm{mul} \mathrm{5})=412.4 \mathrm{mb}$

$\sigma(\mathrm{mul} \mathrm{6})=162.3 \mathrm{mb}$

$\sigma(\mathrm{mul} 7)=23.7 \mathrm{mb}$

10000 cascades covering $79 \%$ of the cross section)

\begin{tabular}{lcccc}
$\begin{array}{l}\sigma_{p} \\
(\mathrm{mb})\end{array}$ & $\begin{array}{c}\sigma_{p} / \sigma \\
(\%)\end{array}$ & $\mathrm{E}_{\gamma 1}$ & $\mathrm{E}_{\gamma 2}$ & $\begin{array}{c}\mathrm{E}_{\gamma 3} \\
(\mathrm{MeV})\end{array}$ \\
4.00 & 0.31 & 5.561 & 2.987 & 0.089 \\
3.85 & 0.30 & 5.366 & 3.182 & 0.089 \\
3.81 & 0.29 & 8.548 & 0.089 & \\
3.78 & 0.29 & 6.536 & 2.011 & 0.089 \\
3.72 & 0.29 & 4.976 & 3.572 & 0.089 \\
& & & & \\
3.72 & 0.29 & 5.756 & 2.792 & 0.089 \\
3.63 & 0.28 & 6.146 & 2.401 & 0.089 \\
3.57 & 0.28 & 5.951 & 2.596 & 0.089 \\
3.54 & 0.27 & 6.731 & 1.816 & 0.089 \\
3.48 & 0.27 & 6.341 & 2.206 & 0.089 \\
& & & & \\
3.24 & 0.25 & 6.927 & 1.621 & 0.089 \\
3.10 & 0.24 & 4.781 & 3.767 & 0.089 \\
3.06 & 0.24 & 4.391 & 4.157 & 0.089 \\
3.02 & 0.23 & 7.122 & 1.426 & 0.089 \\
2.87 & 0.22 & 5.171 & 3.377 & 0.089 \\
& & & & \\
2.85 & 0.22 & 4.547 & 4.001 & 0.089 \\
2.83 & 0.22 & 4.586 & 3.962 & 0.089 \\
2.63 & 0.20 & 4.352 & 4.196 & 0.089 \\
2.53 & 0.20 & 4.742 & 3.806 & 0.089 \\
2.53 & $\underline{0.20}$ & 4.937 & 3.610 & 0.089 \\
& $\Sigma=5.1 \%$ & & & \\
\hline
\end{tabular}




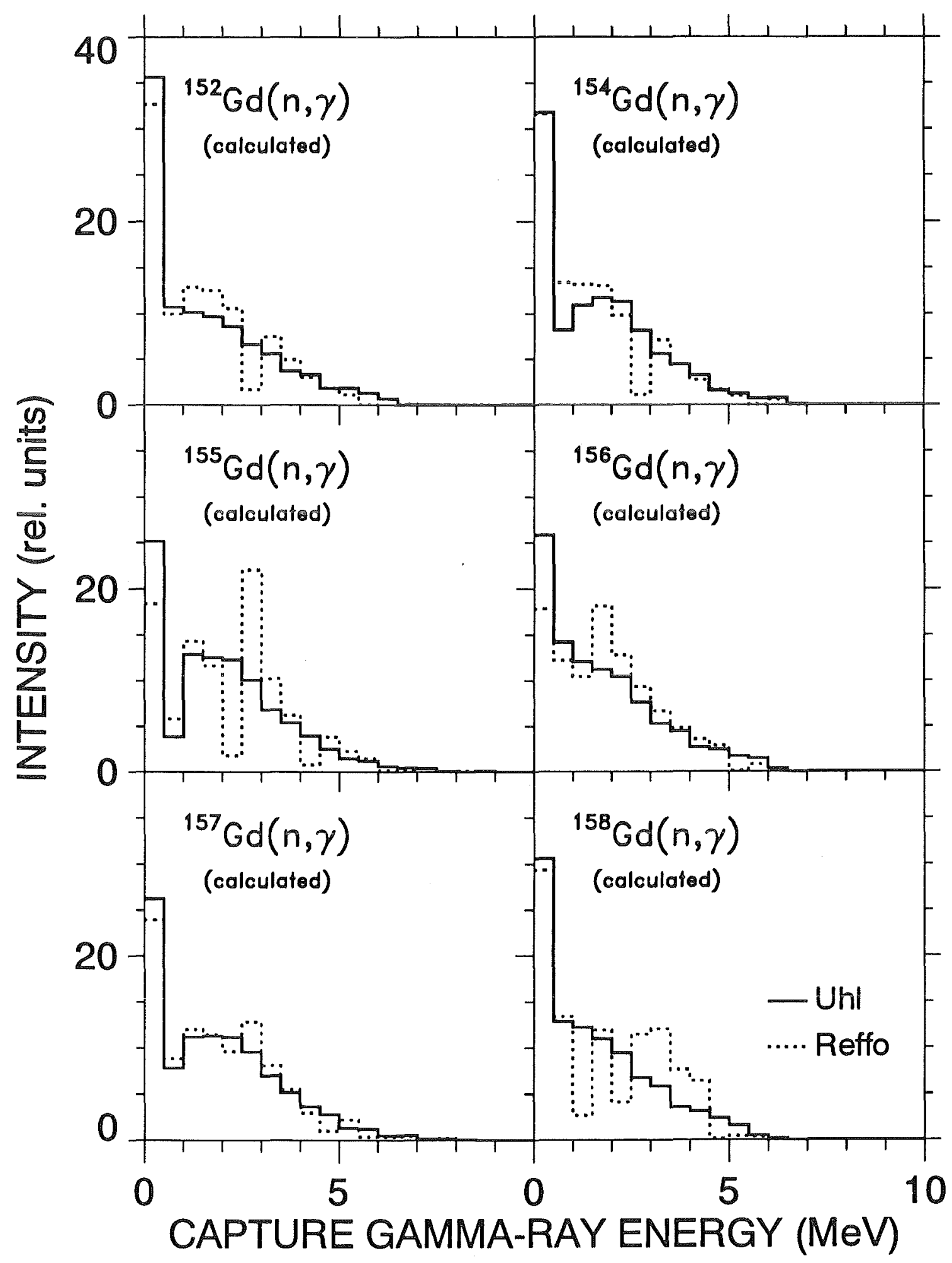

Figure 10: Calculated capture $\gamma$-ray spectra for the gadolinium isotopes. 


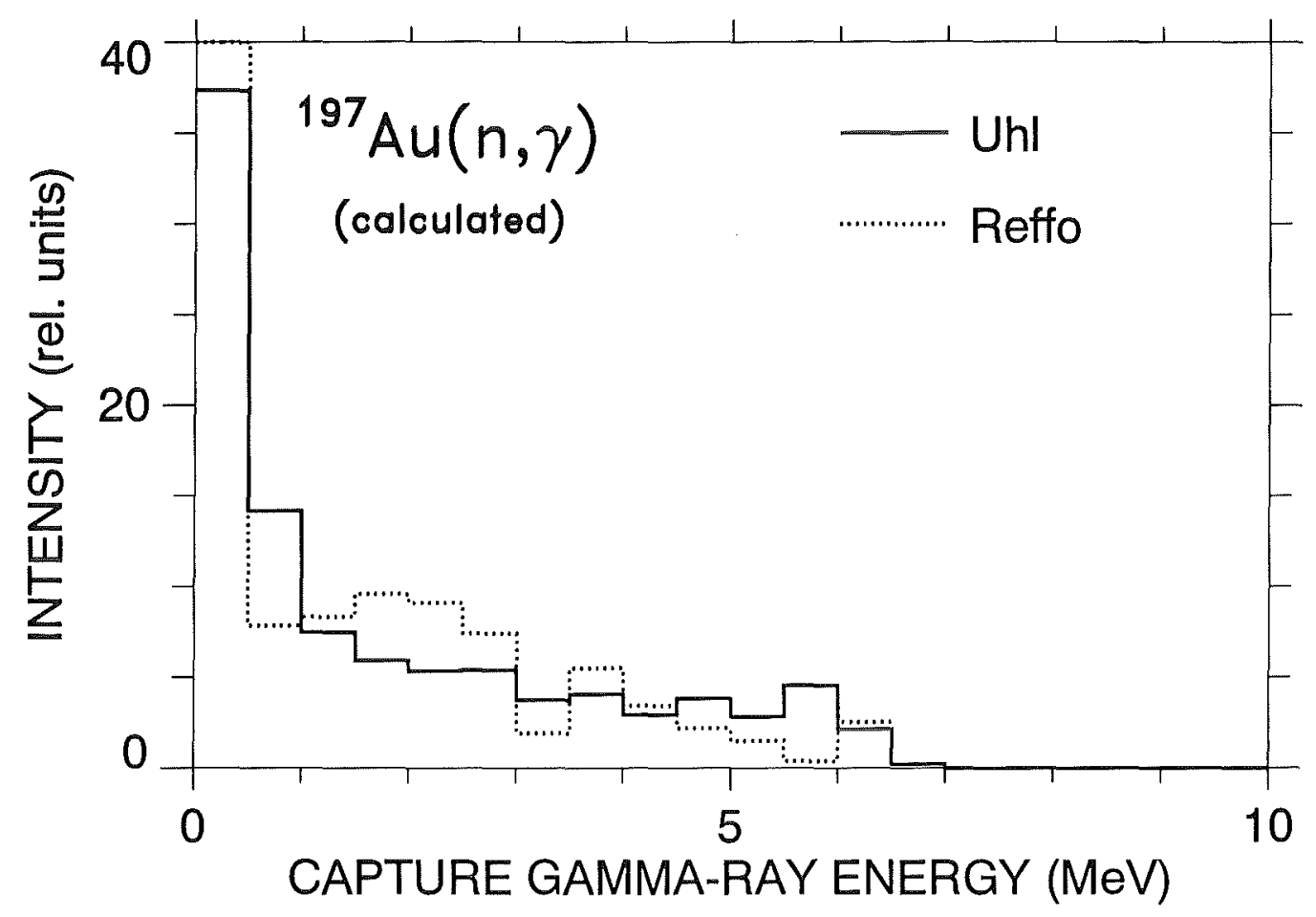

Figure 11: Calculated capture $\gamma$-ray spectra for gold.

The comparison of the two calculations can be summarized by the following remarks:

- The calculations of Reffo were performed at $30 \mathrm{keV}$ neutron energy, those of Uhl at $100 \mathrm{keV}$. Thus, the most important energy range of the present experiment is covered.

- The calculation of Reffo renounced on the correction for width fluctuation since it does not affect the calculated cascades. Therefore, no absolute values could be given for the cross sections, and the data in Table 9 are normalized to the experimental results. In the calculation of Uhl, the parameters were adjusted to fit the experimental cross section. The results are shown in Fig.12, and could be used to extend the investigated range down to low neutron energies for the calculation of Maxwellinan averaged cross sections (see Sec.6.). The notation EGLO and SLO indicates that the $\gamma$-ray strength function for E1 transitions was determined by assuming a generalized Lorentzian with energy-dependent width for the giant resonance, while for M1 transitions a standard Lorentzian shape was adopted (for details see Ref.[20]); KRK indicates that the level density was determined according to the model of Kataria, Ramamurthy and Kapoor [21].

- The cross section for individual cascades is significantly smaller in the calculation of Uhl due to the finer energy grid. Consequently much more cascades are required 
to cover $95 \%$ of the cross section. The respective numbers for the calculation of Reffo are given in the second column of Table 10. The number of cascades given by Uhl is too large for evaluating the correction factor $F_{1}$. Instead, 10000 cascades were used for all isotopes which cover $60-80 \%$ of the cross section (see 6 th column of Table 10). It is somewhat surprising that the number of cascades calculated by Reffo exhibits significant fluctuations for the various isotopes, while Uhl obtained a rather smooth dependence on mass number.

- The average multiplicity is about equal in both calculations, but there are differences with respect to the individual isotopes. While Reffo obtained the largest multiplicity for the even isotope ${ }^{154} \mathrm{Gd}$, the largest value of $\mathrm{Uhl}$ is for the odd isotope ${ }^{155} \mathrm{Gd}$. The experimental multiplicities in Table 10 are given for different thresholds in $\gamma$-ray threshold, since there are many low energy transitions in the gadolinium isotopes. The experimental threshold for individual $\gamma$-rays in the experiment was at $\sim 70$ $\mathrm{keV}$. The experimental multiplicities in the last column correspond to the values given in Fig.9 and refer to the number of modules that fired per capture event. Since these numbers must be corrected for threshold effects and for cross talking between modules, they are presumably overestimating the true multiplicities. Nevertheless, these data are useful for deriving the trends with mass number, confirming larger values for odd than for even isotopes as well as decreasing multiplicities with increasing mass number of the even isotopes. In general, this behavior is reasonably described by the both model calculations.

- Comparison of the capture $\gamma$-ray spectra of the gadolinium isotopes in Fig.10 (which were normalized to equal area), shows good agreement between the calculations. The fluctuations in the spectra of Reffo are due to coarser grid for describing the level density in the excitation energy range between the known discrete levels and the neutron binding energy. In case of ${ }^{158} \mathrm{Gd}$, these fluctuations are largest due to the small number of cascades. The situation for gold is presented in Fig.11. Here, the differences are more pronounced, showing a significantly harder spectrum in the calculations of Uhl, in better agreement with experiment[22].

The efficiency of the $4 \pi \mathrm{BaF}_{2}$ detector was determined experimentally[23] by measuring the response for monoenergetic $\gamma$-rays, which were produced by $(p, \gamma)$-reactions on thin ${ }^{26} \mathrm{Mg}$, ${ }^{30} \mathrm{Si}$, and ${ }^{34} \mathrm{~S}$ targets. In these reactions, certain proton resonances decay predominantly by cascades with only two transitions. Replacing one of the $\mathrm{BaF}_{2}$ modules by a Ge-detector, and looking for $\mathrm{BaF}_{2}-\mathrm{Ge}$-coincidences, two-dimensional spectra, $\mathrm{E}_{\gamma}(\mathrm{Ge})$ versus $\mathrm{E}_{\gamma}\left(\mathrm{BaF}_{2}\right)$, were recorded. The response of the $4 \pi \mathrm{BaF}_{2}$ detector for monoenergetic $\gamma$-rays was then obtained by selecting those events, where the full energy of the complementary $\gamma$-ray is registered in the germanium detector.

Using seven $(\mathrm{p}, \gamma)$-resonances and an ${ }^{88} \mathrm{Y}$ source, the line shapes of $20 \gamma$-transitions in the energy range from 0.843 to $8.392 \mathrm{MeV}$ could be determined. These data were used in the calculation of the spectrum fractions, $f$, and of the correction factors, $F_{1}$, given in Table 8. The resulting sum energy spectra shown in Fig.13 are in good agreement with the experimental spectra of Fig.8, thus confirming the calculation of the correction factors $F_{1}$. 

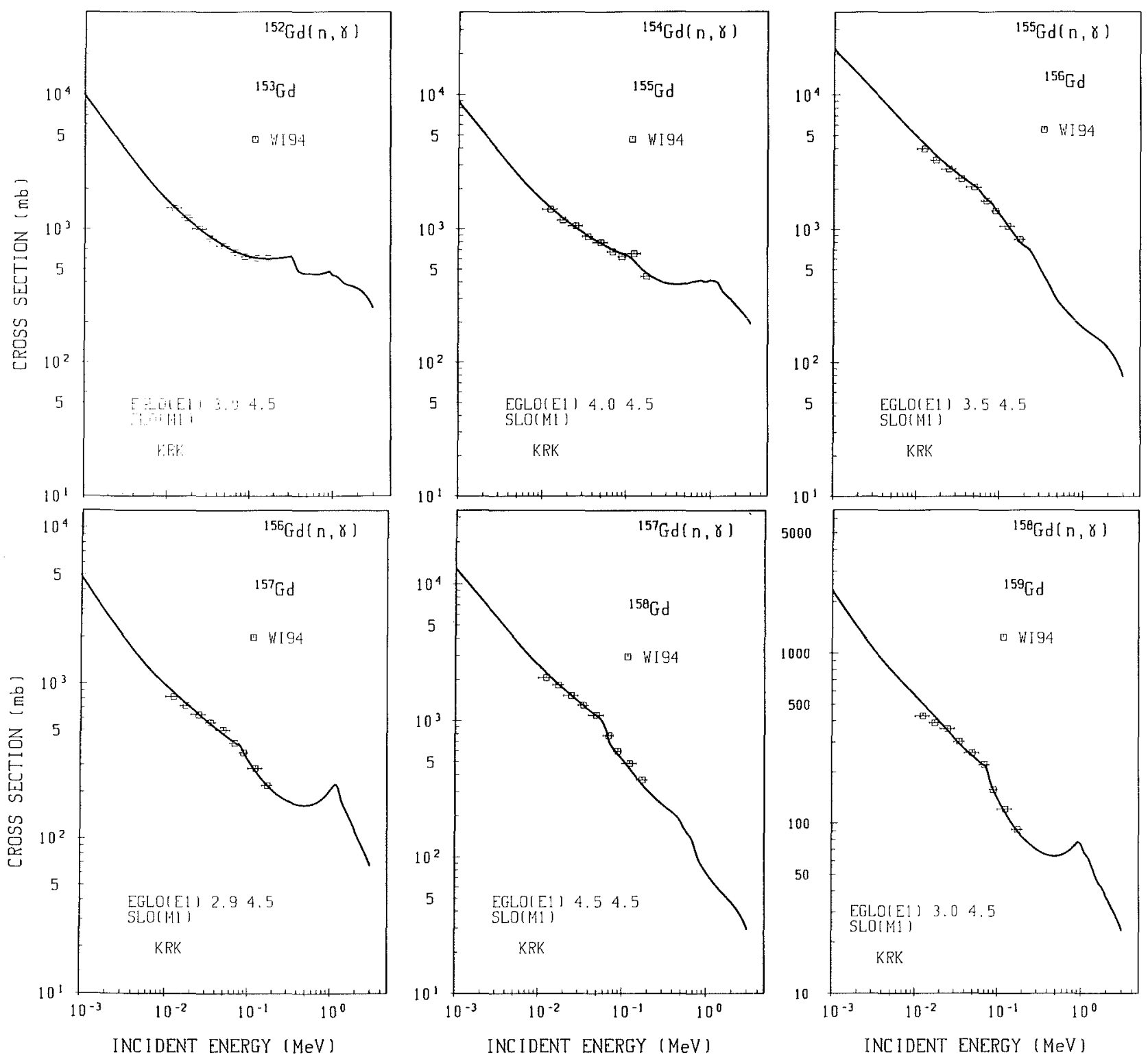

Figure 12: Calculated capture cross sections for the gadolinium isotopes.

The spectrum fractions, $f$, obtained with the different sets of capture cascades are compiled in Table 8. The values calculated with the cascades of Uhl are systematically larger by $\sim 1.7 \%$ for the gold standard, $\sim 1.1 \%$ for the even and $\sim 0.2 \%$ for the odd gadolinium isotopes. This behavior is expected from the comparison of Figs. 10 and 11, where the gold spectra exhibit larger differences than those for the gadolinium isotopes. The related systematic uncertainties for the cross section ratios are discussed in detail in Sec. 5. The adopted values of the correction factors $F_{1}$, in the lower part of Table 8 are the average of both calculations, except for ${ }^{158} \mathrm{Gd}$. The small number of capture cascades given by Reffo caused strong fluctuations in the capture $\gamma$-ray spectrum and, 
Table 10: AVERAGE MULTIPLICITY OF CAPTURE CASCADES IN DEPENDENCE OF THE THRESHOLD IN GAMMA-RAY ENERGY ${ }^{1}$.

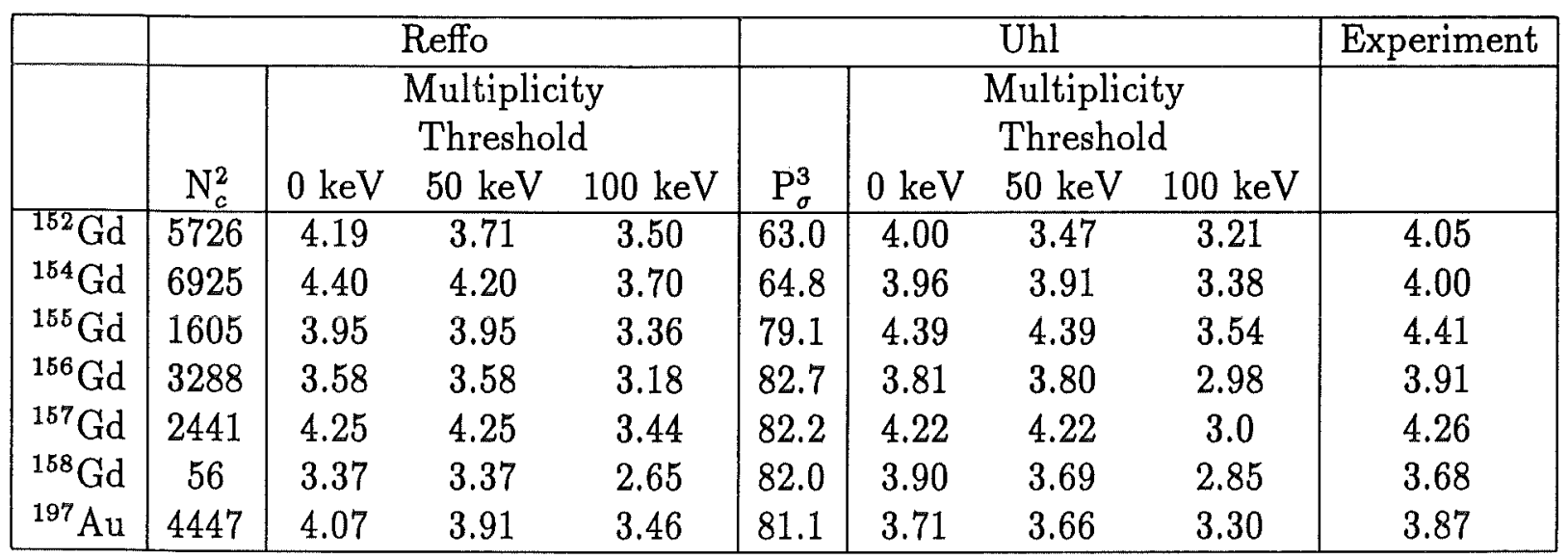

1 The experimental data are not corrected for threshold effects and cross talking between neighboring detector modules and should be used only for discussing relative differences between isotopes

${ }^{2}$ Number of capture cascades covering $95 \%$ of the cross section

${ }^{3}$ Percentage of cross section covered by 10000 cascades

consequently, in the spectrum fraction $\mathrm{f}$. Since these fluctuations seem to result from numerical effects and are not justified by the systematic trend in the even gadolinium isotopes, only the data of Uhl were used for this isotope.

It is important to note that the two improvements of the experimental setup, by which the solid angle was increased to $96 \%$ of $4 \pi$, and the threshold in sum energy was reduced below $1.5 \mathrm{MeV}$, led to a significant increase in the detector efficiency. While in the respective previous measurements of the samarium and barium cross sections $[2,3]$ the fraction of unobserved capture events was $7 \%$ and $6 \%$ for the even isotopes, respectively, values of $2 \%$ could now be reached.

The correction factor $F_{1}$ was redetermined for the samarium [2] and the barium [3] experiment using the capture cascades calculated by Uhl. Here again systematically lower values are obtained compared to the results based on the cascades of Reffo. The effect is even more pronounced as in the previous experiments the solid angle was lower and the threshold energies significantly higher. The systematic difference is again dominated by the gold standard. As a result the absolute values for the cross sections of all isotopes should be lowered by $1.5 \%$ in case of the barium data [3] and by $1.4 \%$ in case of the samarium data [2]. The average spread for the individual isotopes is $\pm 0.5 \%$ and $\pm 0.7 \%$ for the samarium and barium isotopes, respectively, and thus well within the quoted systematic uncertainty. As the astrophysical interpretation is essentially based on cross section ratios, it is not affected by changes in the absolute values. 


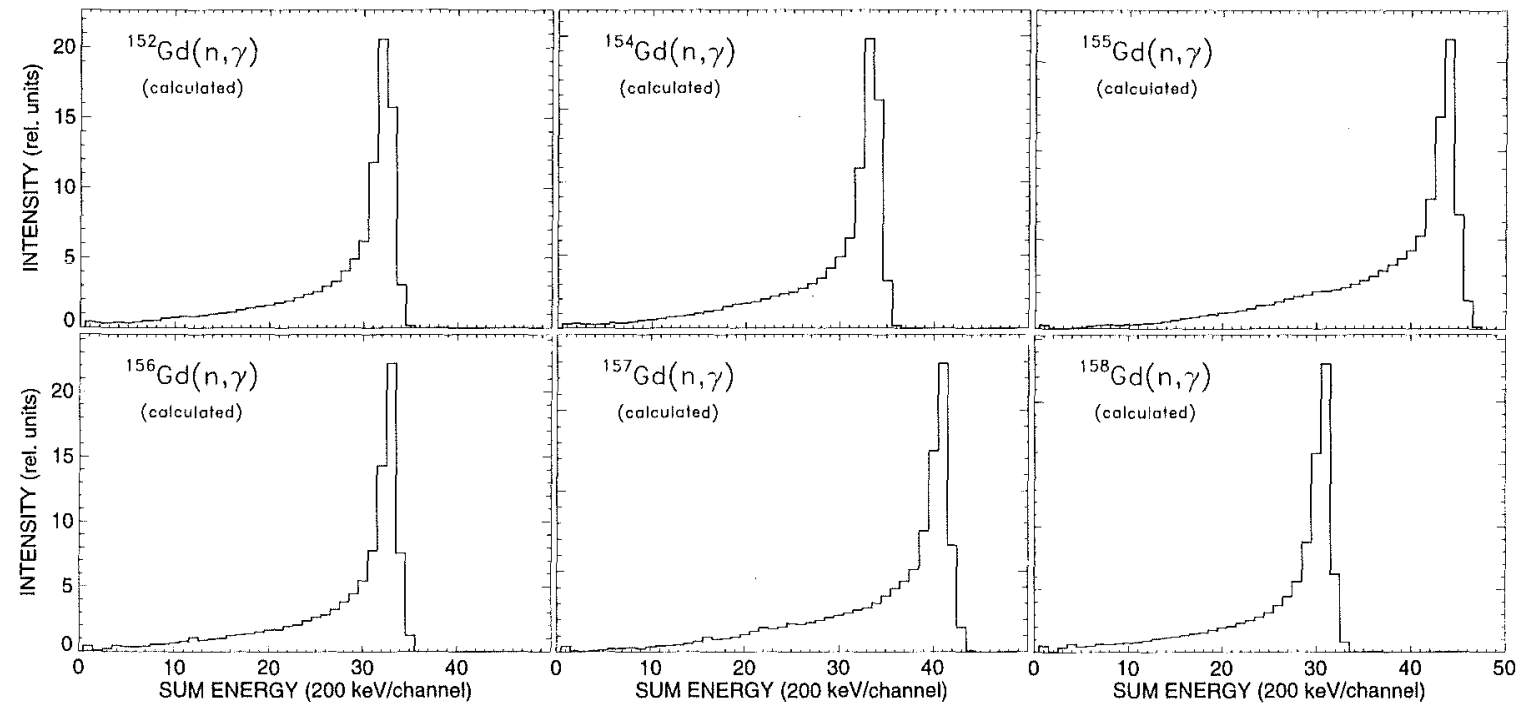

Figure 13: Calculated sum energy spectra of the $4 \pi \mathrm{BaF}_{2}$ detector obtained with the measured lineshape. These spectra were used to derive the correction $F_{1}$ for unobserved capture events.

The correction for neutron multiple scattering and self-shielding was calculated with the SESH code[15]. The search for consistent parameter sets, which allow to reproduce the capture cross section and the total cross section of each isotope, started with the parameters given by Mughabghab[24], and the pairing energies were adopted from Ref.[25]. These data sets were modified until the measured total cross sections of Table 5 could be reproduced within their uncertainties and the capture cross sections within $\sim 10 \%$. The final input parameters are listed in Table 11 together with the calculated total cross sections. In all calculations, the oxygen content was considered according to the stoichiometry of $\mathrm{Gd}_{2} \mathrm{O}_{3}$. The correction factors, $\mathrm{MS}(\mathrm{X})$ and $\mathrm{F}_{2}$, are compiled in Tables 12 and 13.

The corrections for the ${ }^{152} \mathrm{Gd}$ and ${ }^{154} \mathrm{Gd}$ samples required special treatment because of their low isotopic enrichments of $32.5 \%$ and $57.0 \%$. The corrections could be calculated for the total composition of the sample or for the part that remains after the correction for isotopic impurities. In the present experiment, most samples have about the same size and a weight of $\sim 1.3 \mathrm{~g}$. Therefore, it could be assumed, that subtraction of the isotopic 
Table 11: PARAMETERS FOR THE CALCULATION OF NEUTRON SELFSHIELDING AND MULTIPLE SCATTERING CORRECTION FACTORS

\begin{tabular}{|c|c|c|c|c|c|c|c|c|}
\hline Parameter & & ${ }^{152} \mathrm{Gd}$ & ${ }^{154} \mathrm{Gd}$ & ${ }^{156} \mathrm{Gd}$ & ${ }^{156} \mathrm{Gd}$ & ${ }^{157} \mathrm{Gd}$ & ${ }^{158} \mathrm{Gd}$ & ${ }^{16} \mathrm{O}$ \\
\hline Nucleon Number & & 152 & 154 & 155 & 156 & 157 & 158 & 16 \\
\hline Binding Energy $(\mathrm{MeV})$ & & 6.247 & 6.439 & 8.536 & 6.360 & 7.937 & 5.943 & 4.144 \\
\hline Pairing Energy ( $\mathrm{MeV}$ ) & & 0.97 & 0.97 & 1.89 & 0.97 & 1.70 & 0.97 & 2.50 \\
\hline Effective Temperature (K) & & 293 & 293 & 293 & 293 & 293 & 293 & 293 \\
\hline Nuclear Spin & & 0 & 0 & 1.5 & 0 & 1.5 & 0 & 0 \\
\hline Average Radiation & 8 & 0.07 & 0.08 & 0.13 & 0.11 & 0.12 & 0.085 & 0 \\
\hline Width $(\mathrm{eV})$ & $\mathrm{p}$ & 0.06 & 0.06 & 0.14 & 0.09 & 0.035 & 0.06 & \\
\hline Average Level & $\mathrm{s}$ & 15 & 14.5 & 1.6 & 37.8 & 4.9 & 85 & 0 \\
\hline Spacing (eV) & $\mathrm{p}^{1}$ & 5 & 4.83 & 0.8 & 12.6 & 2.45 & 28.3 & \\
\hline Strength Function & $\mathrm{S}_{0}$ & 2.8 & 2.3 & 1.8 & 2.2 & 2.2 & 1.5 & 0 \\
\hline$\left(10^{-4}\right)$ & $S_{1}$ & 1.0 & 1.1 & 1.2 & 0.55 & 1.4 & 1.5 & \\
\hline Nuclear Radius & 8 & 8.0 & 7.9 & 7.8 & 7.7 & 7.6 & 7.5 & 5.5 \\
\hline$(\mathrm{fm})$ & $\mathrm{p}$ & 8.0 & 7.9 & 7.8 & 7.7 & 7.6 & 7.5 & \\
\hline \multicolumn{9}{|c|}{ Calculated total cross sections } \\
\hline $5 \mathrm{keV}$ & & 24.1 & 21.1 & 18.1 & 20.1 & 20.1 & 15.9 & 3.80 \\
\hline $10 \mathrm{keV}$ & & 19.2 & 17.1 & 15.0 & 16.2 & 16.3 & 13.4 & 3.79 \\
\hline $20 \mathrm{keV}$ & & 15.6 & 14.1 & 12.7 & 13.3 & 13.5 & 11.6 & 3.77 \\
\hline $40 \mathrm{keV}$ & & 12.8 & 11.9 & 11.0 & 11.1 & 11.4 & 10.2 & 3.74 \\
\hline $80 \mathrm{keV}$ & & 10.5 & 10.1 & 9.6 & 9.3 & 9.8 & 9.1 & 3.68 \\
\hline $160 \mathrm{keV}$ & & 8.5 & 8.4 & 8.3 & 7.7 & 8.4 & 8.2 & 3.56 \\
\hline $320 \mathrm{keV}$ & & 6.6 & 6.8 & 7.0 & 6.2 & 7.0 & 7.1 & 3.31 \\
\hline
\end{tabular}

${ }^{1}$ Calculated with SESH [15]

Table 12: CORRECTION FACTORS FOR NEUTRON SELF-SHIELDING AND MULTIPLE SCATTERING, MS

\begin{tabular}{cccccccc}
\hline $\begin{array}{c}\text { Energy Range } \\
(\mathrm{keV})\end{array}$ & ${ }^{197} \mathrm{Au}$ & ${ }^{152} \mathrm{Gd}$ & ${ }^{154} \mathrm{Gd}$ & ${ }^{155} \mathrm{Gd}$ & ${ }^{156} \mathrm{Gd}$ & ${ }^{157} \mathrm{Gd}$ & ${ }^{158} \mathrm{Gd}$ \\
\hline $3-5$ & 0.989 & 0.990 & 0.978 & 1.001 & 0.907 & 0.994 & 0.786 \\
$5-7.5$ & 1.012 & 0.997 & 0.995 & 1.007 & 0.956 & 1.005 & 0.884 \\
$7.5-10$ & 1.022 & 0.999 & 1.003 & 1.008 & 0.981 & 1.009 & 0.918 \\
$10-12.5$ & 1.028 & 1.000 & 1.007 & 1.009 & 0.998 & 1.011 & 0.949 \\
$12.5-15$ & 1.031 & 1.000 & 1.008 & 1.010 & 1.008 & 1.013 & 0.965 \\
$15-20$ & 1.033 & 1.000 & 1.009 & 1.010 & 1.012 & 1.015 & 0.981 \\
$20-25$ & 1.034 & 0.999 & 1.009 & 1.011 & 1.016 & 1.016 & 0.990 \\
$25-30$ & 1.033 & 0.999 & 1.008 & 1.012 & 1.017 & 1.016 & 0.995 \\
$30-40$ & 1.032 & 0.998 & 1.007 & 1.012 & 1.018 & 1.017 & 1.000 \\
$40-50$ & 1.030 & 0.997 & 1.005 & 1.012 & 1.018 & 1.017 & 1.004 \\
$50-60$ & 1.029 & 0.997 & 1.004 & 1.012 & 1.017 & 1.017 & 1.007 \\
\hline
\end{tabular}


Table 12 continued

\begin{tabular}{cccccccc}
\hline $60-80$ & 1.027 & 0.997 & 1.003 & 1.011 & 1.016 & 1.017 & 1.009 \\
$80-100$ & 1.025 & 0.996 & 1.003 & 1.011 & 1.015 & 1.016 & 1.011 \\
$100-120$ & 1.024 & 0.996 & 1.002 & 1.011 & 1.015 & 10.16 & 1.012 \\
$120-150$ & 1.023 & 0.995 & 1.002 & 1.010 & 1.014 & 1.015 & 1.012 \\
$150-175$ & 1.022 & 0.995 & 1.001 & 1.010 & 1.014 & 1.015 & 1.012 \\
$175-200$ & 1.021 & 0.995 & 1.001 & 1.010 & 1.013 & 1.014 & 1.012 \\
$200-225$ & 1.020 & 0.995 & 1.001 & 1.009 & 1.013 & 1.013 & 1.012 \\
\hline Uncertainty (\%) & 0.3 & 0.6 & 0.4 & 0.2 & 0.2 & 0.2 & 0.2 \\
\hline
\end{tabular}

Table 13: CORRECTION FACTORS FOR THE CROSS SECTION RATIOS, $\mathrm{F}_{2}=$ $\operatorname{MS}(\mathrm{Au}) / \mathrm{MS}(\mathrm{X})$

\begin{tabular}{ccccccc}
\hline $\begin{array}{c}\text { Energy Range } \\
(\mathrm{keV})\end{array}$ & ${ }^{152} \mathrm{Gd} / \mathrm{Au}$ & ${ }^{154} \mathrm{Gd} / \mathrm{Au}$ & ${ }^{155} \mathrm{Gd} / \mathrm{Au}$ & ${ }^{156} \mathrm{Gd} / \mathrm{Au}$ & ${ }^{157} \mathrm{Gd} / \mathrm{Au}$ & ${ }^{158} \mathrm{Gd} / \mathrm{Au}$ \\
\hline $3-5$ & 0.999 & 1.011 & 0.988 & 1.090 & 0.995 & 1.258 \\
$5-7.5$ & 1.015 & 1.017 & 1.005 & 1.059 & 1.007 & 1.145 \\
$7.5-10$ & 1.023 & 1.019 & 1.014 & 1.042 & 1.013 & 1.113 \\
$10-12.5$ & 1.028 & 1.021 & 1.019 & 1.030 & 1.017 & 1.083 \\
$12.5-15$ & 1.031 & 1.023 & 1.021 & 1.023 & 1.018 & 1.069 \\
$15-20$ & 1.033 & 1.024 & 1.023 & 1.021 & 1.018 & 1.053 \\
$20-25$ & 1.035 & 1.025 & 1.023 & 1.018 & 1.018 & 1.044 \\
$25-30$ & 1.034 & 1.025 & 1.021 & 1.016 & 1.017 & 1.038 \\
$30-40$ & 1.034 & 1.025 & 1.020 & 1.014 & 1.015 & 1.032 \\
$40-50$ & 1.033 & 1.025 & 1.018 & 1.012 & 1.013 & 1.026 \\
$50-60$ & 1.032 & 1.025 & 1.017 & 1.012 & 1.012 & 1.022 \\
$60-80$ & 1.030 & 1.024 & 1.016 & 1.011 & 1.010 & 1.018 \\
$80-100$ & 1.029 & 1.022 & 1.014 & 1.010 & 1.009 & 1.014 \\
$100-120$ & 1.028 & 1.022 & 1.013 & 1.009 & 1.008 & 1.012 \\
$120-150$ & 1.028 & 1.021 & 1.013 & 1.009 & 1.008 & 1.010 \\
$150-175$ & 1.027 & 1.021 & 1.012 & 1.008 & 1.007 & 1.010 \\
$175-200$ & 1.026 & 1.020 & 1.011 & 1.008 & 1.007 & 1.009 \\
$200-225$ & 1.025 & 1.019 & 1.011 & 1.007 & 1.007 & 1.008 \\
\hline Uncertainty (\%) & 0.7 & 0.5 & 0.4 & 0.4 & 0.4 & 0.4 \\
\hline
\end{tabular}

impurities via the spectra of the other samples accounts for the multiple scattering corrections as well. Therefore, these corrections were calculated as if the two samples consisted of the main isotopes, ${ }^{152} \mathrm{Gd}$ or ${ }^{154} \mathrm{Gd}$, only. Due to the comparably small sample masses used in the present experiment, these corrections were only $\sim 2 \%$, except for the lowest neutron energies and for ${ }^{152} \mathrm{Gd}$ and ${ }^{158} \mathrm{Gd}$. The related systematic uncertainties are discussed in Sec.5. 


\section{RESULTS FOR THE NEUTRON CAPTURE CROSS SECTIONS}

The ratios of the neutron capture cross sections of the gadolinium isotopes to that of ${ }^{197} \mathrm{Au}$ are listed in Tables 14 to 19 together with the respective statistical uncertainties. The data are given for the three experimental runs and for the two evaluations discussed in Sec.3. The last column in each table contains the weighted average, the weight being determined by inverse of the squared statistical uncertainties. Since the cross section ratios depend weakly on energy, the averages for the energy interval from 30 to $80 \mathrm{keV}$ are also included to allow for a better comparison of the individual results. The data are free of systematic differences with respect to the different runs or evaluations. This is particularly important for the comparison of runs 1 and 3 , which were made with different data acquisition modes.

As in the previous measurements with the $4 \pi \mathrm{BaF}_{2}$ detector $[1,2,3]$, the final cross section ratios were adopted from evaluation 2 . The respective mean values are compiled for all runs in Table 20 together with the statistical, systematic, and total uncertainties. The energy bins are sufficiently fine to avoid systematic uncertainties in the calculation of the Maxwellian averaged cross sections (Sec.6). The final uncertainties of the cross section ratios are $\sim 1 \%$, which represents a significant improvement compared to previous data $[6,18]$.

The experimental ratios were converted into cross sections using the gold cross section of Macklin[26] after normalization by a factor of 0.989 to the absolute value of Ratynski and Käppeler[27] (Table 21). The uncertainties of these data can be obtained by adding the $1.5 \%$ uncertainty of the reference cross section to the uncertainties of the respective cross section ratios.

The present results are compared to the data of Beer and Macklin[6] in Figures 14 to 16. For these data an accuracy of $3 \%$ is quoted, but without considering the systematic uncertainties of the correction for isotopic impurities (see discussion in Sec.3). In general, good agreement was obtained for ${ }^{152} \mathrm{Gd},{ }^{155} \mathrm{Gd}$, and ${ }^{157} \mathrm{Gd}$ within the quoted uncertainties . However, for ${ }^{154} \mathrm{Gd}$, which is the most important isotope for the astrophysical interpretation, the present results are systematically higher by $16 \%$ in the relevant energy range from 10 to $100 \mathrm{keV}$. An older experiment by Shorin et al. [28] reported a $\sim 15 \%$ higher ${ }^{154} \mathrm{Gd}$ cross section than the present result. A general comparison with all existing data will be discussed in Sec. 6 for the stellar cross sections. 
Table 14: $\sigma\left({ }^{152} \mathrm{Gd}\right) / \sigma\left({ }^{197} \mathrm{Au}\right)$ AND STATISTICAL UNCERTAINTIES IN (\%)

\begin{tabular}{|c|c|c|c|c|c|c|c|c|}
\hline $\begin{array}{c}\text { Energy Range } \\
(\mathrm{keV})\end{array}$ & \multicolumn{2}{|c|}{ Run I } & \multicolumn{2}{|c|}{ Run II } & \multicolumn{2}{|c|}{ Run III } & \multicolumn{2}{|c|}{ Average } \\
\hline \multicolumn{9}{|l|}{ Evaluation 1} \\
\hline $3-5$ & 1.3959 & 14.3 & - & - & 1.3939 & 27.2 & 1.3955 & 12.7 \\
\hline $5-7.5$ & 1.5567 & 6.5 & - & - & 1.5906 & 12.9 & 1.5636 & 5.8 \\
\hline $7.5-10$ & 1.7895 & 7.0 & 1.6859 & 10.2 & 1.4160 & 11.4 & 1.6868 & 5.2 \\
\hline $10-12.5$ & 1.5843 & 5.7 & 1.3768 & 8.8 & 1.6158 & 8.7 & 1.5445 & 4.2 \\
\hline $12.5-15$ & 1.7020 & 4.7 & 1.3826 & 7.6 & 1.7221 & 7.4 & 1.6367 & 3.5 \\
\hline $15-20$ & 1.6972 & 3.0 & 1.5611 & 4.2 & 1.5309 & 4.9 & 1.6268 & 2.2 \\
\hline $20-25$ & 1.8875 & 2.6 & 1.7863 & 3.3 & 1.8065 & 4.0 & 1.8405 & 1.8 \\
\hline $25-30$ & 1.7821 & 2.2 & 1.6700 & 2.8 & 1.8219 & 3.4 & 1.7570 & 1.6 \\
\hline $30-40$ & 1.7695 & 1.8 & 1.7064 & 2.1 & 1.7596 & 2.8 & 1.7465 & 1.2 \\
\hline $40-50$ & 1.9423 & 1.8 & 1.8466 & 2.1 & 1.8896 & 2.8 & 1.9004 & 1.2 \\
\hline $50-60$ & 1.9938 & 1.7 & 1.8202 & 2.1 & 1.9010 & 2.7 & 1.9224 & 1.2 \\
\hline $60-80$ & 1.9907 & 1.5 & 1.9052 & 1.8 & 1.9535 & 2.4 & 1.9555 & 1.0 \\
\hline $80-100$ & 2.1252 & 1.5 & 2.1093 & 1.8 & 2.0812 & 2.4 & 2.1116 & 1.0 \\
\hline $100-120$ & 2.1141 & 1.8 & 2.1369 & 1.8 & 2.1574 & 2.6 & 2.1322 & 1.1 \\
\hline $120-150$ & - & - & 2.2440 & 1.6 & - & - & 2.2440 & 1.6 \\
\hline $150-175$ & - & - & 2.3383 & 1.7 & - & - & 2.3383 & 1.7 \\
\hline $175-200$ & - & - & 2.3925 & 1.8 & - & - & 2.3925 & 1.8 \\
\hline $200-225$ & - & - & 2.5630 & 2.1 & - & - & 2.5630 & 2.1 \\
\hline $30-80$ & 1.9241 & 1.3 & 1.8196 & 1.4 & 1.8759 & 2.2 & 1.8757 & 0.9 \\
\hline \multicolumn{9}{|l|}{ Evaluation 2} \\
\hline $3-5$ & 1.3974 & 10. & - & - & 1.4564 & 22.3 & 1.4073 & 9.1 \\
\hline $5-7.5$ & 1.5802 & 4.7 & - & - & 1.6231 & 10.1 & 1.5877 & 4.2 \\
\hline $7.5-10$ & 1.6884 & 5.3 & 1.6435 & 7.3 & 1.5118 & 9.0 & 1.6431 & 3.9 \\
\hline $10-12.5$ & 1.5704 & 4.3 & 1.4927 & 5.9 & 1.6005 & 6.9 & 1.5549 & 3.1 \\
\hline $12.5-15$ & 1.6666 & 3.7 & 1.5050 & 5.4 & 1.6799 & 5.9 & 1.6288 & 2.7 \\
\hline $15-20$ & 1.7079 & 2.4 & 1.6778 & 3.2 & 1.6610 & 3.9 & 1.6899 & 1.7 \\
\hline $20-25$ & 1.8807 & 2.1 & 1.8054 & 2.6 & 1.8379 & 3.3 & 1.8494 & 1.5 \\
\hline $25-30$ & 1.7506 & 1.8 & 1.6914 & 2.3 & 1.8021 & 2.8 & 1.7435 & 1.3 \\
\hline $30-40$ & 1.7563 & 1.4 & 1.7209 & 1.8 & 1.7728 & 2.2 & 1.7484 & 1.0 \\
\hline $40-50$ & 1.9049 & 1.4 & 1.8606 & 1.8 & 1.8989 & 2.3 & 1.8898 & 1.0 \\
\hline $50-60$ & 1.9513 & 1.4 & 1.8439 & 1.8 & 1.9329 & 2.3 & 1.9169 & 1.0 \\
\hline $60-80$ & 1.9608 & 1.1 & 1.9356 & 1.5 & 1.9721 & 1.9 & 1.9554 & 0.8 \\
\hline $80-100$ & 2.0816 & 1.2 & 2.1128 & 1.5 & 2.0994 & 1.9 & 2.0945 & 0.8 \\
\hline $100-120$ & 2.0713 & 1.5 & 2.1223 & 1.5 & 2.1563 & 2.1 & 2.1091 & 1.0 \\
\hline $120-150$ & - & - & 2.2399 & 1.4 & - & - & 2.2399 & 1.4 \\
\hline $150-175$ & - & - & 2.3238 & 1.5 & - & - & 2.3238 & 1.5 \\
\hline $175-200$ & - & - & 2.4122 & 1.5 & - & - & 2.4122 & 1.5 \\
\hline $200-225$ & - & - & 2.5724 & 1.9 & - & - & 2.5724 & 1.9 \\
\hline $30-80$ & 1.8933 & 0.9 & 1.8403 & 1.1 & 1.8942 & 1.6 & 1.8756 & 0.6 \\
\hline
\end{tabular}


Table 15: $\sigma\left({ }^{154} \mathrm{Gd}\right) / \sigma\left({ }^{197} \mathrm{Au}\right)$ AND STATISTICAL UNCERTAINTIES IN (\%)

\begin{tabular}{|c|c|c|c|c|c|c|c|c|}
\hline $\begin{array}{c}\text { Energy Range } \\
(\mathrm{keV})\end{array}$ & \multicolumn{2}{|c|}{ Run I } & \multicolumn{2}{|c|}{ Run II } & \multicolumn{2}{|c|}{ Run III } & \multicolumn{2}{|c|}{ Average } \\
\hline \multicolumn{9}{|l|}{ Evaluation 1} \\
\hline $3-5$ & 1.3734 & 8.7 & - & - & 1.6121 & 15.5 & 1.4310 & 7.6 \\
\hline $5-7.5$ & 1.4052 & 4.3 & - & - & 1.1544 & 10.0 & 1.3661 & 4.0 \\
\hline $7.5-10$ & 1.6549 & 4.8 & 1.5576 & 7.2 & 1.4202 & 7.0 & 1.5749 & 3.5 \\
\hline $10-12.5$ & 1.5354 & 3.7 & 1.4182 & 5.5 & 1.4588 & 6.0 & 1.4909 & 2.7 \\
\hline $12.5-15$ & 1.5634 & 3.2 & 1.4429 & $4 . \overline{7}$ & 1.7144 & 5.0 & 1.5677 & 2.4 \\
\hline $15-20$ & 1.6319 & 2.0 & 1.5549 & 2.8 & 1.6619 & 3.0 & 1.6185 & 1.5 \\
\hline $20-25$ & 1.8876 & 1.8 & 1.7481 & 2.3 & 1.8984 & 2.6 & 1.8503 & 1.2 \\
\hline $25-30$ & 1.8409 & 1.5 & 1.8277 & 1.9 & 1.8487 & 2.2 & 1.8386 & 1.0 \\
\hline $30-40$ & 1.7781 & 1.2 & 1.7424 & 1.4 & 1.8254 & 1.7 & 1.7769 & 0.8 \\
\hline $40-50$ & 1.9575 & 1.2 & 1.9364 & 1.4 & 1.9532 & 1.7 & 1.9498 & 0.8 \\
\hline $50-60$ & 1.9692 & 1.1 & 1.9362 & 1.5 & 2.0204 & 1.7 & 1.9704 & 0.8 \\
\hline $60-80$ & 2.0007 & 1.0 & 1.9511 & 1.2 & 1.9770 & 1.5 & 1.9804 & 0.7 \\
\hline $80-100$ & 2.1003 & 1.0 & 2.1127 & 1.2 & 2.0932 & 1.5 & 2.1029 & 0.7 \\
\hline $100-120$ & 2.0828 & 1.3 & 2.1129 & 1.2 & 2.0862 & 1.7 & 2.0960 & 0.8 \\
\hline $120-150$ & - & - & 1.9022 & 1.2 & - & - & 1.9022 & 1.2 \\
\hline $150-175$ & - & - & 1.7621 & 1.3 & - & - & 1.7621 & 1.3 \\
\hline $175-200$ & - & - & 1.6864 & 1.3 & - & - & 1.6864 & 1.3 \\
\hline $200-225$ & - & - & 1.6962 & 1.7 & - & - & 1.6962 & 1.7 \\
\hline $30-80$ & 1.9264 & 0.9 & 1.8915 & 0.9 & 1.9440 & 1.3 & 1.9157 & 0.6 \\
\hline \multicolumn{9}{|l|}{ Evaluation 2} \\
\hline $3-5$ & 1.3462 & 6.6 & - & - & 1.5667 & 13.4 & 1.3888 & 5.9 \\
\hline $5-7.5$ & 1.3907 & 3.3 & - & - & 1.2028 & 7.7 & 1.3609 & 3.1 \\
\hline $7.5-10$ & 1.6269 & 3.7 & 1.5682 & 5.1 & 1.5926 & 5.6 & 1.6035 & 2.6 \\
\hline $10-12.5$ & 1.5541 & 2.9 & 1.3891 & 4.0 & 1.4813 & 4.7 & 1.4938 & 2.1 \\
\hline $12.5-15$ & 1.5570 & 2.6 & 1.5206 & 3.6 & 1.6680 & 4.0 & 1.5718 & 1.9 \\
\hline $15-20$ & 1.6594 & 1.7 & 1.5682 & 2.2 & 1.7117 & 2.5 & 1.6453 & 1.2 \\
\hline $20-25$ & 1.8877 & 1.5 & 1.7985 & 1.9 & 1.9307 & 2.2 & 1.8703 & 1.0 \\
\hline $25-30$ & 1.8249 & 1.2 & 1.8185 & 1.6 & 1.8427 & 1.9 & 1.8267 & 0.9 \\
\hline $30-40$ & 1.7666 & 1.0 & 1.7540 & 1.2 & 1.8197 & 1.5 & 1.7735 & 0.7 \\
\hline $40-50$ & 1.9487 & 1.0 & 1.9457 & 1.2 & 1.9518 & 1.5 & 1.9484 & 0.7 \\
\hline $50-60$ & 1.9419 & 0.9 & 1.9153 & 1.3 & 2.0154 & 1.5 & 1.9493 & 0.7 \\
\hline $60-80$ & 1.9785 & 0.8 & 1.9385 & 1.0 & 1.9764 & 1.2 & 1.9668 & 0.6 \\
\hline $80-100$ & 2.0717 & 0.8 & 2.0826 & 1.0 & 2.0817 & 1.3 & 2.0770 & 0.6 \\
\hline $100-120$ & 2.0537 & 1.1 & 2.0854 & 1.0 & 2.0506 & 1.4 & 2.0660 & 0.7 \\
\hline $120-150$ & - & - & 1.8826 & 1.0 & - & - & 1.8826 & 1.0 \\
\hline $150-175$ & - & - & 1.7447 & 1.1 & - & - & 1.7447 & 1.1 \\
\hline $175-200$ & - & - & 1.6678 & 1.2 & - & - & 1.6678 & 1.2 \\
\hline $200-225$ & - & - & 1.6716 & 1.6 & - & - & 1.6716 & 1.6 \\
\hline $30-80$ & 1.9089 & 0.6 & 1.8884 & 0.6 & 1.9408 & 1.0 & 1.0951 & 0.4 \\
\hline
\end{tabular}


Table 16: $\sigma\left({ }^{155} \mathrm{Gd}\right) / \sigma\left({ }^{197} \mathrm{Au}\right)$ AND STATISTICAL UNCERTAINTIES IN (\%)

\begin{tabular}{|c|c|c|c|c|c|c|c|c|}
\hline $\begin{array}{c}\text { Energy Range } \\
\text { (keV) }\end{array}$ & \multicolumn{2}{|c|}{ Run I } & \multicolumn{2}{|c|}{ Run II } & \multicolumn{2}{|c|}{ Run III } & \multicolumn{2}{|c|}{ Average } \\
\hline & & & & & & & & \\
\hline $3-5$ & 3.9090 & 8.0 & - & - & 4.0629 & 14.5 & 3.9447 & 7.0 \\
\hline $5-7.5$ & 3.5639 & 4.0 & - & - & 3.5970 & 7.8 & 3.5708 & 3.6 \\
\hline $7.5-10$ & 4.4291 & 4.5 & 4.1948 & 6.6 & 3.8780 & 6.1 & 4.2231 & 3.2 \\
\hline $10-12.5$ & 4.2011 & 3.3 & 3.9124 & 4.9 & 4.3145 & 5.1 & 4.1560 & 2.4 \\
\hline $12.5-15$ & 4.4774 & 2.9 & 4.2214 & 4.1 & 4.6088 & 4.5 & 4.4399 & 2.1 \\
\hline $15-20$ & 4.5181 & 1.8 & 4.3261 & 2.5 & 4.4381 & 2.7 & 4.4503 & 1.3 \\
\hline $20-25$ & 5.0833 & 1.6 & 4.7883 & 2.1 & 4.9149 & 2.3 & 4.9641 & 1.1 \\
\hline $25-30$ & 4.9526 & 1.3 & 4.8485 & 1.7 & 4.8478 & 1.9 & 4.9003 & 0.9 \\
\hline $30-40$ & 4.8434 & 1.0 & 4.7659 & 1.3 & 4.7935 & 1.5 & 4.8098 & 0.7 \\
\hline $40-50$ & 5.1702 & 1.0 & 5.1054 & 1.3 & 4.9553 & 1.5 & 5.1042 & 0.7 \\
\hline $50-60$ & 5.0652 & 1.0 & 4.9833 & 1.3 & 4.9557 & 1.5 & 5.0187 & 0.7 \\
\hline $60-80$ & 4.8979 & 0.9 & 4.7176 & 1.1 & 4.6888 & 1.3 & 4.8019 & 0.6 \\
\hline $80-100$ & 4.8507 & 0.9 & 4.6949 & 1.1 & 4.7462 & 1.3 & 4.7825 & 0.6 \\
\hline $100-120$ & 4.4059 & 1.1 & 4.2022 & 1.2 & 4.3310 & 1.4 & 4.3138 & 0.7 \\
\hline $120-150$ & - & - & 3.7581 & 1.1 & - & - & 3.7581 & 1.1 \\
\hline $150-175$ & - & - & 3.4679 & 1.2 & - & - & 3.4679 & 1.2 \\
\hline $175-200$ & - & - & 3.2197 & 1.2 & - & - & 3.2197 & 1.2 \\
\hline $200-225$ & - & - & 3.2761 & 1.6 & - & - & 3.2761 & 1.6 \\
\hline $30-80$ & 4.994 & 0.7 & 4.8931 & 0.8 & 4.8483 & 1.1 & 4.9312 & 0.5 \\
\hline \multicolumn{9}{|l|}{ Evaluation 2} \\
\hline $3-5$ & 3.9311 & 5.9 & - & - & 4.4961 & 12.5 & 4.0343 & 5.4 \\
\hline $5-7.5$ & 3.6862 & 3.0 & - & - & 3.7580 & 6.2 & 3.6997 & 2.7 \\
\hline $7.5-10$ & 4.3495 & 3.4 & 4.2230 & 4.7 & 4.2404 & 5.0 & 4.2910 & 2.4 \\
\hline $10-12.5$ & 4.3486 & 2.6 & 3.8595 & 3.5 & 4.3485 & 4.0 & 4.2146 & 1.8 \\
\hline $12.5-15$ & 4.5980 & 2.2 & 4.4559 & 3.1 & 4.5616 & 3.5 & 4.5522 & 1.6 \\
\hline $15-20$ & 4.6649 & 1.4 & 4.5207 & 1.9 & 4.6870 & 2.2 & 4.6299 & 1.0 \\
\hline $20-25$ & 5.0935 & 1.2 & 4.8879 & 1.6 & 5.0201 & 1.9 & 5.0177 & 0.9 \\
\hline $25-30$ & 4.9344 & 1.0 & 4.8877 & 1.3 & 4.8712 & 1.6 & 4.9072 & 0.7 \\
\hline $30-40$ & 4.8501 & 0.8 & 4.8324 & 1.0 & 4.7832 & 1.2 & 4.8307 & 0.6 \\
\hline $40-50$ & 5.1904 & 0.8 & 5.1459 & 1.0 & 4.9962 & 1.2 & 5.1361 & 0.6 \\
\hline $50-60$ & 5.0404 & 0.8 & 5.0196 & 1.0 & 4.9805 & 1.2 & 5.0223 & 0.5 \\
\hline $60-80$ & 4.8328 & 0.6 & 4.7142 & 0.9 & 4.6810 & 1.0 & 4.7680 & 0.5 \\
\hline $80-100$ & 4.7487 & 0.7 & 4.6625 & 0.9 & 4.6753 & 1.0 & 4.7082 & 0.5 \\
\hline $100-120$ & 4.3112 & 0.9 & 4.1688 & 0.9 & 4.2164 & 1.2 & 4.2346 & 0.6 \\
\hline $120-150$ & - & - & 3.7128 & 0.9 & - & - & 3.7128 & 0.9 \\
\hline $150-175$ & - & - & 3.3982 & 1.0 & - & - & 3.3982 & 1.0 \\
\hline $175-200$ & - & - & 3.1807 & 1.0 & - & - & 3.1807 & 1.0 \\
\hline $200-225$ & - & - & 3.1977 & 1.3 & - & - & 3.1977 & 1.3 \\
\hline $30-80$ & 4.9784 & 0.5 & 4.9280 & 0.6 & 4.8602 & 0.8 & 4.9395 & 0.3 \\
\hline
\end{tabular}


Table 17: $\sigma\left({ }^{156} \mathrm{Gd}\right) / \sigma\left({ }^{197} \mathrm{Au}\right)$ AND STATISTICAL UNCERTAINTIES IN (\%)

\begin{tabular}{|c|c|c|c|c|c|c|c|c|}
\hline \multirow{2}{*}{ 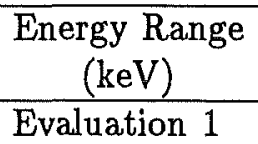 } & \multicolumn{2}{|c|}{ Run I } & \multicolumn{2}{|c|}{ Run II } & \multicolumn{2}{|c|}{ Run III } & \multicolumn{2}{|c|}{ Average } \\
\hline & & & & & & & & \\
\hline $3-5$ & 0.8673 & 8.2 & - & - & 0.8046 & 16.2 & 0.8545 & 7.3 \\
\hline $5-7.5$ & 0.8176 & 4.1 & - & - & 0.7755 & 8.7 & 0.8099 & 3.7 \\
\hline $7.5-10$ & 0.9752 & 4.6 & 0.9514 & 6.7 & 0.8799 & 6.5 & 0.9452 & 3.3 \\
\hline $10-12.5$ & 0.8914 & 3.5 & 0.8400 & 5.1 & 0.9190 & 5.4 & 0.8847 & 2.6 \\
\hline $12.5-15$ & 0.9336 & 3.0 & 0.8656 & 4.3 & 1.0313 & 4.7 & 0.9376 & 2.2 \\
\hline $15-20$ & 1.0195 & 1.9 & 0.9647 & 2.6 & 1.0326 & 2.8 & 1.0079 & 1.3 \\
\hline $20-25$ & 1.1461 & 1.6 & 1.0943 & 2.1 & 1.1177 & 2.5 & 1.1249 & 1.1 \\
\hline $25-30$ & 1.0665 & 1.4 & 1.0373 & 1.8 & 1.0902 & 2.0 & 1.0631 & 1.0 \\
\hline $30-40$ & 1.1235 & 1.1 & 1.1022 & 1.3 & 1.1628 & 1.6 & 1.1251 & 0.7 \\
\hline $40-50$ & 1.2304 & 1.1 & 1.2024 & 1.3 & 1.2416 & 1.6 & 1.2243 & 0.7 \\
\hline $50-60$ & 1.2450 & 1.0 & 1.2143 & 1.3 & 1.2624 & 1.6 & 1.2397 & 0.7 \\
\hline $60-80$ & 1.1999 & 0.9 & 1.1846 & 1.2 & 1.2059 & 1.4 & 1.1966 & 0.6 \\
\hline $80-100$ & 1.1934 & 0.9 & 1.2045 & 1.1 & 1.2111 & 1.4 & 1.2006 & 0.6 \\
\hline $100-120$ & 1.0761 & 1.2 & 1.0815 & 1.2 & 1.0707 & 1.6 & 1.0770 & 0.7 \\
\hline $120-150$ & - & - & 0.9633 & 1.1 & - & - & 0.9633 & 1.1 \\
\hline $150-175$ & - & - & 0.8855 & 1.2 & - & - & 0.8855 & 1.2 \\
\hline $175-200$ & - & - & 0.8157 & 1.3 & - & - & 0.8157 & 1.3 \\
\hline $200-225$ & - & - & 0.8168 & 1.7 & - & - & 0.8168 & 1.7 \\
\hline $30-80$ & 1.1997 & 0.8 & 1.1759 & 0.9 & 1.2182 & 1.2 & 1.1950 & 0.5 \\
\hline \multicolumn{9}{|l|}{ Evaluation 2} \\
\hline $3-5$ & 0.8545 & 6.2 & - & - & 0.8844 & 13.4 & 0.8597 & 5.6 \\
\hline $5-7.5$ & 0.8139 & 3.2 & - & - & 0.7997 & 6.8 & 0.8114 & 2.9 \\
\hline $7.5-10$ & 0.9510 & 3.5 & 0.9380 & 4.8 & 0.9739 & 5.2 & 0.9526 & 2.5 \\
\hline $10-12.5$ & 0.8948 & 2.8 & 0.8271 & 3.7 & 0.9126 & 4.3 & 0.8796 & 2.0 \\
\hline $12.5-15$ & 0.9421 & 2.4 & 0.9022 & 3.3 & 0.9872 & 3.7 & 0.9411 & 1.7 \\
\hline $15-20$ & 1.0157 & 1.5 & 0.9905 & 2.0 & 1.0530 & 2.3 & 1.0167 & 1.1 \\
\hline $20-25$ & 1.1300 & 1.3 & 1.1226 & 1.7 & 1.1597 & 2.0 & 1.1341 & 0.9 \\
\hline $25-30$ & 1.0679 & 1.1 & 1.0559 & 1.4 & 1.0984 & 1.7 & 1.0707 & 0.8 \\
\hline $30-40$ & 1.1182 & 0.9 & 1.1179 & 1.1 & 1.1482 & 1.3 & 1.1243 & 0.6 \\
\hline $40-50$ & 1.2171 & 0.9 & 1.2153 & 1.1 & 1.2291 & 1.3 & 1.2191 & 0.6 \\
\hline $50-60$ & 1.2206 & 0.8 & 1.2162 & 1.1 & 1.2500 & 1.3 & 1.2254 & 0.6 \\
\hline $60-80$ & 1.1796 & 0.7 & 1.1779 & 0.9 & 1.1906 & 1.1 & 1.1814 & 0.5 \\
\hline $80-100$ & 1.1739 & 0.7 & 1.1918 & 0.9 & 1.1957 & 1.1 & 1.1838 & 0.5 \\
\hline $100-120$ & 1.0575 & 1.0 & 1.0708 & 1.0 & 1.0497 & 1.3 & 1.0611 & 0.6 \\
\hline $120-150$ & - & - & 0.9510 & 0.9 & - & - & 0.9510 & 0.9 \\
\hline $150-175$ & - & - & 0.8745 & 1.0 & - & - & 0.8745 & 1.0 \\
\hline $175-200$ & - & - & 0.8111 & 1.1 & - & - & 0.8111 & 1.1 \\
\hline $200-225$ & - & - & 0.7979 & 1.4 & - & - & 0.7979 & 1.4 \\
\hline $30-80$ & 1.1839 & 0.6 & 1.1818 & 0.7 & 1.2045 & 0.9 & 1.1874 & 0.4 \\
\hline
\end{tabular}


Table 18: $\sigma\left({ }^{157} \mathrm{Gd}\right) / \sigma\left({ }^{197} \mathrm{Au}\right)$ AND STATISTICAL UNCERTAINTIES IN (\%)

\begin{tabular}{|c|c|c|c|c|c|c|c|c|}
\hline \multirow{2}{*}{$\begin{array}{c}\begin{array}{c}\text { Energy Range } \\
(\mathrm{keV})\end{array} \\
\text { Evaluation } 1\end{array}$} & \multicolumn{2}{|c|}{ Run I } & \multicolumn{2}{|c|}{ Run II } & \multicolumn{2}{|c|}{ Run III } & \multicolumn{2}{|c|}{ Average } \\
\hline & & & & & & & & \\
\hline $3-5$ & 2.2005 & 7.7 & - & - & 2.2345 & 14.3 & 2.2081 & 6.8 \\
\hline $5-7.5$ & 2.0845 & 3.8 & - & - & 2.0082 & 7.7 & 2.0695 & 3.4 \\
\hline $7.5-10$ & 2.5669 & 4.4 & 2.2110 & 6.5 & 2.2258 & 6.0 & 2.3941 & 3.1 \\
\hline $10-12.5$ & 2.2160 & 3.3 & 1.9955 & 4.8 & 2.2994 & 5.1 & 2.1808 & 2.4 \\
\hline $12.5-15$ & 2.3873 & 2.8 & 2.1992 & 4.1 & 2.5343 & 4.4 & 2.3707 & 2.1 \\
\hline $15-20$ & 2.5426 & 1.8 & 2.3902 & 2.5 & 2.5176 & 2.7 & 2.4976 & 1.3 \\
\hline $20-25$ & 2.7639 & 1.6 & 2.5626 & 2.1 & 2.7254 & 2.3 & 2.6991 & 1.1 \\
\hline $25-30$ & 2.6369 & 1.3 & 2.5812 & 1.7 & 2.6515 & 1.9 & 2.6243 & 0.9 \\
\hline $30-40$ & 2.6193 & 1.0 & 2.5322 & 1.3 & 2.5937 & 1.5 & 2.5873 & 0.7 \\
\hline $40-50$ & 2.7461 & 1.0 & 2.6852 & 1.3 & 2.6866 & 1.5 & 2.7149 & 0.7 \\
\hline $50-60$ & 2.6330 & 1.0 & 2.5643 & 1.3 & 2.5989 & 1.5 & 2.6061 & 0.7 \\
\hline $60-80$ & 2.2694 & 0.9 & 2.1797 & 1.1 & 2.2070 & 1.3 & 2.2297 & 0.6 \\
\hline $80-100$ & 2.0245 & 0.9 & 1.9856 & 1.1 & 2.0019 & 1.3 & 2.0081 & 0.6 \\
\hline $100-120$ & 1.8826 & 1.1 & 1.8266 & 1.2 & 1.8534 & 1.5 & 1.8545 & 0.7 \\
\hline $120-150$ & - & - & 1.6252 & 1.1 & - & - & 1.6252 & 1.1 \\
\hline $150-175$ & - & - & 1.4667 & 1.2 & - & - & 1.4667 & 1.2 \\
\hline $175-200$ & - & - & 1.3522 & 1.2 & - & - & 1.3522 & 1.2 \\
\hline $200-225$ & - & - & 1.3448 & 1.6 & - & - & 1.3448 & 1.6 \\
\hline $30-80$ & 2.5670 & 0.8 & 2.4904 & 0.9 & 2.5216 & 1.1 & 2.5306 & 0.5 \\
\hline \multicolumn{9}{|l|}{ Evaluation 2} \\
\hline $3-5$ & 2.1736 & 5.8 & - & - & 2.5075 & 12.3 & 2.2337 & 5.2 \\
\hline $5-7.5$ & 2.0665 & 2.9 & - & - & 2.0896 & 6.1 & 2.0708 & 2.6 \\
\hline $7.5-10$ & 2.4876 & 3.3 & 2.1813 & 4.6 & 2.3845 & 4.9 & 2.3839 & 2.4 \\
\hline $10-12.5$ & 2.2498 & 2.6 & 1.9195 & 3.5 & 2.3152 & 4.0 & 2.1737 & 1.8 \\
\hline $12.5-15$ & 2.3942 & 2.2 & 2.3159 & 3.1 & 2.5075 & 3.4 & 2.3977 & 1.6 \\
\hline $15-20$ & 2.5894 & 1.4 & 2.4556 & 1.9 & 2.6314 & 2.2 & 2.5617 & 1.0 \\
\hline $20-25$ & 2.7267 & 1.2 & 2.5909 & 1.6 & 2.7722 & 1.9 & 2.6968 & 0.9 \\
\hline $25-30$ & 2.6078 & 1.0 & 2.5827 & 1.3 & 2.6527 & 1.6 & 2.6099 & 0.7 \\
\hline $30-40$ & 2.5920 & 0.8 & 2.5563 & 1.0 & 2.5793 & 1.2 & 2.5783 & 0.6 \\
\hline $40-50$ & 2.7269 & 0.8 & 2.6924 & 1.0 & 2.6992 & 1.2 & 2.7107 & 0.6 \\
\hline $50-60$ & 2.5886 & 0.8 & 2.5745 & 1.0 & 2.6118 & 1.2 & 2.5895 & 0.6 \\
\hline $60-80$ & 2.2304 & 0.7 & 2.1811 & 0.9 & 2.2089 & 1.0 & 2.2123 & 0.5 \\
\hline $80-100$ & 1.9814 & 0.7 & 1.9670 & 0.9 & 1.9962 & 1.1 & 1.9803 & 0.5 \\
\hline $100-120$ & 1.8494 & 0.9 & 1.8132 & 0.9 & 1.8266 & 1.2 & 1.8299 & 0.6 \\
\hline $120-150$ & - & - & 1.6113 & 0.9 & - & - & 1.6113 & 0.9 \\
\hline $150-175$ & - & - & 1.4437 & 1.0 & - & - & 1.4437 & 1.0 \\
\hline $175-200$ & - & - & 1.3498 & 1.0 & - & - & 1.3498 & 1.0 \\
\hline $200-225$ & - & - & 1.3300 & 1.4 & - & - & 1.3300 & 1.4 \\
\hline $30-80$ & 2.5345 & 0.5 & 2.5011 & 0.7 & 2.5248 & 0.8 & 2.5235 & 0.4 \\
\hline
\end{tabular}


Table 19: $\sigma\left({ }^{158} \mathrm{Gd}\right) / \sigma\left({ }^{197} \mathrm{Au}\right)$ AND STATISTICAL UNCERTAINTIES IN (\%)

\begin{tabular}{|c|c|c|c|c|c|c|c|c|}
\hline \multirow{2}{*}{$\begin{array}{c}\text { Energy Range } \\
(\mathrm{keV})\end{array}$} & \multicolumn{2}{|c|}{ Run I } & \multicolumn{2}{|c|}{ Run II } & \multicolumn{2}{|c|}{ Run III } & \multicolumn{2}{|c|}{ Average } \\
\hline & & & & & & & & \\
\hline $3-5$ & 0.3994 & 11.2 & - & - & 0.3587 & 23.5 & 0.3918 & 10.1 \\
\hline $5-7.5$ & 0.4264 & 5.0 & - & - & 0.4315 & 10.4 & 0.4273 & 4.5 \\
\hline $7.5-10$ & 0.5075 & 5.4 & 0.4598 & 8.0 & 0.4598 & 7.7 & 0.4845 & 3.9 \\
\hline $10-12.5$ & 0.4778 & 4.0 & 0.4224 & 5.9 & 0.5298 & 6.1 & 0.4764 & 2.9 \\
\hline $12.5-15$ & 0.5005 & 3.4 & 0.4905 & 4.7 & 0.5873 & 5.2 & 0.5168 & 2.4 \\
\hline $15-20$ & 0.5750 & 2.0 & 0.5407 & 2.8 & 0.5900 & 3.1 & 0.5692 & 1.5 \\
\hline $20-25$ & 0.6710 & 1.7 & 0.6604 & 2.3 & 0.6686 & 2.7 & 0.6674 & 1.2 \\
\hline $25-30$ & 0.6045 & 1.5 & 0.6023 & 1.9 & 0.6232 & 2.2 & 0.6079 & 1.0 \\
\hline $30-40$ & 0.6222 & 1.2 & 0.6109 & 1.5 & 0.6317 & 1.8 & 0.6207 & 0.8 \\
\hline $40-50$ & 0.6477 & 1.2 & 0.6371 & 1.5 & 0.6420 & 1.8 & 0.6433 & 0.8 \\
\hline $50-60$ & 0.6482 & 1.1 & 0.6401 & 1.5 & 0.6501 & 1.8 & 0.6463 & 0.8 \\
\hline $60-80$ & 0.6600 & 1.0 & 0.6422 & 1.3 & 0.6506 & 1.6 & 0.6528 & 0.7 \\
\hline $80-100$ & 0.5291 & 1.1 & 0.5366 & 1.3 & 0.5358 & 1.6 & 0.5328 & 0.7 \\
\hline $100-120$ & 0.4741 & 1.3 & 0.4632 & 1.3 & 0.4665 & 1.8 & 0.4683 & 0.8 \\
\hline $120-150$ & - & - & 0.4101 & 1.3 & - & - & 0.4101 & 1.3 \\
\hline $150-175$ & - & - & 0.3617 & 1.4 & - & - & 0.3617 & 1.4 \\
\hline $175-200$ & - & - & 0.3553 & 1.4 & - & - & 0.3553 & 1.4 \\
\hline $200-225$ & - & - & 0.3561 & 1.8 & - & - & 0.3561 & 1.8 \\
\hline $30-80$ & 0.6445 & 0.9 & 0.6326 & 1.1 & 0.6436 & 1.4 & 0.6405 & 0.6 \\
\hline \multicolumn{9}{|l|}{ Evaluation 2} \\
\hline $3-5$ & 0.4027 & 8.4 & - & - & 0.4286 & 18.2 & 0.4072 & 7.7 \\
\hline $5-7.5$ & 0.4163 & 3.9 & - & - & 0.4291 & 8.4 & 0.4186 & 3.5 \\
\hline $7.5-10$ & 0.4792 & 4.2 & 0.4623 & 5.7 & 0.5122 & 6.2 & 0.4822 & 3.0 \\
\hline $10-12.5$ & 0.4849 & 3.1 & 0.4234 & 4.3 & 0.5282 & 4.8 & 0.4779 & 2.2 \\
\hline $12.5-15$ & 0.5127 & 2.6 & 0.5086 & 3.6 & 0.5921 & 4.0 & 0.5293 & 1.9 \\
\hline $15-20$ & 0.5778 & 1.6 & 0.5511 & 2.2 & 0.6092 & 2.5 & 0.5772 & 1.2 \\
\hline $20-25$ & 0.6582 & 1.4 & 0.6644 & 1.8 & 0.6839 & 2.1 & 0.6654 & 1.0 \\
\hline $25-30$ & 0.5933 & 1.2 & 0.6042 & 1.5 & 0.6225 & 1.8 & 0.6027 & 0.8 \\
\hline $30-40$ & 0.6106 & 0.9 & 0.6153 & 1.2 & 0.6270 & 1.4 & 0.6154 & 0.6 \\
\hline $40-50$ & 0.6336 & 0.9 & 0.6387 & 1.2 & 0.6386 & 1.4 & 0.6361 & 0.6 \\
\hline $50-60$ & 0.6323 & 0.9 & 0.6366 & 1.2 & 0.6560 & 1.4 & 0.6383 & 0.6 \\
\hline $60-80$ & 0.6408 & 0.7 & 0.6360 & 1.0 & 0.6469 & 1.2 & 0.6408 & 0.5 \\
\hline $80-100$ & 0.5132 & 0.8 & 0.5270 & 1.1 & 0.5338 & 1.2 & 0.5213 & 0.6 \\
\hline $100-120$ & 0.4608 & 1.1 & 0.4571 & 1.1 & 0.4623 & 1.4 & 0.4598 & 0.7 \\
\hline $120-150$ & - & - & 0.4060 & 1.0 & - & - & 0.4060 & 1.0 \\
\hline $150-175$ & - & - & 0.3553 & 1.2 & - & - & 0.3553 & 1.2 \\
\hline $175-200$ & - & - & 0.3518 & 1.2 & - & - & 0.3518 & 1.2 \\
\hline $200-225$ & - & - & 0.3464 & 1.6 & - & - & 0.3464 & 1.6 \\
\hline $30-80$ & 0.6293 & 0.6 & 0.6317 & 0.8 & 0.6421 & 1.0 & 0.6324 & 0.4 \\
\hline
\end{tabular}


Table 20: FINAL NEUTRON CAPTURE CROSS SECTION RATIOS OF ${ }^{152} \mathrm{Gd},{ }^{154} \mathrm{Gd}$, ${ }^{155} \mathrm{Gd},{ }^{156} \mathrm{Gd}{ }^{157} \mathrm{Gd}$, AND ${ }^{158} \mathrm{Gd}$ RELATIVE TO ${ }^{197} \mathrm{Au}$

\begin{tabular}{|c|c|c|c|c|c|c|c|c|c|c|c|c|}
\hline \multirow{2}{*}{$\begin{array}{c}\text { Energy }^{1} \\
(\mathrm{keV})\end{array}$} & \multirow[t]{2}{*}{$\frac{\sigma\left({ }^{152} \mathrm{Gd}\right)}{\sigma\left({ }^{197} \mathrm{Au}\right)}$} & \multicolumn{3}{|c|}{ Uncertainty (\%) } & \multirow[t]{2}{*}{$\frac{\sigma\left({ }^{154} \mathrm{Gd}\right)}{\sigma\left({ }^{197} \mathrm{Au}\right)}$} & \multicolumn{3}{|c|}{ Uncertainty (\%) } & \multirow[t]{2}{*}{$\frac{\sigma\left({ }^{165} \mathrm{Gd}\right)}{\sigma\left({ }^{137} \mathrm{Au}\right)}$} & \multicolumn{3}{|c|}{ Uncertainty (\%) } \\
\hline & & stat & sys & tot & & stat & sys & tot & & stat & sys & tot \\
\hline $3-5$ & 1.407 & 9.1 & 1.4 & 9.2 & 1.389 & 5.9 & 1.0 & 6.0 & 4.034 & 5.4 & 1.0 & 5.5 \\
\hline $5-7.5$ & 1.588 & 4.3 & 1.4 & 4.5 & 1.361 & 3.1 & 1.0 & 3.3 & 3.700 & 2.7 & 1.0 & 2.9 \\
\hline $7.5-10$ & 1.643 & 3.9 & 1.4 & 4.1 & 1.604 & 2.6 & 1.0 & 2.8 & 4.291 & 2.4 & 1.0 & 2.6 \\
\hline $10-12.5$ & 1.555 & 3.1 & 1.4 & 3.4 & 1.494 & 2.1 & 1.0 & 2.3 & 4.215 & 1.8 & 1.0 & 2.1 \\
\hline $12.5-15$ & 1.629 & 2.7 & 1.4 & 3.0 & 1.572 & 1.9 & 1.0 & 2.1 & 4.552 & 1.6 & 1.0 & 1.9 \\
\hline $15-20$ & 1.690 & 1.7 & 1.4 & 2.2 & 1.645 & 1.2 & 1.0 & 1.6 & 4.630 & 1.0 & 1.0 & 1.4 \\
\hline $20-25$ & 1.850 & 1.5 & 1.4 & 2.1 & 1.870 & 1.0 & 1.0 & 1.4 & 5.018 & 0.9 & 1.0 & 1.3 \\
\hline $25-30$ & 1.744 & 1.3 & 1.4 & 1.9 & 1.827 & 0.9 & 1.0 & 1.3 & 4.907 & 0.7 & 1.0 & 1.2 \\
\hline $30-40$ & 1.748 & 1.0 & 1.4 & 1.7 & 1.774 & 0.7 & 1.0 & 1.2 & 4.831 & 0.6 & 1.0 & 1.2 \\
\hline $40-50$ & 1.890 & 1.0 & 1.4 & 1.7 & 1.948 & 0.7 & 1.0 & 1.2 & 5.136 & 0.6 & 1.0 & 1.2 \\
\hline $50-60$ & 1.917 & 1.0 & 1.4 & 1.7 & 1.949 & 0.7 & 1.0 & 1.2 & 5.022 & 0.5 & 1.0 & 1.1 \\
\hline $60-80$ & 1.955 & 0.8 & 1.4 & 1.6 & 1.967 & 0.6 & 1.0 & 1.2 & 4.768 & 0.5 & 1.0 & 1.1 \\
\hline $80-100$ & 2.095 & 0.8 & 1.4 & 1.6 & 2.077 & 0.6 & 1.0 & 1.2 & 4.708 & 0.5 & 1.0 & 1.1 \\
\hline $100-120$ & 2.109 & 1.0 & 1.4 & 1.7 & 2.066 & 0.7 & 1.0 & 1.2 & 4.235 & 0.6 & 1.0 & 1.2 \\
\hline $120-150$ & 2.240 & 1.4 & 1.4 & 2.0 & 1.883 & 1.0 & 1.0 & 1.4 & 3.713 & 0.9 & 1.0 & 1.3 \\
\hline $150-175$ & 2.324 & 1.5 & 1.4 & 2.1 & 1.745 & 1.1 & 1.0 & 1.5 & 3.398 & 1.0 & 1.0 & 1.4 \\
\hline $175-200$ & 2.412 & 1.5 & 1.4 & 2.1 & 1.668 & 1.2 & 1.0 & 1.6 & 3.181 & 1.0 & 1.0 & 1.4 \\
\hline $200-225$ & 2.572 & 1.9 & 1.4 & 2.4 & 1.672 & 1.6 & 1.0 & 1.9 & 3.198 & 1.3 & 1.0 & 1.6 \\
\hline
\end{tabular}

$\begin{array}{lllllll}\text { Energy }^{1} & \frac{\sigma\left({ }^{156} \mathrm{Gd}\right)}{\sigma\left({ }^{197} \mathrm{Au}\right)} & \text { Uncertainty (\%) } & \frac{\left.\sigma{ }^{157} \mathrm{Gd}\right)}{\sigma\left({ }^{197} \mathrm{Au}\right)} & \text { Uncertainty (\%) } & \frac{\sigma\left({ }^{158} \mathrm{Gd}\right)}{\sigma\left({ }^{197} \mathrm{Au}\right)} & \text { Uncertainty (\%) }\end{array}$

\begin{tabular}{|c|c|c|c|c|c|c|c|c|c|c|c|c|}
\hline$(\mathrm{keV})$ & & stat & sys & tot & & stat & sys & tot & & stat & sys & tot \\
\hline $3-5$ & 0.860 & 5.6 & 0.6 & 5.6 & 2.234 & 5.2 & 0.9 & 5.3 & 0.407 & 7.7 & 0.6 & 7.7 \\
\hline $5-7.5$ & 0.811 & 2.9 & 0.6 & 3.0 & 2.071 & 2.6 & 0.9 & 2.8 & 0.419 & 3.5 & 0.6 & 3.6 \\
\hline $7.5-10$ & 0.953 & 2.5 & 0.6 & 2.6 & 2.384 & 2.4 & 0.9 & 2.6 & 0.482 & 3.0 & 0.6 & 3.1 \\
\hline $10-12.5$ & 0.880 & 2.0 & 0.6 & 2.1 & 2.174 & 1.8 & 0.9 & 2.0 & 0.478 & 2.2 & 0.6 & 2.3 \\
\hline $12.5-15$ & 0.941 & 1.7 & 0.6 & 1.8 & 2.398 & 1.6 & 0.9 & 1.8 & 0.529 & 1.9 & 0.6 & 2.0 \\
\hline $15-20$ & 1.017 & 1.1 & 0.6 & 1.3 & 2.562 & 1.0 & 0.9 & 1.3 & 0.577 & 1.1 & 0.6 & 1.3 \\
\hline $20-25$ & 1.134 & 0.9 & 0.6 & 1.1 & 2.697 & 0.9 & 0.9 & 1.3 & 0.665 & 1.0 & 0.6 & 1.2 \\
\hline $25-30$ & 1.071 & 0.8 & 0.6 & 1.0 & 2.610 & 0.7 & 0.9 & 1.1 & 0.603 & 0.8 & 0.6 & 1.2 \\
\hline $30-40$ & 1.124 & 0.6 & 0.6 & 0.8 & 2.578 & 0.6 & 0.9 & 1.1 & 0.615 & 0.6 & 0.6 & 0.8 \\
\hline $40-50$ & 1.219 & 0.6 & 0.6 & 0.8 & 2.711 & 0.6 & 0.9 & 1.1 & 0.636 & 0.6 & 0.6 & 0.8 \\
\hline $50-60$ & 1.225 & 0.6 & 0.6 & 0.8 & 2.590 & 0.6 & 0.9 & 1.1 & 0.638 & 0.6 & 0.6 & 0.8 \\
\hline $60-80$ & 1.181 & 0.5 & 0.6 & 0.8 & 2.212 & 0.5 & 0.9 & 1.0 & 0.641 & 0.5 & 0.6 & 0.8 \\
\hline $80-100$ & 1.184 & 0.5 & 0.6 & 0.8 & 1.980 & 0.5 & 0.9 & 1.0 & 0.521 & 0.6 & 0.6 & 0.8 \\
\hline $100-120$ & 1.061 & 0.6 & 0.6 & 0.8 & 1.830 & 0.6 & 0.9 & 1.1 & 0.460 & 0.7 & 0.6 & 0.9 \\
\hline $120-150$ & 0.951 & 0.9 & 0.6 & 1.1 & 1.611 & 0.9 & 0.9 & 1.3 & 0.406 & 1.0 & 0.6 & 1.2 \\
\hline $150-175$ & 0.875 & 1.0 & 0.6 & 1.2 & 1.444 & 1.0 & 0.9 & 1.3 & 0.355 & 1.2 & 0.6 & 1.3 \\
\hline $175-200$ & 0.811 & 1.1 & 0.6 & 1.3 & 1.350 & 1.0 & 0.9 & 1.3 & 0.352 & 1.2 & 0.6 & 1.3 \\
\hline $200-225$ & 0.798 & 1.4 & 0.6 & 1.5 & 1.330 & 1.4 & 0.9 & 1.7 & 0.346 & 1.6 & 0.6 & 1.7 \\
\hline
\end{tabular}

${ }^{1}$ Energy intervals chosen for calculating the Maxwellian averaged cross sections 
Table 21: NEUTRON CAPTURE CROSS SECTIONS OF ${ }^{152} \mathrm{Gd},{ }^{154} \mathrm{Gd},{ }^{155} \mathrm{Gd},{ }^{156} \mathrm{Gd}$, ${ }^{157} \mathrm{Gd}$, AND ${ }^{158} \mathrm{Gd}$

\begin{tabular}{cccccccc}
\hline $\begin{array}{c}\text { Energy Interval } \\
(\mathrm{keV})\end{array}$ & $\begin{array}{c}\sigma\left({ }^{197} \mathrm{Au}\right)^{2} \\
(\mathrm{mbarn})\end{array}$ & $\begin{array}{c}\sigma\left({ }^{152} \mathrm{Gd}\right) \\
(\mathrm{mbarn})\end{array}$ & $\begin{array}{c}\sigma\left({ }^{154} \mathrm{Gd}\right) \\
(\mathrm{mbarn})\end{array}$ & $\begin{array}{c}\sigma\left({ }^{155} \mathrm{Gd}\right) \\
(\mathrm{mbarn})\end{array}$ & $\begin{array}{c}\sigma\left({ }^{156} \mathrm{Gd}\right) \\
(\mathrm{mbarn})\end{array}$ & $\begin{array}{c}\sigma\left({ }^{157} \mathrm{Gd}\right) \\
(\mathrm{mbarn})\end{array}$ & $\begin{array}{c}\sigma\left({ }^{158} \mathrm{Gd}\right) \\
(\mathrm{mbarn})\end{array}$ \\
\hline $3-5$ & 2266.7 & 3190. & 3148. & 9145. & 1949. & 5063. & 923.1 \\
$5-7.5$ & 1726.7 & 2742. & 2350. & 6388. & 1401. & 3576. & 722.7 \\
$7.5-10$ & 1215.7 & 1998. & 1949. & 5217. & 1158. & 2898. & 586.2 \\
$10-12.5$ & 1066.7 & 1659. & 1593. & 4496. & 938.3 & 2319. & 509.8 \\
$12.5-15$ & 878.0 & 1430. & 1380. & 3997. & 826.3 & 2105. & 464.7 \\
$15-20$ & 738.8 & 1248. & 1215. & 3420. & 751.1 & 1893. & 426.4 \\
$20-25$ & 600.0 & 1110. & 1122. & 3011. & 680.5 & 1618. & 399.2 \\
$25-30$ & 570.8 & 995.2 & 1043. & 2801. & 611.2 & 1490. & 344.0 \\
$30-40$ & 500.4 & 874.9 & 887.5 & 2417. & 562.6 & 1290. & 307.9 \\
$40-50$ & 433.3 & 818.9 & 844.3 & 2225. & 528.3 & 1175. & 275.7 \\
$50-60$ & 389.6 & 746.9 & 759.5 & 1957. & 477.5 & 1009. & 248.7 \\
$60-80$ & 349.4 & 683.2 & 687.1 & 1666. & 412.7 & 772.9 & 223.9 \\
$80-100$ & 298.3 & 624.8 & 619.6 & 1404. & 353.1 & 590.7 & 155.5 \\
$100-120$ & 290.1 & 611.9 & 599.4 & 1229. & 307.9 & 530.9 & 133.4 \\
$120-150$ & 274.1 & 614.0 & 516.1 & 1018. & 260.7 & 441.7 & 111.3 \\
$150-175$ & 263.7 & 612.7 & 460.0 & 895.9 & 230.6 & 380.6 & 93.68 \\
$175-200$ & 252.6 & 609.2 & 421.3 & 803.3 & 204.9 & 340.9 & 88.86 \\
$200-225$ & 248.5 & 639.1 & 415.3 & 794.5 & 198.3 & 330.5 & 86.07 \\
\hline
\end{tabular}

${ }^{1}$ chosen for calculating the Maxwellian averaged cross sections

${ }^{2}$ based on the ${ }^{197} \mathrm{Au}$ data from literature[26, 27] 

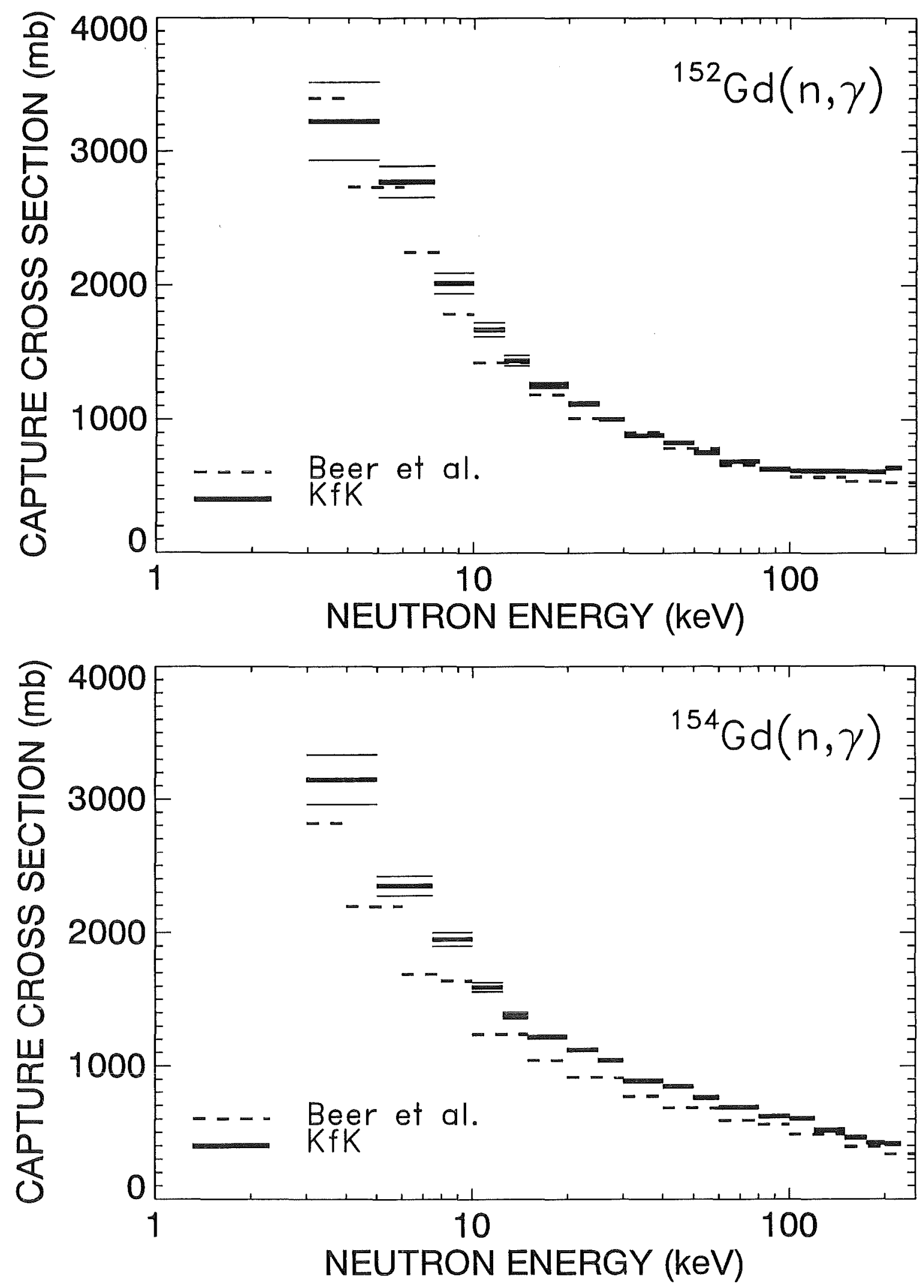

Figure 14: The neutron capture cross sections of ${ }^{152} \mathrm{Gd}$ and ${ }^{154} \mathrm{Gd}$ compared to the data of Beer and Macklin (Ref.6). 

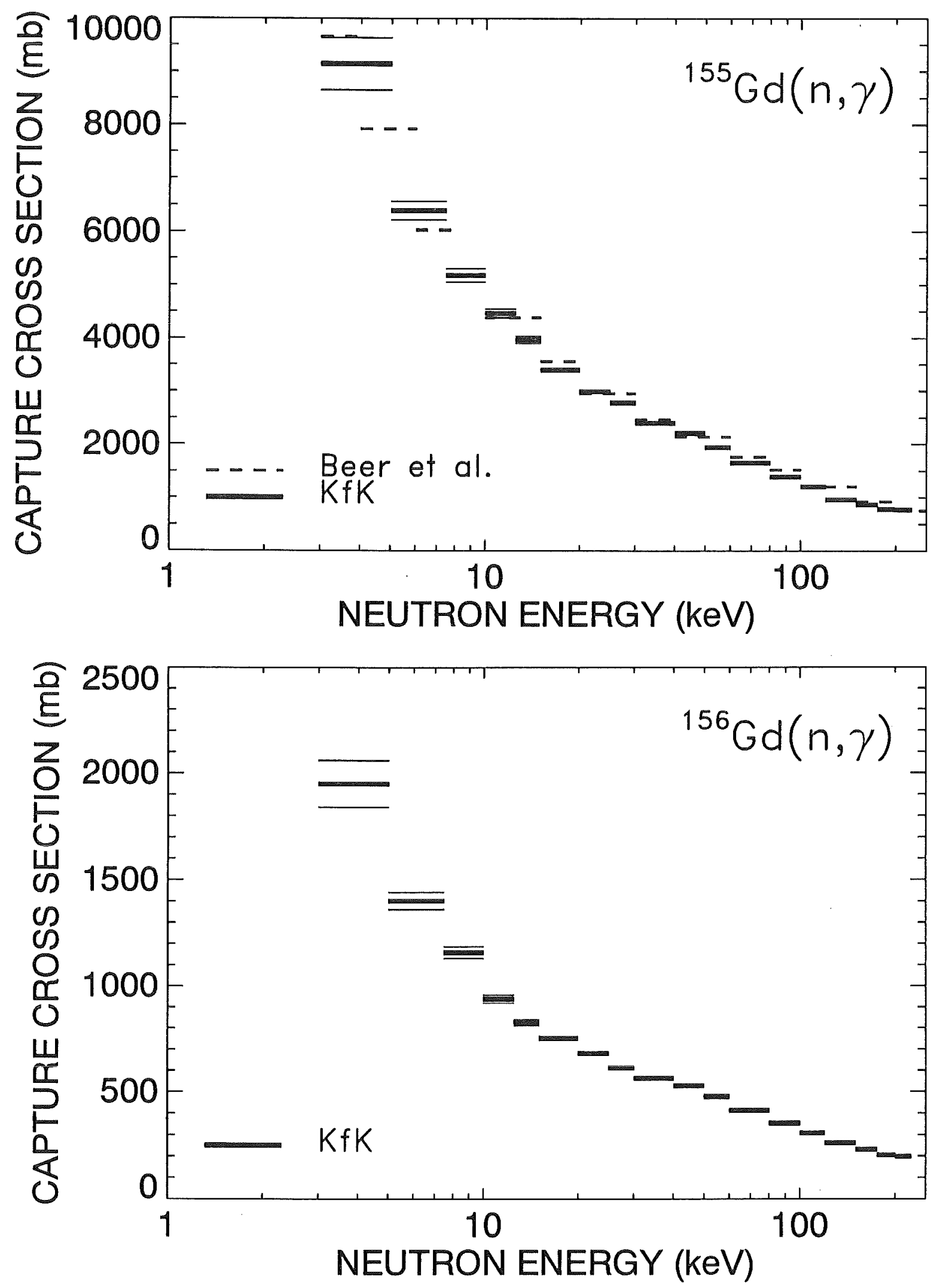

Figure 15: The neutron capture cross sections of ${ }^{155} \mathrm{Gd}$ and ${ }^{156} \mathrm{Gd}$ compared to the data of Beer and Macklin (Ref. $6{ }^{155} \mathrm{Gd}$ only). 

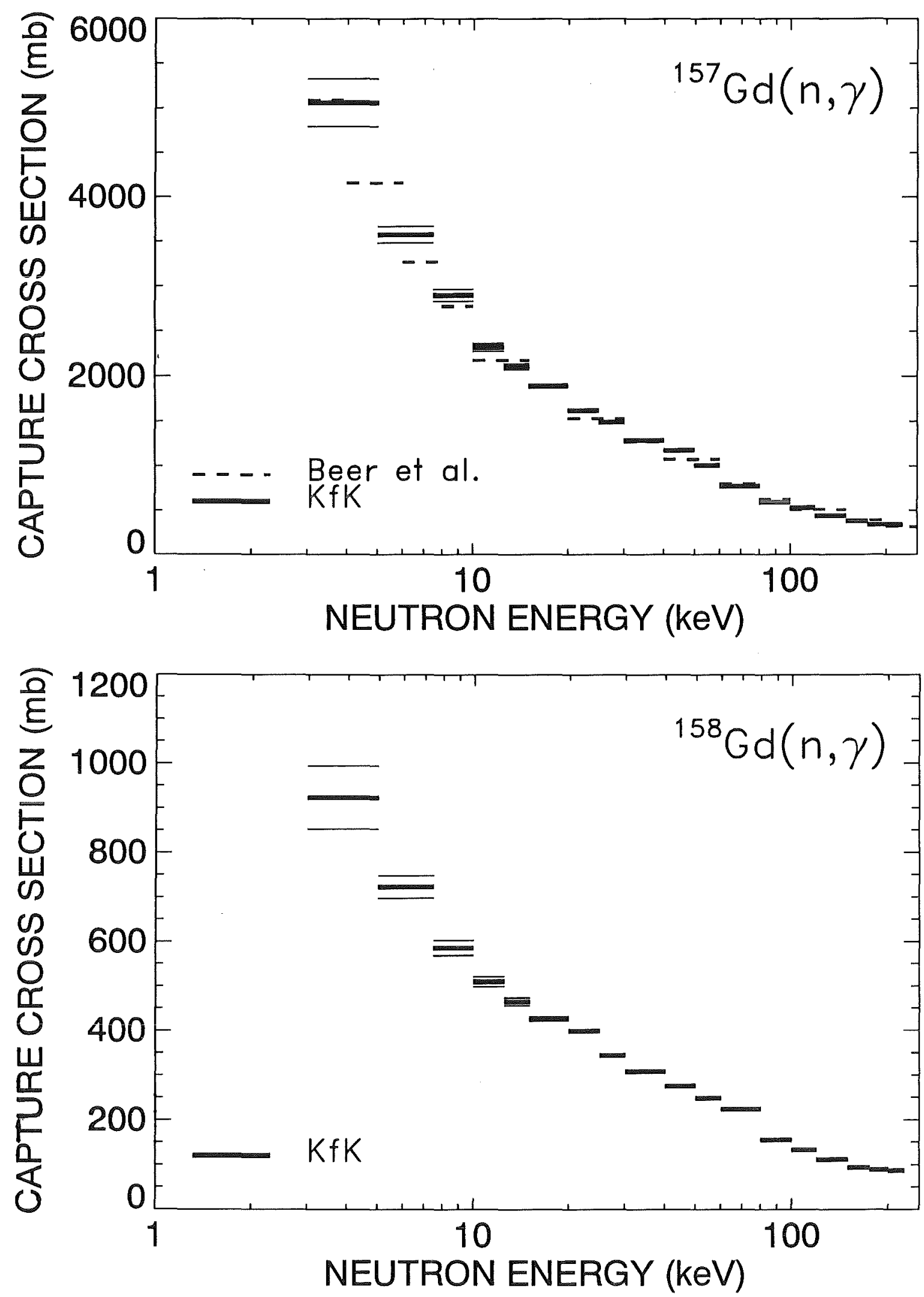

Figure 16: The neutron capture cross sections of ${ }^{157} \mathrm{Gd}$ and ${ }^{158} \mathrm{Gd}$ compared to the data of Beer and Macklin (Ref. $6{ }^{157} \mathrm{Gd}$ only). 


\section{DISCUSSION OF UNCERTAINTIES}

The determination of statistical and systematic uncertainties in measurements with the $4 \pi \mathrm{BaF}_{2}$ detector has been described in Refs.[1, 2, 14]. In the present experiment most of the uncertainties are very similar to those of the samarium cross sections[2]. Therefore, the following discussion concentrates on the particular aspects of the present experiment. The various uncertainties are compiled in Table 22.

The low enrichment of the ${ }^{152} \mathrm{Gd}$ and ${ }^{154} \mathrm{Gd}$ samples requires special attention. The isotopic composition is specified by the supplier with an absolute uncertainty of $\pm 0.2 \%$. In view of the good agreement obtained in the checks of the isotopic composition of the samarium isotopes[2] this seems to be a conservative estimate. Consequently, the main isotope in the highly enriched samples can be quoted with a relative uncertainty of $0.2 \%$, but for the low enrichments of the ${ }^{152} \mathrm{Gd}$ and ${ }^{154} \mathrm{Gd}$ samples relative uncertainties are $0.6 \%$ and $0.4 \%$ had to be adopted for the isotopic composition, respectively (Table22).

With the absolute uncertainty of $0.2 \%$ in the isotopic composition of Table 2, the relative uncertainties due to the even and odd impurity isotopes in the ${ }^{152} \mathrm{Gd}$ sample can be estimated to be $1.06 \%$ and $1.09 \%$, respectively. Evaluation of the spectra in Figure 5 yields the following contributions to the measured count rate in the relevant region between threshold and neutron binding energy in ${ }^{152} \mathrm{Gd}$ (channels 14 to 82 ): $47 \%$ from ${ }^{152} \mathrm{Gd}, 45 \%$ from the odd and $8 \%$ from the even impurity isotopes. This results in a systematic uncertainty of $1.0 \%$ for the isotopic correction of the ${ }^{152} \mathrm{Gd}$ spectrum. The corresponding uncertainty for the ${ }^{154} \mathrm{Gd}$ spectrum is $0.6 \%$. For all other spectra, the specified uncertainty of $0.2 \%$ was adopted.

The correction for multiple scattering and self-shielding is also problematic for the samples with low enrichment. The multiple scattering effect may either not be completely considered or even overcompensated by subtracting the normalized spectra of the impurity isotopes. This holds certainly if the individual sample masses are significantly different. Therefore, the calculation of the correction factors MS were performed for the total sample as well as for the isotope remaining after the isotopic correction. The respective differences (Table 12) were $2.4 \%$ and $1.6 \%$ for the ${ }^{152} \mathrm{Gd}$ and ${ }^{154} \mathrm{Gd}$ samples, nearly independent of the neutron energy. Therefore, $25 \%$ of this difference was adopted as a reasonable estimate for the systematic uncertainty.

The systematic uncertainties of the corrections for undetected events, $F_{1}$, were estimated from the differences resulting from the use of the capture cascades of Reffo and of Uhl. While the differences in the spectrum fractions, $f$, are sizeable (Sec.3), but some of them cancel out in the cross section ratio part. Hence, the correction factors, $F_{1}$, differed on the average only by $\pm 0.3 \%$ from the mean of both calculations for the even and by $\pm 0.8 \%$ for the odd isotopes. These differencee were assumed as the related systematic uncertainties. The larger uncertainty for the odd isotopes is due to the larger difference 
Table 22: SYSTEMATIC UNCERTAINTIES (\%)

\begin{tabular}{ll} 
Flight path & 0.1 \\
Neutron flux normalization & 0.2 \\
Sample mass (impurity elements) & 0.2 \\
Isotopic composition $\left({ }^{152} \mathrm{Gd} /{ }^{154} \mathrm{Gd} /{ }^{15 x} \mathrm{Gd}^{1}\right.$ samples) & $0.6 / 0.4 / 0.2$ \\
Isotopic correction $\left({ }^{152} \mathrm{Gd} /{ }^{154} \mathrm{Gd} /{ }^{15 x} \mathrm{Gd}^{1}\right.$ samples) & $1.0 / 0.6 / 0.2$ \\
Multiple scattering and self-shielding: $\mathrm{F}_{2}$ & \\
$\quad\left({ }^{152} \mathrm{Gd} /{ }^{154} \mathrm{Gd} /{ }^{15 x} \mathrm{Gd}^{1}\right.$ samples) & $0.7 / 0.5 / 0.4$ \\
Undetected events: $\mathrm{F}_{1}$ & \\
$\quad$ even $\mathrm{Gd}$ isotopes & 0.3 \\
$\quad$ odd $\mathrm{Gd}$ isotopes & 0.8 \\
\hline
\end{tabular}

total systematic uncertainties

$\begin{array}{ll}\sigma\left({ }^{152} \mathrm{Gd}\right) / \sigma(\mathrm{Au}) & 1.4 \\ \sigma\left({ }^{154} \mathrm{Gd}\right) / \sigma(\mathrm{Au}) & 1.0 \\ \sigma\left({ }^{155} \mathrm{Gd}\right) / \sigma(\mathrm{Au}) & 1.0 \\ \sigma\left({ }^{156} \mathrm{Gd}\right) / \sigma(\mathrm{Au}) & 0.6 \\ \sigma\left({ }^{157} \mathrm{Gd}\right) / \sigma(\mathrm{Au}) & 0.9 \\ \sigma\left({ }^{158} \mathrm{Gd}\right) / \sigma(\mathrm{Au}) & 0.6\end{array}$

${ }^{1} \mathrm{x}$ stands for the numbers $5,6,7$, and 8 .

in binding energy compared to the gold standard. For the even isotopes, the uncertainty is significantly smaller than in the previous experiments with the $4 \pi \mathrm{BaF}_{2}$ detector as a consequence of the increase in efficiency from $\sim 95$ to $98 \%$. The comparably large uncertainty for the odd isotopes is determined by the differences of both calculations for the gold sample. However, this remaining problem affects only the cross section ratios relative to gold, whereas the ratios of two gadolinium isotopes can be given with significantly better accuracy. The systematic uncertainties in the ratio of two even isotopes are only $0.15 \%$, those for the ratios of an odd and an even isotope are $0.45 \%$. Fig. 17 confirms the previous observations $[1,2,3]$ that the correction factor $F_{1}$ is in very good approximation proportional the difference between the binding energies of the investigated isotope and the gold standard. 


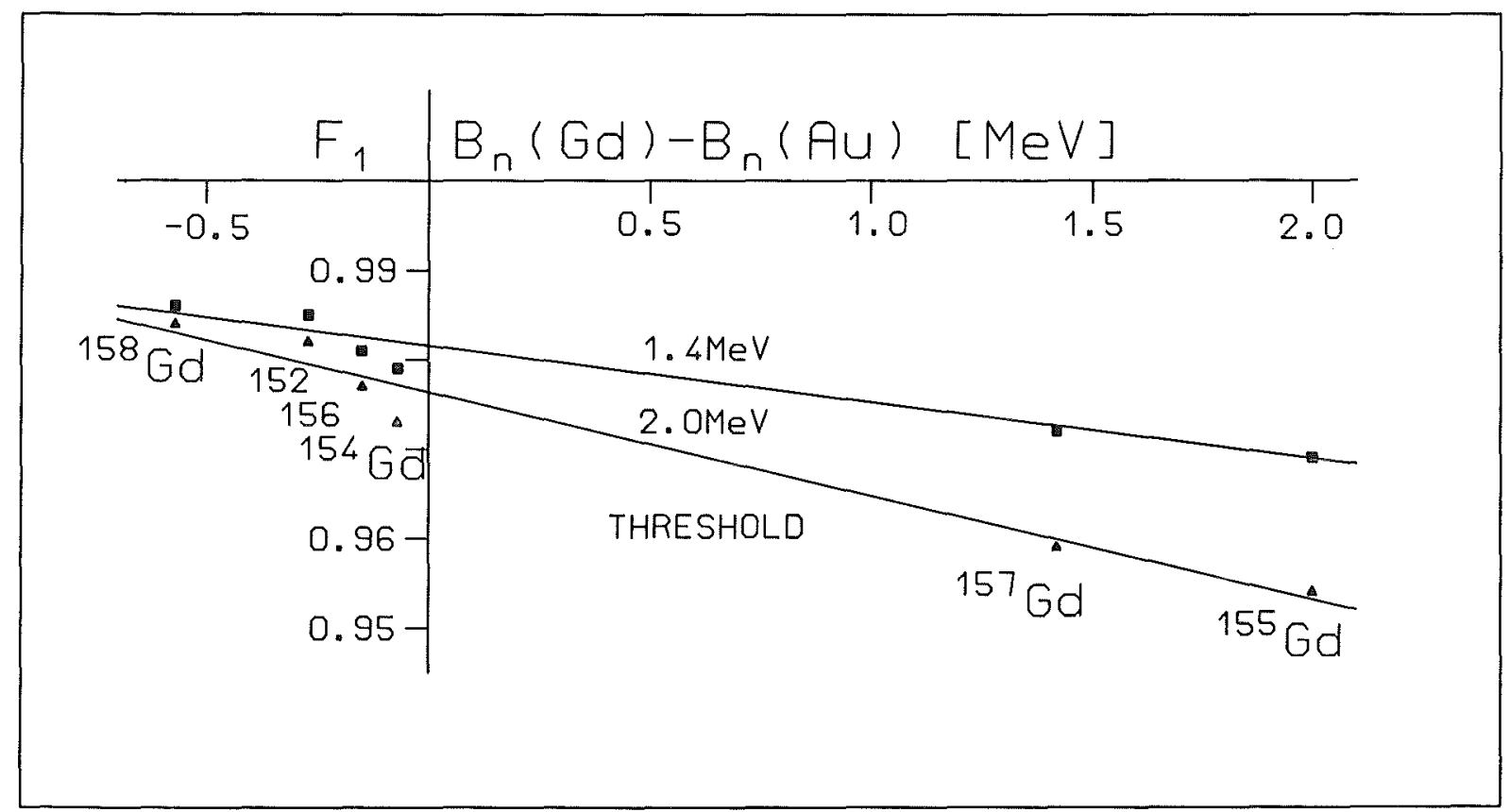

Figure 17: The correction $\mathrm{F}_{1}$ for unobserved capture events, plotted versus the difference in binding energy between the investigated gadolinium isotopes and the gold standard.

\section{MAXWELLIAN AVERAGED CROSS SECTIONS}

Maxwellian averaged cross sections were calculated in the same way as described in Refs. [1, 14]. The neutron energy range from 0 to $700 \mathrm{keV}$ was divided into three intervals according to the origin of the adopted cross sections. The respective contributions $\mathrm{I}_{x}$ are given in Table 23. The main contributions from the interval $I_{2}$ are provided by the present experiment (Table 21). The present data are presented with sufficient resolution to avoid systematic uncertainties that may result from a coarse energy grid. 
Table 23: MAXWELLIAN AVERAGED NEUTRON CAPTURE CROSS SECTIONS OF THE GADOLINIUM ISOTOPES (CONTRIBUTIONS $I_{x}$ FROM DIFFERENT ENERGY INTERVALS ARE QUOTED EXPLICITELY WITH THEIR STATISTICAL UNCERTAINTIES)

\begin{tabular}{|c|c|c|c|c|c|c|c|}
\hline \multicolumn{8}{|c|}{${ }^{152} \mathrm{Gd}$} \\
\hline $\begin{array}{c}\Delta \mathrm{E} \\
\text { Data: }\end{array}$ & $\begin{array}{l}0-3 \mathrm{keV} \\
\text { see text }\end{array}$ & $\begin{array}{c}3-225 \mathrm{keV} \\
\text { this work }\end{array}$ & $\begin{array}{l}225-700 \mathrm{keV} \\
\text { from Ref.[16 }]^{1}\end{array}$ & \multicolumn{4}{|c|}{ Thermal Spectrum } \\
\hline $\begin{array}{c}\mathrm{kT} \\
(\mathrm{keV})\end{array}$ & $\begin{array}{c}\mathrm{I}_{1} \\
(\mathrm{mbarn})\end{array}$ & $\begin{array}{c}\mathrm{I}_{2} \\
(\mathrm{mbarn})\end{array}$ & $\begin{array}{c}\mathrm{I}_{3} \\
\text { (mbarn) }\end{array}$ & \multicolumn{4}{|c|}{$<\sigma \mathrm{v}\rangle / \mathrm{v}_{T}(\mathrm{mbarn})$} \\
\hline 10 & $340.2 \pm 34$ & $1611 . \pm 26$ & 0.0 & 1951. & 43. & 23. & 49. \\
\hline 12 & $241.9 \pm 24$ & $1490 . \pm 21$ & 0.0 & 1732. & 32. & 21. & 38. \\
\hline 20 & $91.3 \pm 9.1$ & $1189 . \pm 12$ & 0.1 & 1280. & 15. & 17. & 23. \\
\hline 25 & $59.3 \pm 5.9$ & $1082 . \pm 9.3$ & 0.8 & 1142. & 11. & 15. & 19. \\
\hline 30 & $41.6 \pm 4.2$ & $1004 . \pm 8.0$ & $3.0 \pm 0.1$ & 1049. & 9.0 & 14. & 17. \\
\hline 40 & $23.7 \pm 2.4$ & $894.4 \pm 6.6$ & $15.0 \pm 0.4$ & 933.1 & 7.0 & 13. & 15. \\
\hline 50 & $15.3 \pm 1.5$ & $811.1 \pm 5.9$ & $38.0 \pm 1.1$ & 864.4 & 6.2 & 12. & 14. \\
\hline 52 & $14.1 \pm 1.4$ & $795.9 \pm 5.8$ & $43.6 \pm 1.3$ & 853.6 & 6.1 & 12. & 13. \\
\hline 60 & $10.6 \pm 1.1$ & $738.8 \pm 5.4$ & $68.6 \pm 2.2$ & 818.0 & 5.9 & 11. & 12. \\
\hline 70 & $7.8 \pm 0.8$ & $673.3 \pm 5.1$ & $102.5 \pm 3.4$ & 783.6 & 6.2 & 11. & 13. \\
\hline 80 & $6.0 \pm 0.6$ & $613.8 \pm 4.7$ & $136.5 \pm 4.8$ & 756.3 & 6.7 & 11. & 13. \\
\hline 90 & $4.8 \pm 0.5$ & $559.9 \pm 4.4$ & $168.4 \pm 6.2$ & 733.1 & 7.6 & 10. & 13. \\
\hline 100 & $3.9 \pm 0.4$ & $511.3 \pm 4.1$ & $197.1 \pm 7.6$ & 712.3 & 8.6 & 10. & 13. \\
\hline \multicolumn{8}{|c|}{${ }^{154} \mathrm{Gd}$} \\
\hline $\begin{array}{c}\Delta \mathrm{E} \\
\text { Data: }\end{array}$ & $\begin{array}{c}0-3 \mathrm{keV} \\
\text { see text }\end{array}$ & $\begin{array}{l}3-225 \mathrm{keV} \\
\text { this work }\end{array}$ & $\begin{array}{l}225-700 \mathrm{keV} \\
\text { from Ref.[16] }\end{array}$ & \multicolumn{4}{|c|}{ Thermal Spectrum } \\
\hline $\mathrm{kT}$ & $\mathrm{I}_{1}$ & $\mathrm{I}_{2}$ & $\mathrm{I}_{3}$ & \multicolumn{4}{|c|}{$\langle\sigma \mathrm{v}\rangle / \mathrm{v}_{T}(\mathrm{mbarn})$} \\
\hline$(\mathrm{keV})$ & (mbarn) & (mbarn) & (mbarn) & & stat & sys $^{2}$ & tot \\
\hline 10 & $303.5 \pm 30$ & $1559 . \pm 16$ & 0.0 & 1863. & 34. & 16. & 38. \\
\hline 12 & $216.2 \pm 22$ & $1452 . \pm 13$ & 0.0 & 1668. & 26. & 15. & 30. \\
\hline 20 & $81.9 \pm 8.2$ & $1176 . \pm 7.3$ & 0.1 & 1258. & 11. & 12. & 16. \\
\hline 25 & $53.3 \pm 5.3$ & $1070 . \pm 5.8$ & 0.5 & 1124. & 7.9 & 11. & 14. \\
\hline 30 & $37.4 \pm 3.7$ & $989.0 \pm 4.9$ & $1.9 \pm 0.1$ & 1028. & 6.1 & 10. & 12. \\
\hline 40 & $21.3 \pm 2.1$ & $866.6 \pm 3.9$ & $9.8 \pm 0.3$ & 897.7 & 4.4 & 8.8 & 9.8 \\
\hline 50 & $13.7 \pm 1.4$ & $770.8 \pm 3.3$ & $25.0 \pm 0.7$ & 809.5 & 3.7 & 8.0 & 8.8 \\
\hline 52 & $12.7 \pm 1.3$ & $753.6 \pm 3.2$ & $28.8 \pm 0.9$ & 795.1 & 3.6 & 7.8 & 8.6 \\
\hline 60 & $9.6 \pm 1.0$ & $689.5 \pm 2.9$ & $45.4 \pm 1.4$ & 744.5 & 3.4 & 7.3 & 8.1 \\
\hline 70 & $7.0 \pm 0.7$ & $618.7 \pm 2.6$ & $68.3 \pm 2.3$ & 694.0 & 3.5 & 6.9 & 7.7 \\
\hline 80 & $5.4 \pm 0.5$ & $556.6 \pm 2.4$ & $91.4 \pm 3.3$ & 653.4 & 4.1 & 6.5 & 7.7 \\
\hline 90 & $4.3 \pm 0.4$ & $502.2 \pm 2.2$ & $113.5 \pm 4.3$ & 620.0 & 4.8 & 6.2 & 7.8 \\
\hline 100 & $3.5 \pm 0.4$ & $454.3 \pm 2.0$ & $133.6 \pm 5.3$ & 591.4 & 5.7 & 5.9 & 8.2 \\
\hline
\end{tabular}


TABLE 23 (continued)

${ }^{155} \mathrm{Gd}$

$\Delta \mathrm{E} \quad 0-3 \mathrm{keV} \quad 3-225 \mathrm{keV} \quad 225-700 \mathrm{keV} \quad$ Thermal Spectrum Data: see text this work from Ref.[16 ${ }^{1}$

\begin{tabular}{|c|c|c|c|c|c|c|c|}
\hline $\mathrm{kT}$ & 11 & 12 & $\mathrm{I}_{3}$ & $<\sigma$ & $>/ v_{I}$ & $(\mathrm{mba}$ & \\
\hline$(\mathrm{keV})$ & (mbarn) & (mbarn) & (mbarn) & & stat & sys $^{2}$ & tot \\
\hline 10 & $723.0 \pm 72$ & $4307 . \pm 41$. & 0.0 & 5030. & 83. & 43. & 93. \\
\hline 12 & $515.6 \pm 52$ & $3991 . \pm 33$. & 0.0 & 4507. & 62. & 40. & 74. \\
\hline 20 & $195.9 \pm 20$ & $3151 . \pm 18$ & 0.1 & 3347. & 27. & 32. & 42. \\
\hline 25 & $127.4 \pm 13$ & $2815 . \pm 14$. & 0.9 & 2943. & 19. & 28. & 34. \\
\hline 30 & $89.4 \pm 8.9$ & $2555 . \pm 12$ & $3.4 \pm 0.1$ & 2648. & 15. & 26. & 30. \\
\hline 40 & $51.0 \pm 5.1$ & $2165 . \pm 9.0$ & $17.0 \pm$ & 2233. & 10. & 22. & 24. \\
\hline 50 & $32.9 \pm 3.3$ & $1873 . \pm 7.6$ & $42.1 \pm 1$ & 1948. & 8.4 & 19. & 21. \\
\hline 52 & $30.4 \pm 3.0$ & $1823 . \pm 7.3$ & $48.2 \pm 1.4$ & 1902. & 8.0 & 19. & 21. \\
\hline 60 & $23.0 \pm 2.3$ & $1640 . \pm 6.6$ & $74.6 \pm 2$ & 1738. & 7.4 & 17. & 19. \\
\hline 70 & $16.9 \pm 1.7$ & 144 & $4=$ & 1574. & 7.1 & 16. & 18. \\
\hline 80 & $13.0 \pm 1.3$ & $1285 . \pm 5.3$ & $13.1 \pm 4.8$ & 1441. & 7.3 & 14. & 16. \\
\hline 90 & $10.3 \pm 1.0$ & $1148 . \pm 4.8$ & $173.5 \pm 6.0$ & 1332. & 7.7 & 13. & 15. \\
\hline 100 & $8.4 \pm 0.8$ & $1030 . \pm 4.4$ & $199.9 \pm 7.2$ & 1238. & 8.5 & 12. & 15. \\
\hline
\end{tabular}

${ }^{156} \mathrm{Gd}$

$\triangle \mathrm{E} \quad 0-3 \mathrm{keV} \quad 3-225 \mathrm{keV} \quad 225-700 \mathrm{keV} \quad$ Thermal Spectrum Data: see text this work from Ref.[16 $]^{1}$

\begin{tabular}{cccccccc}
\hline $\mathrm{kT}$ & $\mathrm{I}_{1}$ & $\mathrm{I}_{2}$ & $\mathrm{I}_{3}$ & \multicolumn{3}{c}{$\langle\sigma \mathrm{v}\rangle / \mathrm{v}_{T}$} & $(\mathrm{mbarn})$ \\
$(\mathrm{keV})$ & $(\mathrm{mbarn})$ & $(\mathrm{mbarn})$ & $(\mathrm{mbarn})$ & & stat $^{2}$ & sys $^{2}$ & tot \\
\hline 10 & $173.6 \pm 17$. & $943.5 \pm 9.4$ & 0.0 & 1117. & 19. & 5.7 & 20. \\
12 & $123.6 \pm 12$. & $880.3 \pm 7.5$ & 0.0 & 1004. & 14. & 5.3 & 15. \\
20 & $46.9 \pm 4.7$ & $713.5 \pm 4.2$ & 0.0 & 760.4 & 6.3 & 4.3 & 7.6 \\
25 & $30.5 \pm 3.1$ & $646.0 \pm 3.4$ & 0.3 & 676.8 & 4.6 & 3.9 & 6.0 \\
30 & $21.4 \pm 2.1$ & $592.8 \pm 2.9$ & 1.0 & 615.2 & 3.6 & 3.6 & 5.1 \\
40 & $12.2 \pm 1.2$ & $510.7 \pm 2.3$ & $5.1 \pm 0.1$ & 528.0 & 2.6 & 3.1 & 4.0 \\
50 & $7.8 \pm 0.8$ & $447.1 \pm 2.0$ & $13.1 \pm 0.4$ & 468.0 & 2.2 & 2.8 & 3.6 \\
52 & $7.3 \pm 0.7$ & $435.8 \pm 1.9$ & $15.1 \pm 0.5$ & 458.2 & 2.1 & 2.7 & 3.4 \\
60 & $5.5 \pm 0.6$ & $394.7 \pm 1.7$ & $23.9 \pm 0.8$ & 424.1 & 2.0 & 2.5 & 3.2 \\
70 & $4.0 \pm 0.4$ & $350.3 \pm 1.6$ & $36.0 \pm 1.2$ & 390.3 & 2.0 & 2.3 & 3.0 \\
80 & $3.1 \pm 0.3$ & $312.5 \pm 1.4$ & $48.3 \pm 1.7$ & 363.9 & 2.2 & 2.2 & 3.1 \\
90 & $2.5 \pm 0.3$ & $279.9 \pm 1.3$ & $60.1 \pm 2.3$ & 342.5 & 2.7 & 2.0 & 3.4 \\
100 & $2.0 \pm 0.2$ & $251.8 \pm 1.2$ & $70.7 \pm 2.8$ & 324.5 & 3.1 & 1.9 & 3.6 \\
\hline & & & & & & &
\end{tabular}


TABLE 23 (continued)

\begin{tabular}{|c|c|c|c|c|c|c|c|}
\hline \multicolumn{8}{|c|}{${ }^{157} \mathrm{Gd}$} \\
\hline $\begin{array}{c}\Delta \mathrm{E} \\
\text { Data: }\end{array}$ & $\begin{array}{c}0-3 \mathrm{keV} \\
\text { see text }\end{array}$ & $\begin{array}{c}3-225 \mathrm{keV} \\
\text { this work }\end{array}$ & $\begin{array}{l}225-700 \mathrm{keV} \\
\text { from Ref.[16] }\end{array}$ & \multicolumn{4}{|c|}{ Thermal Spectrum } \\
\hline $\mathrm{kT}$ & $\mathrm{I}_{1}$ & $\mathrm{I}_{2}$ & $\mathrm{I}_{3}$ & \multicolumn{4}{|c|}{$\langle\sigma \mathrm{v}\rangle / \mathrm{v}_{T}(\mathrm{mbarn})$} \\
\hline$(\mathrm{keV})$ & (mbarn) & (mbarn) & (mbarn) & & stat & sys $^{2}$ & tot \\
\hline 10 & $467.7 \pm 47$ & $2335 . \pm 22$ & 0.0 & 2803. & 52. & 21. & 56. \\
\hline 12 & $333.0 \pm 33$ & $2154 . \pm 18$ & 0.0 & 2487. & 38. & 19. & 42. \\
\hline 20 & $126.1 \pm 13$ & $1665 . \pm 9.5$ & 0.0 & 1791. & 16. & 15. & 22. \\
\hline 25 & $81.9 \pm 8.2$ & $1465 . \pm 7.5$ & 0.4 & 1547. & 11. & 13. & 17. \\
\hline 30 & $57.5 \pm 5.8$ & $1310 . \pm 6.2$ & 1.5 & 1369. & 8.5 & 12. & 15. \\
\hline 40 & $32.8 \pm 3.3$ & $1083 . \pm 4.7$ & $7.4 \pm 0.2$ & 1123. & 5.7 & 9.8 & 11. \\
\hline 50 & $21.1 \pm 2.1$ & $919.2 \pm 3.9$ & $18.5 \pm 0.5$ & 958.8 & 4.5 & 8.4 & 9.5 \\
\hline 52 & $19.5 \pm 2.0$ & $891.5 \pm 3.8$ & $21.3 \pm 0.6$ & 932.3 & 4.3 & 8.2 & 9.3 \\
\hline 60 & $14.8 \pm 1.5$ & $793.1 \pm 3.3$ & $33.2 \pm 1.0$ & 841.1 & 3.8 & 7.4 & 8.3 \\
\hline 70 & $10.9 \pm 1.1$ & $692.0 \pm 2.9$ & $49.4 \pm 1.6$ & 752.3 & 3.5 & 6.7 & 7.6 \\
\hline 80 & $8.4 \pm 0.8$ & $609.0 \pm 2.6$ & $65.3 \pm 2.3$ & 682.7 & 3.6 & 6.1 & 7.1 \\
\hline 90 & $6.6 \pm 0.7$ & $539.8 \pm 2.4$ & $80.2 \pm 2.9$ & 626.6 & 3.8 & 5.6 & 6.8 \\
\hline 100 & $5.4 \pm 0.5$ & $481.6 \pm 2.1$ & $93.3 \pm 3.5$ & 580.3 & 4.1 & 5.2 & 6.6 \\
\hline \multicolumn{8}{|c|}{${ }^{158} \mathrm{Gd}$} \\
\hline$\Delta \mathrm{E}$ & $0-3 \mathrm{keV}$ & $3-225 \mathrm{keV}$ & $225-700 \mathrm{keV}$ & \multirow{2}{*}{\multicolumn{4}{|c|}{ Thermal Spectrum }} \\
\hline Data: & see text & this work & from Ref.[16] ${ }^{1}$ & & & & \\
\hline $\mathrm{kT}$ & $\mathrm{I}_{1}$ & $\mathrm{I}_{2}$ & $\mathrm{I}_{3}$ & \multicolumn{4}{|c|}{$\langle\sigma \mathrm{v}\rangle / \mathrm{v}_{T}(\mathrm{mbarn})$} \\
\hline$(\mathrm{keV})$ & (mbarn) & (mbarn) & (mbarn) & & stat & sys $^{2}$ & tot \\
\hline 10 & $90.0 \pm 9.0$ & $505.4 \pm 5.9$ & 0.0 & $5 \overline{95.4}$ & 11. & 3.0 & 11. \\
\hline 12 & $64.2 \pm 6.4$ & $474.0 \pm 4.7$ & 0.0 & 538.2 & 7.9 & 2.8 & 8.4 \\
\hline 20 & $24.3 \pm 2.4$ & $383.3 \pm 2.6$ & 0.0 & 407.6 & 3.5 & 2.3 & 4.2 \\
\hline 25 & $15.8 \pm 1.6$ & $343.9 \pm 2.1$ & 0.1 & 359.8 & 2.6 & 2.1 & 3.3 \\
\hline 30 & $11.1 \pm 1.1$ & $312.1 \pm 1.7$ & 0.4 & 323.6 & 2.0 & 1.9 & 2.8 \\
\hline 40 & $6.4 \pm 0.6$ & $262.9 \pm 1.3$ & $2.2 \pm 0.1$ & 271.5 & 1.4 & 1.6 & 2.1 \\
\hline 50 & $4.1 \pm 0.4$ & $225.8 \pm 1.1$ & $5.6 \pm 0.2$ & 235.5 & 1.2 & 1.4 & 1.8 \\
\hline 52 & $3.8 \pm 0.4$ & $219.4 \pm 1.1$ & $6.5 \pm 0.2$ & 229.7 & 1.2 & 1.4 & 1.8 \\
\hline 60 & $2.8 \pm 0.3$ & $6.3 \pm 1.0$ & $10.2 \pm 0.3$ & 209.3 & 1.1 & 1.2 & 1.6 \\
\hline 70 & $2.1 \pm 0.2$ & $172.1 \pm 0.9$ & $15.3 \pm 0.5$ & 189.5 & 1.0 & 1.1 & 1.5 \\
\hline 80 & $1.6 \pm 0.2$ & $152.1 \pm 0.8$ & $20.5 \pm 0.7$ & 174.2 & 1.1 & 1.0 & 1.5 \\
\hline 90 & $1.2 \pm 0.1$ & $135.2 \pm 0.7$ & $25.4 \pm 1.0$ & 161.8 & 1.2 & 1.0 & 1.6 \\
\hline 100 & $1.0 \pm 0.1$ & $120.8 \pm 0.6$ & $29.8 \pm 1.2$ & 151.6 & 1.3 & 0.9 & 1.6 \\
\hline
\end{tabular}

${ }^{1}$ normalized to present data

${ }^{2}$ The $1.5 \%$ uncertainty of the gold standard is not included here, since it cancels out in most applications of relevance for nuclear astrophysics 
The contributions $I_{1}$ from the energy range from 0 to $3 \mathrm{keV}$ were determined in three different ways. First, the cross section shapes from statistical model calculations were fitted to the present results and at lower energies to the data that were calculated from resonance parameters[24, 30]. In a second calculation, the cross sections of the Joint Evaluated File [16] were normalized to the present data between 3 to $10 \mathrm{keV}$. The respective normalization factors were less than $\sim 20 \%$ except for ${ }^{152} \mathrm{Gd}$, where a factor of two was required. Finally, this procedure was repeated using the calculated cross section of Uhl (Fig. 12). The adopted values for the contributions $I_{1}$ are the averages of these three calculations. The quoted uncertainties of $10 \%$ correspond to the observed differences from the mean, and include the respective systematic uncertainties.

The energy interval from 225 to $700 \mathrm{keV}$ contributes very little to the Maxwellian average at typical s-process temperatures. There, the JEF data[16] were normalized to the present results between 100 to $200 \mathrm{keV}$. The uncertainties were calculated under the assumption that the uncertainties of the normalized cross sections increase from $2 \%$ at $225 \mathrm{keV}$ to $10 \%$ at $700 \mathrm{keV}$ neutron energy.

The systematic uncertainties of the Maxwellian averaged cross sections in Table 22 correspond to the uncertainties of the cross section ratios (Table 20) and consider the contributions of the summed intensities, $\mathrm{I}_{2}+\mathrm{I}_{3}$. The $1.5 \%$ uncertainty of the gold standard was not included since it cancels out in most applications of relevance for s-process studies (Sec.7). The total uncertainties in the last column are dominated by the systematic uncertainties, except for ${ }^{156} \mathrm{Gd}$ and ${ }^{158} \mathrm{Gd}$. At low values of the thermal energy, the statistical uncertainties dominate for all isotopes.

The present results at $\mathrm{kT}=30 \mathrm{keV}$ are eventually compared in Table 24 with previous experiments and with the compilations of Bao and Käppeler[18] and Beer, Voss, and Winters[29]. While the individual results are in fair agreement within the quoted uncertainties for ${ }^{152} \mathrm{Gd},{ }^{155} \mathrm{Gd},{ }^{156} \mathrm{Gd}$, and ${ }^{157} \mathrm{Gd}$, significant differences are found for ${ }^{154} \mathrm{Gd}$ and ${ }^{158} \mathrm{Gd}$. In all cases, the uncertainties have been reduced significantly by the present experimental technique. 
Table 24: MAXWELLIAN AVERAGED CROSS SECTIONS AT kT=30 keV COMPARED TO PREVIOUS EXPERIMENTS AND EVALUATIONS

\begin{tabular}{|c|c|c|c|c|}
\hline \multirow[t]{2}{*}{ Isotope } & \multicolumn{2}{|c|}{ Experiment } & \multicolumn{2}{|c|}{ Evaluation } \\
\hline & $\begin{array}{c}\text { Cross section } \\
(\mathrm{mb})\end{array}$ & Reference & $\begin{array}{c}\text { Bao and Käppeler } \\
{[18]}\end{array}$ & $\begin{array}{c}\text { Beer, Voss, Winters } \\
{[29]}\end{array}$ \\
\hline${ }^{152} \mathrm{Gd}$ & $\begin{array}{c}1049 \pm 17 \\
1003 \pm 30 \\
997 \pm 62\end{array}$ & $\begin{array}{c}\text { present work }^{1} \\
\text { Beer and Macklin [6] } \\
\text { Beer et al. }[31]\end{array}$ & $985 \pm 61$ & $1045 \pm 65$ \\
\hline${ }^{154} \mathrm{Gd}$ & $\begin{array}{l}1028 \pm 12 \\
878 \pm 27 \\
1184 \pm 94\end{array}$ & $\begin{array}{c}\text { present work }{ }^{1} \\
\text { Beer and Macklin [6] } \\
\text { Shorin et al. }[28]\end{array}$ & $1278 \pm 102$ & $878 \pm 27$ \\
\hline${ }^{155} \mathrm{Gd}$ & $\begin{array}{c}2648 \pm 30 \\
2990 \pm 150 \\
2721 \pm 90 \\
2595 \pm 260\end{array}$ & $\begin{array}{c}\text { present work }^{1} \\
\text { Nakajima et al. }[32] \\
\text { Beer and Macklin [6] } \\
\text { Shorin et al. }[28]\end{array}$ & $2800 \pm 280$ & $2721 \pm 90$ \\
\hline${ }^{156} \mathrm{Gd}$ & $\begin{array}{c}615.2 \pm 5.1 \\
592 \pm 59\end{array}$ & $\begin{array}{l}\text { present work }^{1} \\
\text { Kononov et al. }\end{array}$ & $639 \pm 64$ & $639 \pm 64$ \\
\hline${ }^{157} \mathrm{Gd}$ & $\begin{array}{c}1369 \pm 15 \\
1366 \pm 70 \\
1355 \pm 39 \\
1425 \pm 142\end{array}$ & $\begin{array}{c}\text { present work }^{1} \\
\text { Nakajima et al. }[32] \\
\text { Beer and Macklin [6] } \\
\text { Shorin } \text { et al. }[28]\end{array}$ & $1538 \pm 154$ & $1355 \pm 39$ \\
\hline${ }^{158} \mathrm{Gd}$ & $\begin{array}{c}323.6 \pm 2.8 \\
304 \pm 20 \\
211 \pm 19 \\
392 \pm 39 \\
477 \pm 292 \\
523 \pm 60\end{array}$ & $\begin{array}{l}\text { present work }{ }^{1} \\
\text { Bokhovko et al. }[34] \\
\text { Beer et al. }[31] \\
\text { Kononov et al. }[33] \\
\text { Thirumala et al. }[35] \\
\text { Stupegia et al. }[36]\end{array}$ & $208 \pm 19$ & $221 \pm 20$ \\
\hline
\end{tabular}

${ }^{1}$ The $1.5 \%$ uncertainty of the gold cross section is not included here, since it cancels out in most applications of relevance for nuclear astrophysics. 


\section{ASTROPHYSICAL IMPLICATIONS}

\subsection{The s-Process Branchings between ${ }^{150} \mathrm{Sm}$ and ${ }^{156} \mathrm{Gd}$}

The s-process reaction flow in the Sm-Eu-Gd region exhibits a number of branching points as indicated in Figure 1. The strength of these branchings is defined by the abundances of the s-only isotopes ${ }^{152} \mathrm{Gd}$ and ${ }^{154} \mathrm{Gd}$, which are shielded against the $\beta$ decay chains from the $\mathrm{r}$-process region by their samarium isobars.

Since the rare earth elements are chemically nearly identical, their abundance ratios are known to $\pm 1.3 \%$ on average [5]. Hence, the following analyses can be normalized via the unbranched s-only isotope ${ }^{150} \mathrm{Sm}$. This allows to treat the branchings to ${ }^{152} \mathrm{Gd}$ and ${ }^{154} \mathrm{Gd}$ independent of each other. Compared to the previous analysis of Beer and Macklin [6], which concentrated on the ${ }^{152} \mathrm{Gd} /{ }^{154} \mathrm{Gd}$ ratio, this offers the advantage of a reduced sensitivity with respect to $\mathrm{p}$-process corrections and to a possible enhancement of the stellar neutron capture rate of ${ }^{154} \mathrm{Gd}$ (see below).

The resulting s-abundances of ${ }^{152} \mathrm{Gd}$ and ${ }^{154} \mathrm{Gd}$ are mainly determined by the branching points ${ }^{151} \mathrm{Sm}$ and ${ }^{154} \mathrm{Eu}$. The branching at ${ }^{155} \mathrm{Eu}$ is required for determining the s-process abundance of ${ }^{155} \mathrm{Gd}$, an important test for the identification of pure s-process gadolinium that may be discovered in meteoritic material. The additional branchings at ${ }^{152} \mathrm{Eu}$ and ${ }^{153} \mathrm{Gd}$ are too weak to produce a noticeable effect on the abundance pattern.

Since the decay rates of the main brach point nuclei exhibit a significant temperaturedependence, these branchings can be analyzed in terms of the s-process temperature. The determination of the branching factors

$$
f_{\beta}=\frac{\lambda_{\beta}}{\lambda_{\beta}+\lambda_{n}}
$$

requires the stellar rates for $\beta$-decay, $\lambda_{\beta}=\ln 2 / t_{1 / 2}$, and for neutron capture, $\lambda_{n}=\mathrm{n}_{n}$ $\mathrm{v}_{T}\langle\sigma\rangle$, where $\mathrm{n}_{n}$ denotes the neutron density during the s-process, $\mathrm{v}_{T}=(2 \mathrm{kT} / \mu)^{1 / 2}$ the mean thermal velocity, and $\langle\sigma\rangle$ the Maxwellian averaged cross section. Most of these data are related to the nuclear properties of the involved nuclei and are discussed in the following section. Only the neutron density has to be determined independently, either by analysis of complementary branchings, which are insensitive to temperature, or directly from a stellar model of the s-process site as described in the section on model calculations.

\subsection{Input data}

Cross sections: The most important data for defining the branchings of Figure 1 are the stellar cross sections of the s-only nuclei ${ }^{152} \mathrm{Gd},{ }^{154} \mathrm{Gd}$ determined in this work, and of 
${ }^{150} \mathrm{Sm}[2]$, which are now all known to $\pm 1 \%$. The total s-process flow is characterized by the $\langle\sigma\rangle \mathrm{N}_{s}$-value of the unbranched isotope ${ }^{150} \mathrm{Sm}$ (the product of stellar cross section times the s-process abundance), while the effect of the branchings can be expressed by the $\langle\sigma\rangle \mathrm{N}_{s}$ ratios of ${ }^{152} \mathrm{Gd}$ and ${ }^{154} \mathrm{Gd}$ relative to ${ }^{150} \mathrm{Sm}$.

The cross sections of the remaining stable isotopes, ${ }^{152} \mathrm{Sm},{ }^{151} \mathrm{Eu}$, and ${ }^{153} \mathrm{Eu}$ are adopted from Refs.[2, 37], but have relatively little impact for the branching analyses. In contrast, the cross sections for the main branch point isotopes are crucial for the reaction flow. For ${ }^{151} \mathrm{Sm}$, the calculated value of Ref.[38] could be adopted, which is based on a carefully evaluated local parameter systematics. Since this cross section is still affected by the $25 \%$ uncertainty inherent to the statistical model, an experimental determination (which appears feasible with existing techniques [39]) would be highly desirable.

For ${ }^{154} \mathrm{Eu}$ the situation is even worse. The available data are summarized in Figure 18, which illustrates the evaluation of the here adopted value. Experimental cross sections (solid squares) are known for the stable isotopes ${ }^{151} \mathrm{Eu}$ and ${ }^{153} \mathrm{Eu}$ [37] as well as for the unstable branch point ${ }^{155} \mathrm{Eu}$ [40]. Within their quoted uncertainties of $50 \%$, the existing statistical model calculations $[10,11]$ (open symbols) are in agreement with these values. If the cross section trend with mass number of the experimental values is adopted for the odd-odd isotopes as well, the shaded band describes a range of plausible values, which fits quite well with the average (open square) obtained by normalization of the calculated cross section sets to the experimental data. This value of $2900 \mathrm{mb}$ was adopted here despite of the existence of an integral cross section value of $4420 \pm 663 \mathrm{mb}$ measured in a fast reactor [41]. The preference for the smaller cross section based on the systematics of Figure 18 is supported by the comparably small cross section differences recently obtained for the similar case of the odd-even and odd-odd isotopes of promethium [38].

Another serious uncertainty refers to a possible stellar enhancement of the ${ }^{154} \mathrm{Gd}$ cross section due to the population of low-lying excited nuclear states in the thermal photon bath. If the population probabilities are high enough, such an enhancement may result from differences in the neutron capture cross sections of ground state and excited states. This effect has been considered in the calculations of Harris [10] and of Holmes et al. [11], leading to enhancement factors of $10 \%$ and $1 \%$ at $\mathrm{kT}=30 \mathrm{keV}$, respectively. In view of this discrepancy, no correction for this effect was made, but it should certainly be addressed in future studies.

Beta decay rates: The stellar beta decay rates were adopted from the tables of Takahashi and Yokoi [42]. These rates were evaluated for complete thermal equilibrium between the ground state and the excited nuclear states, an assumption that is satisfied for all unstable nuclei of interest here. It holds, in particular for ${ }^{152} \mathrm{Eu}$, where the stellar halflife is determined by the short-lived isomer rather than by the ground state. Apart from temperature effects, there is also a (weaker) influence of electron density on the relevant decay rates, except for ${ }^{153} \mathrm{Sm}$ and ${ }^{154} \mathrm{Eu}$. In all cases, where $\beta^{-}$decay competes with $\beta^{+}$ or EC decay, the $\beta^{-}$-channel is much faster.

Abundances: The s-process calculations presented in the following were normalized to the solar abundance of ${ }^{150} \mathrm{Sm}$. Though the solar abundances of $\mathrm{Sm}, \mathrm{Eu}$, and Gd are given with uncertainties of only $1.3 \%, 1.6 \%$, and $1.4 \%$ (Anders and Grevesse [5]), an additional uncertainty arises from possible p-process contributions to the abundances of the s-only isotopes. An empirical estimate based on the abundances of nearby p- 


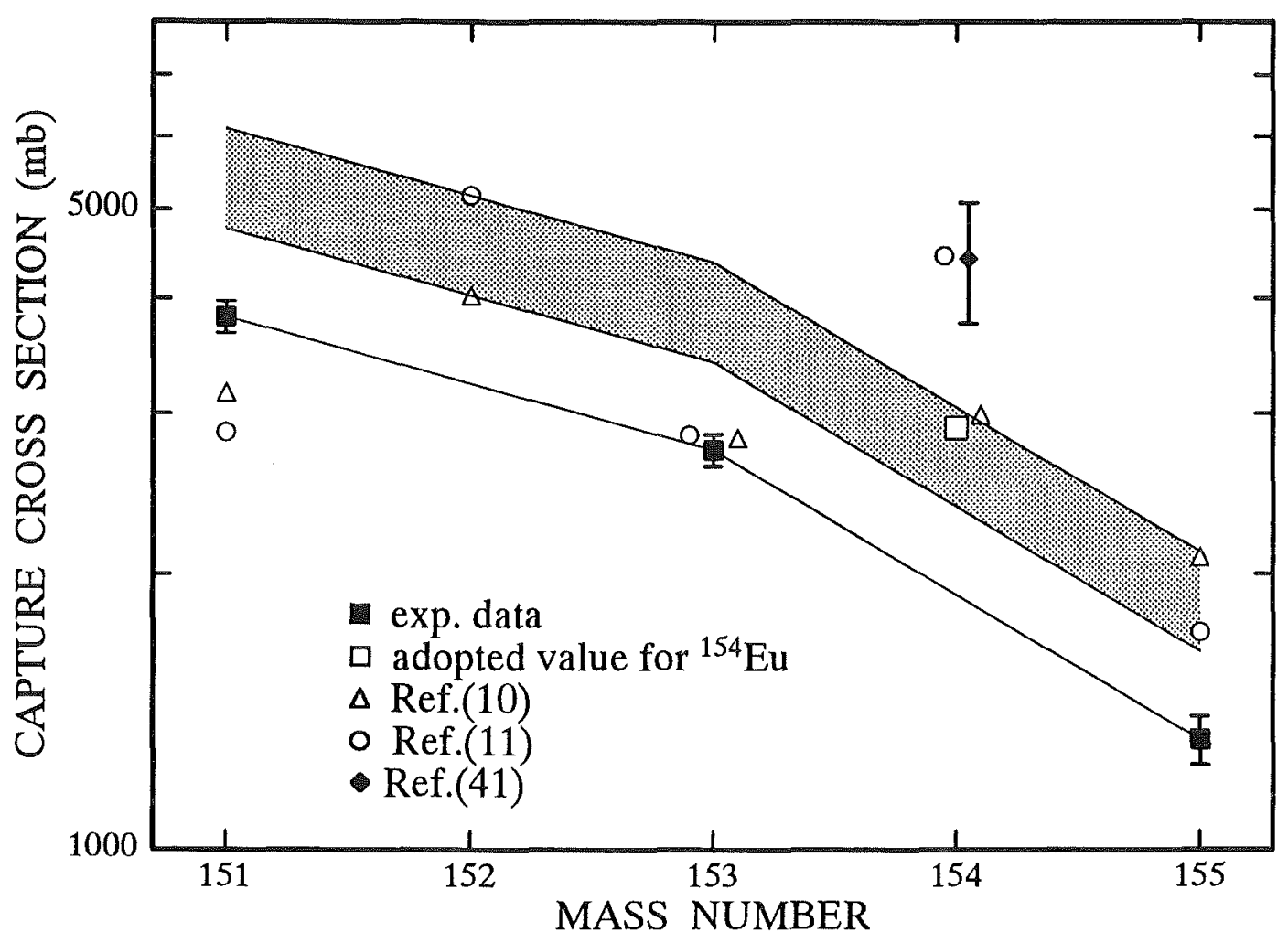

Figure 18: The stellar $(\mathrm{n}, \gamma)$ cross sections of the europium isotopes. Experimental and calculated values are indicated by solid and open squares, respectively. Based on this systematics, a value of $2900 \mathrm{mb}$ was adopted for ${ }^{154} \mathrm{Eu}$.

only isotopes suggests a large correction for ${ }^{152} \mathrm{Gd}$ of up to $50 \%$ [6]. However, improved calculations $[7,8,43]$ have reported $p$-process yields of less than $12 \%$ for this isotope. Another contribution to the ${ }^{152} \mathrm{Gd}$ abundance comes from the s-process in massive stars, which is estimated to account for about $6 \%$ of the solar value [9]. Fortunately, the pprocess yields for ${ }^{154} \mathrm{Gd}$ and ${ }^{150} \mathrm{Sm}$ are much smaller (below $1.5 \%$ and $0.2 \%$, respectively [44]) and, therefore, less critical.

\section{3 s-Process models}

Analyses of the s-process reaction flow in the Sm-Eu-Gd region were carried out by means of the classical approach as well as by a stellar model for helium shell burning in low mass stars. Only a brief sketch of these models is given here since a more detailed description can be found elsewhere [45].

The - purely phenomenological - classical approach has been formulated before stellar models for the helium burning stage were available $[46,47]$. Since then, it became a useful tool, not only for reproducing the s-abundances but also for characterizing the physical conditions during the s-process in an empirical way. Meanwhile, the two components of the classical approach could be assigned to stellar scenarios. The weak component, which is important in the mass range between $\mathrm{Fe}$ and $\mathrm{Zr}$, was attributed to helium core burning 
in massive stars [9], while the main component occurs during helium shell burning in low mass stars and accounts for the s-abundances in the mass range $A>100$. For the main component, irradiation of an iron seed by an exponential distribution of neutron exposures was assumed. With the further assumption of a constant neutron density and temperature, the $s$-process reaction flow is characterized in this approach by the iterative expression

$$
<\sigma>N_{s}(A)=\frac{G N_{\odot}^{56}}{\tau_{0}} \prod_{i=56}^{A}\left(1+\frac{1}{\sigma_{i} \tau_{0}}\right)^{-1} .
$$

The two free parameters, the fraction $\mathrm{G}$ of the observed ${ }^{56} \mathrm{Fe}$ abundance required as seed, and the mean neutron exposure $\tau_{0}$, are determined by fitting the empirical $\langle\sigma\rangle \mathrm{N}_{s}$ values of those $s$-only isotopes that experience the entire reaction flow. For the present analysis,

$$
\tau_{0}=(0.303 \pm 0.010)\left(\frac{k T[k e V]}{30}\right)^{1 / 2} \quad m b^{-1},
$$

has been adopted from Ref.[2], whereas $G$ was defined by normalization to the $\langle\sigma\rangle \mathrm{N}_{s}$ value of ${ }^{150} \mathrm{Sm}$.

Branchings in the s-process path have to be treated separately $[48,45]$ via the branching factors defined by Eq.(2). The adopted half-lives and Maxwellian averaged cross sections are discussed above, and the neutron density, $\mathrm{n}_{n}=(4.1 \pm 0.6) 10^{8} \mathrm{~cm}^{-3}$, was taken from Ref.[38].

The combined effect of the branchings in Figure 1 can be deduced from the $\langle\sigma\rangle \mathrm{N}_{s}$ ratios of the partially bypassed s-only isotopes ${ }^{152} \mathrm{Gd}$ and ${ }^{154} \mathrm{Gd}$ relative to ${ }^{150} \mathrm{Sm}$, which is exposed to the entire s-process flow. Since the neutron density is defined by the branchings in the neodymium/promethium region, reproduction of the ${ }^{152} \mathrm{Gd}$ and ${ }^{154} \mathrm{Gd}$ abundances requires the proper choice of the effective stellar temperature via the temperaturedependent $\beta$-decay rates of the branch point isotopes, mainly of ${ }^{151} \mathrm{Sm}$ and ${ }^{154} \mathrm{Eu}$.

The only stellar model for describing the s-process in the mass range $A>100$ in a satisfactory way has been suggested by Iben and Renzini $[49,50]$ for helium shell burning in low mass stars (LMS). This model was shown to reproduce successfully the s-process abundances by the operation of two neutron sources during a series of subsequent helium shell flashes $[51,52,45]$. First, the ${ }^{13} \mathrm{C}(\alpha, \mathrm{n}){ }^{16} \mathrm{O}$ reaction occurrs by ingestion of a ${ }^{13} \mathrm{C}$ pocket into the convective helium burning zone, giving rise to more than $90 \%$ of the neutron exposure, followed by a second burst of neutrons from the ${ }^{22} \mathrm{Ne}(\alpha, \mathrm{n})^{25} \mathrm{Mg}$ reaction. Both neutron sources work at different temperatures and neutron densities. The ${ }^{13} \mathrm{C}$ source lasts for typically $20 \mathrm{yr}$ at a thermal energy of $12 \mathrm{keV}$ producing neutron densities of a few times $10^{8} \mathrm{~cm}^{-3}$. After an interpulse period of $\sim 20 \mathrm{yr}$, the ${ }^{22} \mathrm{Ne}$ source burns for about $3 \mathrm{yr}$ when thermal energies around $26 \mathrm{keV}$ are reached at the end of the helium burning episode. Then follows a period of hydrogen shell burning, which takes some $10^{5}$ yr to replenish the consumed helium for the next shell flash to start. These shell flashes may occur up to 20 times.

The pulsed nature of this model implies additional parameters compared to the classical case: the gradients in neutron density and temperature for each burst as well as the respective time scales. It is important to note that pulse durations and interpulse periods 
Table 25: ${ }^{152} \mathrm{Gd}$ AND ${ }^{154} \mathrm{Gd}$ ABUNDANCES FROM CLASSICAL APPROACH

\begin{tabular}{|c|c|c|c|}
\hline Run & $N_{s}\left({ }^{152} \mathrm{Gd}\right)^{a)}$ & $N_{s}\left({ }^{154} \mathrm{Gd}\right)^{b)}$ & Comment \\
\hline $\left.\mathrm{n} 35 \mathrm{t} 29 \mathrm{e} 20^{c}\right)$ & $0.463(70 \%)$ & $6.782(94 \%)$ & $(+)$ \\
\hline $\mathrm{n} 47 \mathrm{t} 29 \mathrm{e} 20$ & $0.347(53 \%)$ & $6.522(91 \%)$ & - \\
\hline $\mathrm{n} 35 \mathrm{t} 32 \mathrm{e} 20$ & $0.598(91 \%)$ & $6.935(97 \%)$ & $(-)$ \\
\hline $\mathrm{n} 47 \mathrm{t} 32 \mathrm{e} 20$ & $0.456(69 \%)$ & $6.700(93 \%)$ & $(-)$ \\
\hline n 35 t $29 \mathrm{e} 29$ & $0.435(66 \%)$ & $6.753(94 \%)$ & + \\
\hline $\mathrm{n} 47 \mathrm{t} 32 \mathrm{e} 29$ & $0.436(66 \%)$ & $6.705(93 \%)$ & + \\
\hline & $\begin{array}{l}<12 \% \\
\sim 6 \%\end{array}$ & $<2 \%$ & $\begin{array}{c}\text { p-Process } \\
\text { Massive stars }\end{array}$ \\
\hline
\end{tabular}

a) all abundances times 1000;

b) including the decay of ${ }^{154} \mathrm{Eu}$;

c) $\left(\mathrm{n}_{n}=3.510^{8} \mathrm{~cm}^{-3}, \mathrm{kT}=29 \mathrm{keV}, \mathrm{n}_{e}=2.010^{27} \mathrm{~cm}^{-3}\right)$.

have negligible influence on the abundances of the branchings discussed here because the neutron capture cross sections in this mass region are large enough that typical neutron capture times are significantly shorter than the duration of the neutron exposures. Hence, there is ample time to readjust the abundance pattern in the ${ }^{22} \mathrm{Ne}$ phase, regardless of the situation after the ${ }^{13} \mathrm{C}$ phase. Therefore, the temperature measured by the $A=151-154$ branchings corresponds to that at the end of the He shell flash when the ${ }^{22} \mathrm{Ne}$ source is activated.

Accordingly, the branchings to ${ }^{152} \mathrm{Gd}$ and ${ }^{154} \mathrm{Gd}$ are not sensitive to a recent modification of the LMS model by Straniero et al. [53], who discovered a considerable modification with respect to the ${ }^{13} \mathrm{C}$ source. Instead of waiting in the radiative envelope until being engulfed by the convective He burning shell, the ${ }^{13} \mathrm{C}$ synthesized at the $\mathrm{H} / \mathrm{He}$ interface during the interpulse period is completely burnt in the radiative environment. Since this occurs at a lower temperature corresponding to $\mathrm{kT}=8 \mathrm{keV}$, the related neutron densities are restricted to a few $10^{7} \mathrm{~cm}^{-3}$. This difference to the first LMS model has practically no consequences for the final abundances, which are dominated by the characteristics of the ${ }^{22} \mathrm{Ne}$ phase.

\subsection{Results and Discussion}

The results obtained with the classical approach are indicated in Table 25 for different choices of thermal energy and electron density. The last two lines in Table 25 refer to the abundance contributions from alternative production sites, which provide a non-neglible 
fraction of ${ }^{152} \mathrm{Gd}$. Though not very efficient in the mass range $A>100$, the s-process in massive stars was shown to account for about $6 \%$ of the rare ${ }^{152} \mathrm{Gd}[9]$. This value corresponds to the final ${ }^{152} \mathrm{Gd}$ abundance including the carbon burning phase, which causes a depletion of the ${ }^{152} \mathrm{Gd}$ synthezised earlier during the helium burning phase ( $\sim 40 \%$ for a $25 \mathrm{M}_{\odot}$ star). The quoted p-process abundances are from model calculations for $\mathrm{Ne} / \mathrm{O}$ burning in supernovae of type II $[44,43]$. These calculations start from an initial s-process abundance distribution due to helium core burning in the (massive) SNII precursor, but without considering any modification during the intermediate carbon burning phase. Therefore, the $\mathrm{p}$-process contribution to ${ }^{152} \mathrm{Gd}$ of $12 \%$ should rather be taken as an upper limit. In total, only about $80 \%$ of the solar ${ }^{152} \mathrm{Gd}$ but practically all of the ${ }^{154} \mathrm{Gd}$ should be accounted for by the main s-process component.

The upper part of Table 25 shows the s-abundances obtained with the classical approach. First, the results obtained with the previous best estimates for neutron density $\left(\mathrm{n}_{n}=(4.1 \pm 0.6) 10^{8} \mathrm{~cm}^{-3}[38]\right)$, thermal energy $(\mathrm{kT}=29 \mathrm{keV}[45])$, electron density $\left(\mathrm{n}_{e}=2.0\right.$ $10^{27} \mathrm{~cm}^{-3}[54]$ ) are presented (lines 1 and 2). Obviously, an acceptable solution exists only for the lower limit of the neutron density range. Increasing the temperature (lines 3 and 4) seems to improve the agreement with the solar abundances. However, these parameters are in conflict with the nearby branching at $A=163$, where they cause an overproduction of ${ }^{164} \mathrm{Er}$ [55]. This problem can only be removed if the electron density is raised by $50 \%$ as well (lines 5 and 6 ).

The results of Table 25 can be summarized in four points:

(i) With the present cross section data, the acceptable range of thermal energies could be reduced to $28<\mathrm{kT}<33 \mathrm{keV}$, which represents a significant improvement compared to the previously reported interval of $29 \pm 5 \mathrm{keV}$ [45].

(ii) The electron density has little influence on the branchings to ${ }^{152} \mathrm{Gd}$ and ${ }^{154} \mathrm{Gd}$ (line 1 and 5), but it is important for the branching to ${ }^{164} \mathrm{Er}$.

(iii) The acceptable solutions suggest that only $70 \%$ of ${ }^{152} \mathrm{Gd}$ are produced by the main s-process component. The remaining $30 \%$ must be ascribed to other processes, but are not completely accounted for by the weak s-process component from massive stars [9] and by the p-process in supernovae of type II [43].

(iv) Practically all solutions indicate that only $94 \%$ of ${ }^{154} \mathrm{Gd}$ could be produced by the main s-process component. The most plausible explanation for this deficiency would be the stellar enhancement of the $(n, \gamma)$ rate calculated by Harris [10], who reports a $10 \%$ larger cross section at a thermal energy of $\mathrm{kT}=30 \mathrm{keV}$ due to captures in excited states. However, this enhancement factor requires verification since Holmes et al. [11] found an almost negligible effect.

The gadolinium abundances obtained with both s-process models and the resulting $r$-process residuals are summarized in Table 26.

The s-abundances resulting from the LMS model were calculated with the network code NETZ [56] using the profiles for neutron density, temperature, and electron density from the work of Gallino et al. [57]. Contrary to most other branchings, there are significant differences in the gadolinium yields compared to the classical approach. The abundance evolution during a helium shell flash is plotted in Figure 19 for the investigated s-only nuclei together with the neutron density profiles from the ${ }^{13} \mathrm{C}$ and the ${ }^{22} \mathrm{Ne}$ sources.

The unbranched isotope ${ }^{150} \mathrm{Sm}$ shows a very smooth abundance build-up during the 

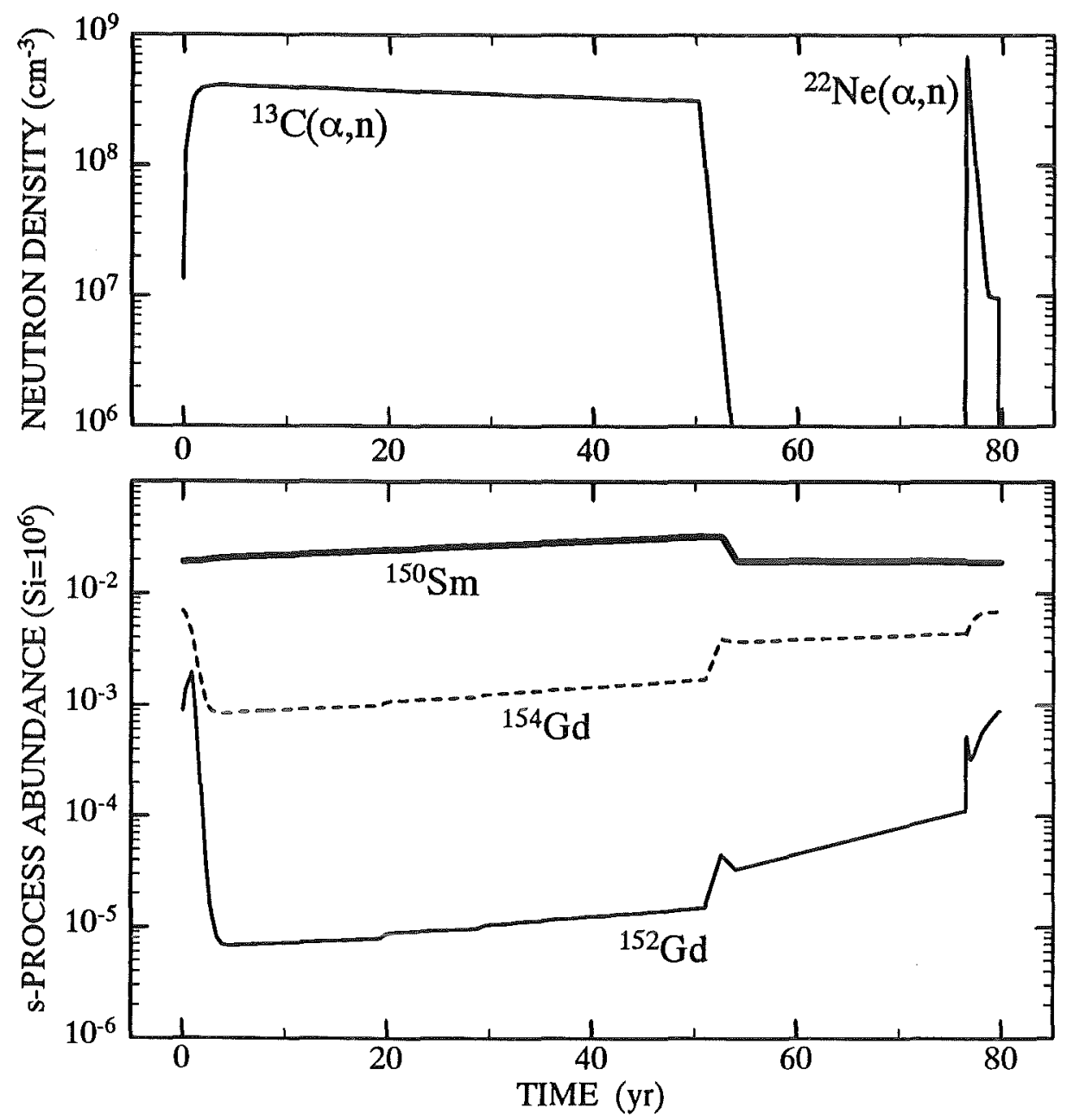

Figure 19: The abundance evolution of the s-only isotopes during a helium shell flash. The neutron density profiles are shown in the inset.

${ }^{13} \mathrm{C}$ phase, which is decreasing due to the later mixing with unprocessed material when the convective helium shell is progressing beyond the ${ }^{13} \mathrm{C}$ pocket. The different pattern obtained for the two $\mathrm{Gd}$ isotopes results from the temperature-dependence of the preceding branch points. The smaller $\beta$-decay rates at the lower temperature during the ${ }^{13} \mathrm{C}$ phase are favoring the neutron capture part of the branchings, so that more of the reaction flow is bypassing ${ }^{152} \mathrm{Gd}$ and ${ }^{154} \mathrm{Gd}$. This depletion during the ${ }^{13} \mathrm{C}$ phase is followed by an increase due to mixing with unprocessed material as the shell flash progresses beyond the ${ }^{13} \mathrm{C}$ pocket. In between the ${ }^{13} \mathrm{C}$ phase, and the ${ }^{22} \mathrm{Ne}$ phase, the ${ }^{152} \mathrm{Gd}$ abundance increases further due to the decay of ${ }^{152} \mathrm{Eu}$.

The second exposure by the ${ }^{22} \mathrm{Ne}$ reaction at the end of the helium shell flash has a different effect on the two Gd isotopes. The ${ }^{154} \mathrm{Gd}$ abundance shows a smooth increase and stabilizes at $96 \%$ of the solar abundance. Since the temperature during neutron freezeout is already lower than during the maximum, the stellar cross section enhancement is less important in this model. The most severe problem for the stellar model is, however, 
Table 26: s-ABUNDANCES AND r-PROCESS RESIDUALS OF THE GADOLINIUM ISOTOPES

\begin{tabular}{ccccc}
\hline \hline & & & & \\
Isotope & $\mathrm{N}_{\odot}^{a)}$ & \multicolumn{2}{c}{ Classical approach } & LMS model \\
\cline { 3 - 4 } & & $N_{s}^{b)}$ & $\mathrm{N}_{r}=\mathrm{N}_{\odot}-N_{s}$ & $N_{s}^{b)}$ \\
\hline${ }^{150} \mathrm{Sm}$ & $19.1 \pm 0.25$ & $19.10 \pm 0.25$ & - & 19.1 \\
${ }^{152} \mathrm{Sm}$ & $68.9 \pm 0.90$ & $15.94 \pm 0.35$ & $53.0 \pm 1.0$ & 15.6 \\
${ }^{154} \mathrm{Sm}$ & $58.6 \pm 0.76$ & - & $58.6 \pm 0.8$ & - \\
${ }^{153} \mathrm{Eu}$ & $50.8 \pm 0.81$ & $2.92 \pm 0.13$ & $47.9 \pm 0.8$ & 2.95 \\
${ }^{152} \mathrm{Gd}$ & $0.66 \pm 0.009$ & $0.44 \pm 0.05$ & - & 0.88 \\
${ }^{154} \mathrm{Gd}$ & $7.19 \pm 0.10$ & $6.73 \pm 0.55$ & - & 6.91 \\
${ }^{155} \mathrm{Gd}$ & $48.8 \pm 0.68$ & $3.30 \pm 0.30$ & $45.5 \pm 0.8$ & 2.93 \\
${ }^{156} \mathrm{Gd}$ & $67.6 \pm 0.95$ & $12.87 \pm 0.15$ & $54.7 \pm 1.0$ & 12.5 \\
${ }^{157} \mathrm{Gd}$ & $51.6 \pm 0.72$ & $5.77 \pm 0.06$ & $45.8 \pm 0.8$ & 5.46 \\
${ }^{158} \mathrm{Gd}$ & $82.0 \pm 1.15$ & $24.17 \pm 0.25$ & $57.8 \pm 1.2$ & 23.6 \\
\hline \hline
\end{tabular}

a) all abundances times 1000 ;

b) including the decay of isobars.

that ${ }^{152} \mathrm{Gd}$ is overproduced by $33 \%$. Instead of stabilizing at a certain value, the ${ }^{152} \mathrm{Gd}$ abundance exhibits an interesting behavior during the ${ }^{22} \mathrm{Ne}$ phase. In the beginning, it follows the neutron density profile almost instantaneously, since the ${ }^{151} \mathrm{Sm}$ branching is activated by the higher temperature. This close correlation confirms that the branching is not sensitive to pulses longer than a few months. However, freeze-out seems to be very important: Even after the ${ }^{151} \mathrm{Sm}$ branching was deactivated due to the decreasing temperature, the ${ }^{152} \mathrm{Gd}$ abundance continues to increase as a result of neutron captures on the remaining ${ }^{151} \mathrm{Eu}$. This further ${ }^{152} \mathrm{Gd}$ production during freeze-out is favored by the large ${ }^{151}$ Eu cross section.

That the final ${ }^{152} \mathrm{Gd}$ yield is indeed determined by freeze-out can be seen at the beginning of the ${ }^{13} \mathrm{C}$ exposure. At first, the ${ }^{152} \mathrm{Gd}$ abundance continues to increase until the ${ }^{151} \mathrm{Eu}$ reservoir of the preceding helium shell flash is exhausted. Only then, it drops to the level corresponding to the reduced ${ }^{151} \mathrm{Sm}$ branching probability at the lower temperature. This result means that the ${ }^{152} G d$ production can be used to probe the profiles for neutron density and temperature during helium shell burning.

The revised LMS model where the ${ }^{13} \mathrm{C}$ source burns under radiative conditions at $\mathrm{kT}=8 \mathrm{keV}$ shows essentially the same significant overproduction of ${ }^{152} \mathrm{Gd}$ ( $37 \%$ according to Refs. $[53,57])$. This is not surprising since the decisive neutron burst from the ${ }^{22} \mathrm{Ne}$ source is unchanged.

Table 26 shows that the two models differ also with respect to the s-abundance of ${ }^{155} \mathrm{Gd}$. In view of the much smaller cross section uncertainties, this $13 \%$ difference is 
sufficiently significant to provide an important test if s-only gadolinium can be isolated from meteoritic material.

\section{SUMMARY}

The Karlsruhe $4 \pi$ Barium Fluoride Detector has been improved by replacing the six crystals with the highest $\alpha$ background and by adding a pierced crystal in the zero degree position at the exit of the neutron beam. These changes allowed to reduce the electronic threshold to $1.5 \mathrm{MeV}$ in the $\gamma$-ray spectrum and to cover a solid angle of $96 \%$ of $4 \pi$. In this way, overall detection probabilities of $98 \%$ and $99 \%$ could be reached for neutron captures in for the even and odd Gd isotopes, respectively.

The total cross sections and the $(\mathrm{n}, \gamma)$ cross sections were measured for the stable isotopes ${ }^{152} \mathrm{Gd},{ }^{154} \mathrm{Gd},{ }^{155} \mathrm{Gd},{ }^{156} \mathrm{Gd},{ }^{157} \mathrm{Gd}$, and ${ }^{158} \mathrm{Gd}$. The total cross sections could be determined from 10 to $200 \mathrm{keV}$ with typical uncertainties from 5 to $25 \%$, depending on the required correction for isotopic impurities. The neutron capture cross sections were measured from 3 to $225 \mathrm{keV}$. In this case, corrections for the large isotopic impurities of the ${ }^{152} \mathrm{Gd}$ and ${ }^{154} \mathrm{Gd}$ samples could be made with much better accuracy due to the spectroscopic features of the $\mathrm{BaF}_{2}$ detector. Maxwellian averaged $(\mathrm{n}, \gamma)$ cross sections were derived for thermal energies from 10 to $100 \mathrm{keV}$. The astrophysically relevant cross section ratios could be determined with an overall uncertainty of typically $1 \%$, an improvement by factors of five to ten compared to existing data. Severe discrepancies were found with respect to previous results.

An updated analysis of the s-process reaction flow in the mass region $150<A<160$ was performed on the basis of the Gd cross sections presented here and with additional experimental information on the Eu isotopes. This mass region is important because of the temperature-dependent branchings at ${ }^{151} \mathrm{Sm},{ }^{154} \mathrm{Eu}$, and ${ }^{155} \mathrm{Eu}$. Two s-process models were applied, the classical approach and a stellar model for helium shell burning in low mass stars. The empirical feature of the classical approach could be used to constrain the effective s-process temperature to a range of thermal energies between $\mathrm{kT}=28 \mathrm{keV}$ and $33 \mathrm{keV}$ without overproducing the s-only isotopes. This analysis seemed also to support a stellar enhancement of the neutron capture rate of ${ }^{154} \mathrm{Gd}$.

The LMS model was found to suffer from a significant overproduction of ${ }^{152} \mathrm{Gd}$ by $33 \%$ which persists also after a revision of this scenario with respect to neutron density and temperature during the operation of the ${ }^{13} \mathrm{C}$ neutron source. This overproduction was shown to depend strongly on the neutron freeze-out at the end of the helium shell burning episodes, so that the ${ }^{152} \mathrm{Gd}$ abundance might be used to probe this effect.

Remaining problems for further $\mathrm{s}$-process discussions of the mass region between samarium and gadolinium are the improvement of the stellar cross sections for the branch points ${ }^{151} \mathrm{Sm}$ and ${ }^{154} \mathrm{Eu}$. Another important point is to study the possible stellar enhancement of the ${ }^{154} \mathrm{Gd}$ cross section. Such an investigation should include the unbranched s-only isotope ${ }^{160} \mathrm{Dy}$, where this effect can be tested by comparison of the empirical 
$\langle\sigma\rangle \mathrm{N}_{s}$ value with the overall systematics. The availability of accurate cross sections for the $\mathrm{Gd}$ isotopes would certainly justify a renewed search for isotopic anomalies in order to check the present analyses with pure s-process material.

\section{ACKNOWLEDGMENTS}

We would like to thank F.H. Fröhner and B. Krieg for providing us with the JEF data. The continuous support of the Van de Graaff crew, D. Roller, E.-P. Knaetsch and W. Seith, who ran the accelerator in a most efficient way, is gratefully acknowledged. The optimization of the experimental setup would have not been possible without the amazing skill of G. Rupp.

\section{References}

[1] K. Wisshak, F. Voss, F. Käppeler, and G. Reffo, Phys. Rev. C 45, 2470 (1992).

[2] K. Wisshak, K. Guber, F. Voss, F. Käppeler, and G. Reffo, Phys. Rev. C 48, 1401 (1993).

[3] F. Voss, K. Wisshak, K. Guber, F.Käppeler, and G. Reffo, Phys. Rev. C 50, 2582 (1994).

[4] K. Takahashi and K. Yokoi, Atomic Data Nucl. Data Tables 36, 375 (1987).

[5] E. Anders and N. Grevesse, Geochim. Cosmochim. Acta 53, 197 (1989).

[6] H. Beer and R.L. Macklin, Astrophys. J. 331, 1047 (1988).

[7] N. Prantzos, M. Hashimoto, M. Rayet, and M. Arnould, Astron. Astrophys. 238, 455 (1990).

[8] W. Howard, B. Meyer, and S. Woosley, Ap. J. 373, L5 (1991).

[9] C.M. Raiteri, R. Gallino, M. Busso, D. Neuberger, and F. Käppeler, Astrophys. J. 419, 207 (1993).

[10] M. J. Harris, Ap. Space Sci. 77, 357 (1981).

[11] J. A. Holmes, S. E. Woosley, W. A. Fowler, and B. A. Zimmerman, Atomic Data and Nucl. Data Tables 18, 305 (1976). 
[12] F. Corvi, A. Prevignano, H. Liskien, and P. B. Smith, Nucl. Instr. Meth. A 265, 475 (1988).

[13] K. Wisshak, K. Guber, F. Käppeler, J. Krisch, H. Müller, G. Rupp, and F. Voss, Nucl. Instr. Meth. A 292, 595 (1990).

[14] K. Wisshak, F. Voss, F. Käppeler, and G. Reffo, Phys. Rev. C 42, 1731 (1990).

[15] F. H. Fröhner, Technical report, Gulf General Atomic (unpublished).

[16] C. Nordborg, H. Gruppelaar, and M. Salvatores, in Nuclear Data for Science and Technology, edited by S. Qaim (Springer, Berlin, 1992), p. 782.

[17] V. McLane, C. L. Dunford, and P. F. Rose, in Neutron Cross Sections, Vol. 2 (Academic Press, New York, 1988).

[18] Z. Y. Bao and F. Käppeler, Atomic Data Nucl. Data Tables 36, 411 (1987).

[19] G. Reffo, F. Fabbri, K. Wisshak, and F. Käppeler, Nucl. Sci. Eng. 80, 630 (1982).

[20] M. Uhl and J. Kopecky, Nuclei in the Cosmos, Eds. F. Käppeler and K. Wisshak, IOP Publishing Bristol and Philadelphia (1993) p.259.

[21] S.K. Katarina, V.S. Ramamurthy, and S.S. Kapor, Phys. Rev. C 18, 549 (1978).

[22] F. Käppeler, K. Wisshak, and K. Guber, Proc. of a Specialists' Meeting on Measurement, Calculation and Evaluation of Photon Production Data, Bologna, Italy, November 9-11, 1994, p247.

[23] N. Weber, diplom thesis, University of Karlsruhe (1993).

[24] J. F. Mughabghab, M. Divadeenam, and N. E. Holden, in Neutron Cross Sections, Vol. 1, Part A (Academic Press, New York, 1981).

[25] A. Gilbert and A.G.W. Cameron, Can.J.Phys. 43,1446 (1965).

[26] R. L. Macklin, private communication (unpublished).

[27] W. Ratynski and F. Käppeler, Phys. Rev. C 37, 595 (1988).

[28] V.S. Shorin, V.N. Kononov, and E.D. Poletaev, Sov. J. Nucl. Phys. 19, 2 (1974).

[29] H. Beer, F. Voss, and R.R. Winters, Astrophys. J. Suppl. 80, 403 (1992).

[30] R.L. Macklin, Nucl. Sci. Eng. 95, 304 (1987).

[31] H. Beer, F. Käppeler, K. Yokoi, and K. Takahashi, Astrophys. J. 278,388 (1984).

[32] Y. Nakajima, I. Tsubone, M. Mizumoto, Y. Furuta, M. Ohkubo, M. Sugimoto, and Y. Kawarasaki, Ann. Nucl. Energy 16, 589 (1989). 
[33] V.N. Kononov, B.D. Yurlov, E.D. Poletaev, and V.M. Timokhov, Sov. J. Nucl. Phys. 27, 5 (1978).

[34] M.V. Bokhovko, A.A. Woewodskij, V.N. Kononov, E.D. Poletaev, and V.M. Timokhov, report FEI-2169, Fiziko Energetscheskij Institut, Obninsk 1991.

[35] B.V. Thirumala Rao, J. Rama Rao, and E. Kondaiah, J. Phys. A 5, 468 (1972).

[36] D.C. Stupegia, M. Schmidt, C.R. Keedy, and A.A. Madson, J. Nucl. Energy 22, 267 (1968).

[37] H. Stoll, Diplomarbeit, University of Karlsruhe, 1993.

[38] K. Toukan, K. Debus, F. Käppeler, and G. Reffo, Phys. Rev. C 51, (1995).

[39] F. Käppeler, in Radioactive Nuclear Beams, edited by T. Delbar (Adam Hilger, Bristol, 1992), p. 305.

[40] S. Jaag and F. Käppeler, Phys. Rev. C, in print.

[41] R. Anderl, F. Schmittroth, and Y. Harker, Technical report (unpublished).

[42] K. Takahashi and K. Yokoi, Atomic Data Nucl. Data Tables 36, 375 (1987).

[43] M. Rayet, M. Arnould, M. Hashimoto, N. Prantzos, and K. Nomoto, Astron. Astrophys. in print.

[44] M. Rayet, private communication (unpublished).

[45] F. Käppeler, R. Gallino, M. Busso, G. Picchio, and C. Raiteri, Astrophys. J. 354, 630 (1990).

[46] E. Burbidge, G. Burbidge, W. Fowler, and F. Hoyle, Rev. Mod. Phys. 29, 547 (1957).

[47] P. Seeger, W. Fowler, and D. Clayton, Astrophys. J. Suppl. 97, 121 (1965).

[48] R. Ward, M. Newman, and D. Clayton, Astron. Astrophys. 103, 189 (1981).

[49] I. Iben Jr, and A. Renzini, Astrophys. J. 259, L79 (1982).

[50] I. Iben Jr, and A. Renzini, Astrophys. J. 263, L23 (1982).

[51] D. E. Hollowell and I. Iben Jr., Astrophys. J. 333, L25 (1988).

[52] R. Gallino, M. Busso, G. Picchio, and C. Raiteri, Astrophys. J. 334, L45 (1988).

[53] O. Straniero, R. Gallino, M. Busso, A. Chieffi, C. Raiteri, M. Limongi, and M. Salaris, Astrophys. J. 440, L85 (1995).

[54] H. Beer, G. Walter, and R. Macklin, in Capture Gamma-Ray Spectroscopy and Related Topics, edited by S. Raman (AIP, New York, 1985), p. 778. 
[55] S. Jaag, Wissenschaftliche Berichte FZKA-5554 Forschungszentrum Karlsruhe 1995.

[56] S. Jaag, Diplomarbeit, University of Karlsruhe, 1990.

[57] R. Gallino, private communication (unpublished). 